\title{
Bias in patient and population preferences
}

Citation for published version (APA):

Dolders, M. G. T. (2005). Bias in patient and population preferences. [Doctoral Thesis, Maastricht University]. Universiteit Maastricht. https://doi.org/10.26481/dis.20050630md

Document status and date:

Published: 01/01/2005

DOI:

10.26481/dis.20050630md

Document Version:

Publisher's PDF, also known as Version of record

\section{Please check the document version of this publication:}

- A submitted manuscript is the version of the article upon submission and before peer-review. There can be important differences between the submitted version and the official published version of record.

People interested in the research are advised to contact the author for the final version of the publication, or visit the DOI to the publisher's website.

- The final author version and the galley proof are versions of the publication after peer review.

- The final published version features the final layout of the paper including the volume, issue and page numbers.

Link to publication

\footnotetext{
General rights rights.

- You may freely distribute the URL identifying the publication in the public portal. please follow below link for the End User Agreement:

www.umlib.nl/taverne-license

Take down policy

If you believe that this document breaches copyright please contact us at:

repository@maastrichtuniversity.nl

providing details and we will investigate your claim.
}

Copyright and moral rights for the publications made accessible in the public portal are retained by the authors and/or other copyright owners and it is a condition of accessing publications that users recognise and abide by the legal requirements associated with these

- Users may download and print one copy of any publication from the public portal for the purpose of private study or research.

- You may not further distribute the material or use it for any profit-making activity or commercial gain

If the publication is distributed under the terms of Article $25 \mathrm{fa}$ of the Dutch Copyright Act, indicated by the "Taverne" license above, 


\section{BIAS IN PATIENT AND POPULATION PREFERENCES}

Maria Gerarda Theresia Dolders 
Production: PrintPartners Ipskamp, Enschede, the Netherlands

Lay-out: BiFab, Mevr. B. Fraats

Cover design: Dhr. T. Gulikers

ISBN 90-9019491-6

Copyright ${ }^{\bullet} 2005$, Maria Dolders 


\title{
BIAS IN PATIENT AND POPULATION PREFERENCES
}

\author{
PROEFSCHRIFT
}

ter verkrijging van de graad van doctor aan de Universiteit Maastricht, op gezag van de Rector Magnificus, Prof. mr. G.P.M.F. Mols

volgens het besluit van het College van Decanen, in het openbaar te verdedigen op donderdag 30 juni 2005 om 16.00 uur

door

Maria Gerarda Theresia Dolders 
Promotor:

Prof. dr. W. Groot

\section{Co-promotor:}

Dr. A. Ament

Beoordelingscommissie:

Prof. dr. J. Severens (voorzitter)

Prof. dr. M. Berger

Prof. dr. E. van Doorslaer (Erasmus Universiteit Rotterdam)

Prof. dr. F. Hendrikse

Prof. dr. M. Sprangers (Universiteit van Amsterdam) 
"Just a page in my history"

(from: Misled by C. Dion) 


\section{CONTENTS}

1. GENERAL OVERVIEW 9

2. COST-EFFECTIVENESS OF FOLDABLE MULTIFOCAL INTRAOCULAR 25 LENSES COMPARED TO FOLDABLE MONOFOCAL INTRAOCULAR LENSES FOR CATARACT SURGERY

3. (UN)BIASED PREFERENCES IN A REFERENCE CASE SCENARIO FOR SENILE CATARACT

4. WHOSE VALUES COUNT? A META-ANALYSIS OF PATIENT AND POPULATION PREFERENCES

5. HEALTH RELATED QUALITY OF LIFE EVALUATIONS AND RESPONSE SHIFT. THE CASE OF CATARACT PATIENTS

6. INDIVIDUAL SPECIFIC FACTORS INFLUENCING RESPONSE SHIFT IN PATIENT PREFERENCES. THE CASE OF CATARACT PATIENTS

7. CONCLUSIONS AND DISCUSSION

SUMMARY

SAMENVATTING

APPENDIX A

ACKNOWLEDGEMENTS 


\title{
1 \\ GenerAL OVERVIEW
}

\author{
INTRODUICTION
}

One of the tools providing information that can help allocate scarce resources in the health care sector efficiently is that of economic evaluations. An economic evaluation is defined as "a comparative analysis of alternative courses of action in terms of both their costs and consequences". ${ }^{1}$ Costs are measured in monetary units, whereas the measurement of consequences differs in various types of economic evaluation. The subject of this thesis is the consequences in economic evaluations. For decades, prolonging life was the ultimate outcome parameter of health care interventions. Nowadays, health-related quality of life (HRQoL) has been incorporated in the outcome parameter, resulting in Quality Adjusted Life Years (QALYS). QALYS are used as an outcome parameter in cost-utility analysis, a more desirable type of economic evaluation than cost-effectiveness analysis. The QALY is a concept that combines changes in the quantity of life (mortality) and changes in the quality of life (morbidity) in a single generic outcome measure. One QALY is defined as one year gained in perfect health. In QALY calculations, the quality adjustment weight for a particular health state is multiplied by the time spent in that health state (which may be discounted) and thereafter summed to calculate the number of quality-adjusted life years. The quality adjustment weights for particular health states are measured by means of preferences. Preferences in health care are quantitative expressions or valuations for certain health states, which reflect the relative desirability of the various health states."

Preferences are embedded in welfare economics, ${ }^{2}$ a theoretical framework which also serves as a foundation for cost-utility analysis. ${ }^{3}$ The next section provides a description of the welfare economic foundations of cost-utility analysis.

\section{THEORETICAL FRAMEWORK}

Welfare economics is defined as the branch of study which endeavors to formulate propositions by which it can be indicated whether the social welfare in one economic situation is higher or lower than in another. ${ }^{2}$

The propositions of welfare economics that are relevant to cost-utility analysis are utility maximization and individual sovereignty. The proposition of 
utility maximization, which is essentially a behavioral assumption, refers to individuals choosing rationally by ranking a given set of options and choosing the most preferred among these options according to certain conditions of logical consistency. With respect to this behavioral assumption, economists divide preferences into two categories: stated preferences and revealed preferences. Stated preferences are based on how individuals say they would behave, whereas revealed preferences are derived from actual behavior. In this thesis, the term preferences refers to stated preferences. The proposition of individual sovereignty asserts that individuals are the best judges of their own welfare.

The overall welfare of society is defined as a function of individual utilities. ${ }^{2,4}$ There are many different approaches to defining the function of individual utifities or the social welfare function (for an overview see Dolan ${ }^{5}$ ). With respect to the measurement of QALYs, there are two approaches that are relevant and aim at the question what QALYs really represent. A discussion of the question whether QALYs represent a cardinal utility index (welfarists) or a cardinal utility index of health (extra-welfarists), is beyond the scope of this thesis. Nevertheless, both approaches share the view that to some extent, individual preferences matter. The next section scrutinizes the measurement of individual preferences.

\section{INDIVIDUAL PREFERENCES}

In this thesis, the QALY (as a measure of HRQoL) is used as a basis for resource allocation decisions, as opposed to the use of HRQoL (a) in randomized clinical trials, to determine whether an intervention produces greater gains (in terms of HRQOL) or fewer losses (in terms of side effects), (b) in individual patient care, to improve clinical practice or (c) in describing. monitoring, and predicting overall levels of population health. Since the Panel on Cost-Effectiveness in Heaith and Medicine recommends a societal perspective, resource allocation decisions should reflect the preferences of those who will be affected by these decisions. Resource allocation decisions at the societal level affect not only patients but also the general population. This results in the recommendation to measure both patient and general population preferences in a representative sample of the population: the so-called Reference Case. "However, this recommendation is based upon the assumption that patient preferences do not differ markedly from population preferences. In contrast, empirical research has shown that patients experiencing a particular health state give a significantly different evaluation of that health state 
than the general population, which is not experiencing this health state. ${ }^{8-11}$ Nevertheless, it still is debatable whether it matters to use patient or population preferences in cost-utility analysis aimed at resource allocations at the societal level. ${ }^{12,13}$ In any case, whether patient or population preferences should be used, these individual preferences have to be representative, informative, and unbiased. ${ }^{7}$ Before describing the possible bias occurring when eliciting population preferences and the bias regarding the assessment of patient preferences, the next section addresses the measurement methods to assess preferences directly.

\section{PREFERENCE-BASED MEASUREMENT METHODS}

The three valuation methods used extensively in economic evaluations to measure individual preferences directly are the Visual Analogue Scale (VAS), the Time Trade-Off (TTO), and the Standard Gamble (SG). ${ }^{14}$

The VAS is commonly represented as a vertical thermometer-type line or a horizontal line of $10 \mathrm{~cm}$ with endpoints 0 'dead/worst possible health state' and 1 'perfect health/best possible health state'. The respondent has to rate health states on this scale. Since the VAS is a non-preference based method, preferences are called values.

The TTO is defined as a choice between two alternatives. Based on the assumption that a state of chronic illness is better than death, the first alternative offered is the life expectancy with the chronic disease (t), whereas the second alternative is being healthy for time $\mathrm{x}<\mathrm{t}$, followed by death. Time $\mathrm{x}$ is then varied until the subject is indifferent between the two alternatives. For a temporary state, intermediate states are measured relative to the best state (healthy) and the worst state (temporary state). The TTO is a preference-based method under certainty.

The SG is a method that is based on the normative axioms of expected utility theory. ${ }^{15}$ Preferences derived from this theory are used in situations under risk and uncertainty. The SG is a technique in which choices are offered to the subjects between living with a chronic condition for the rest of their lives or undergoing a treatment with a certain probability of returning to a state of perfect health $(p)$ and a certain probability that the treatment will result in death (1-p). The probability of treatment success is varied until the subject is indifferent between remaining in the chronic condition or risk the treatment. At this indifference point, the utility equals $p$. Since the SG deals with uncertainty, it is often supplemented with visual aids. ${ }^{16}$ 
Preferences based on expected utility theory are also called utitities. In this thesis, the term preferences is used as the umbrella term for utilities and values.

In addition to the methods that measure preferences directly, other available methods include magnitude estimation methods and multi-attribute health status classification methods. The three main multi-attribute health status classification methods in economic evaluations are the Quality of Well-Being Scale (QWB)/General Health Policy Model, ${ }^{17}$ three Health Utility Indexes (HUI-1, HUH-II and $\mathrm{HUI}-1 \mathrm{II}),{ }^{48}$ and the EuroQol-5D (EQ-5D). ${ }^{19}$ These methods describe a health status in several dimensions. Since the research reported on in this thesis classified health status by means of the EuroQol-5D, this system is explained below in more detail.

The EQ-5D describes the HRQOL in terms of five dimensions: mobility, selfcare, usual activities, pain/discomfort, and anxiety/depression. Each dimension is recorded at three levels of severity: $1=$ no problems, $2=$ moderate problems, and $3=$ severe problems. Thus, a patient's current EQ-5D health status results in a fivedigit code based upon a classification of problems for all five dimensions. For example, health status 11312 represents no problems with mobility, no problems with self-care, severe problems with usual activities, no problems of pain/discomfort, and moderate problems of anxiety/depression. Preferences for the EQ-5D health status and the other multi-attribute health status classification systems are derived from a sample of the general population. The next section addresses possible bias in population preferences.

\section{BIAS IN POPULATION PREFERENCES}

As mentioned above, population preferences should be unbiased, informative and representative. If these requirements are met, they can be used as input in economic evaluations that serve as a tool to allocate scarce resources efficiently. This section addresses the three requirements with regard to population preferences.

The most cited empirical research in which population preferences were measured is the Beaver Dam Health Outcomes Study. ${ }^{20}$ This study summarized age-adjusted mean Quaiity of Well Being (QWB) scores ${ }^{17.21}$ and Time Trade-Off (TTO) preferences ${ }^{14}$ of persons affected or unaffected by various health conditions. If the preferences of persons unaffected by the health condition are used in economic evaluations aimed at resource allocation, these population preferences 
do not match the goal of the decision-making process. The population preferences in the Beaver Dam Health Outcomes Study contributed to the quantification of a population's burden of disease. ${ }^{20}$ In guiding the decision-making process to allocate scarce resources, the relevant preferences are classified into current patient preferences and hypothetical population preferences. Current patient preferences are valuations for a health condition or a disease assigned by an individual experiencing this health condition or disease. Hypothetical population preferences are valuations for a health condition which is not experienced by the individuals assigning valuations. Most of the empirical research to elicit hypothetical population preferences has used the EQ-5D questionnaire. ${ }^{19,22,23,24}$

In population preferences with regard to hypothetical health conditions, information bias might occur due to message framing effects. Tversky and Kahneman ${ }^{25}$ use the term message framing to refer to the fact that very small changes in the wording of decision problems can lead to preference reversals. Empirical studies have established that preferences differ according to how health states or health outcomes are described (see for a recent overview Kuehberger ${ }^{26}$ ). Although it is obvious that in a Reference Case, the general population has to be informed about the health status that is to be valued, bias with regard to message framing effects is beyond the scope of this thesis. Although a Reference Case is recommended for a societal perspective, problems occur in measuring the individual patient preferences. The next section describes these preferences and the accompanying bias.

\section{BIAS IN PATIENT PREFERENCES}

Bias in measuring patient preferences is very likely to occur, especially when preference-based instruments are used. The application of these instruments is based on the implicit assumption of stability of preferences, that is, they assume that individual preferences do not change. ${ }^{27}$ Since individual preferences are attached to certain health states, and health states are an important component of HRQoL, it is assumed that HRQOL does not change over time. However, HRQoL is considered by many to be a dynamic construct. ${ }^{28}$ This construct dynamism can affect the measurement of treatment-induced HRQOL change with respect to subjective assessments in patients. ${ }^{29}$ One of the theories dealing with changes in self-reported HRQOL is the theory of adaptation. Adaptation can be described as "an intra-psychic process in which past, present, and future situations and 
circumstances are given such cognitive and emotional meaning that an acceptable level of well-being is achieved" ${ }^{30}$ Adaptation is used by patients to recuperate psychologically after a setback. It differs from coping in that coping theory does not predict the outcome of the process; the outcome in coping theory can be either positive or negative. By contrast, adaptation implies a certain recovery of wellbeing after a setback and hence a favorable outcome. The adaptation process can be categorized by three important mechanisms: the shift of intra-psychic criteria, cognitive reconstruction of past and present circumstances, and future-time perception. Whilst the latter two are important mechanisms, the focus of this thesis is on the shift in intra-psychic criteria. Intra-psychic criteria refer to a standard of measurement or an internal reference scale. A shift in intra-psychic criteria reflects a change in internal standards of measurement, which means that a respondent operates as a differently calibrated person after an event compared to the situation before that event. This may bias the internal validity of the outcome measurement. The shift in internal standards of measurement is also known as scale recalibration, one of the aspects of response shift theory. ${ }^{31}$ The next section reviews response shift theory, determinants of response shift, and methods to measure response shift (see for an extensive overview Schwartz and Sprangers ${ }^{31}$ ). Furthermore, it presents an overview of empirical research done to establish and explain response shift.

\section{RESPONSE SHIFT THEORY}

A working definition of response shift has been given by Sichwartz and Sprangers: "response shift refers to a change in the meaning of one's self-evaluation of a target construct as a result of: (a) a change in the respondent's internal standards of measurement (scale recalibration), (b) a change in the respondent's values (reprioritization), or (c) a redefinition of the target consitruct (reconceptualization)". 31

The first aspect of response shift is scale recalibration, which refers to a change in internalized perceptions (an internal standard of measurement) of the level of functioning on a given (health-related) dimension. Respondents understand what the points on the response scale mean to them, based on their own particular experiences and perceptions. New experiences over time can alter this understanding. Thus, response scales stretch or condense to fit the experience 
continuum, resulting in different internal standards of measurement. Recalibration response shift occurs within one dimension.

The second aspect of response shift is reprioritization, which occurs when respondents change their values over time. For example, respondents may value the physical dimension higher than the social dimension before surgery, whereas after surgery, the social dimension becomes more important. The quality-of-life construct has not changed, but the importance respondents attach to the different dimensions has changed, causing a change in values. Reprioritization response shift occurs between dimensions.

The third aspect of response shift is a redefinition of the target construct, that is, reconceptualization. Reconceptualization occurs when the dimensions of the target construct (i.e. the quality-of-life dimensions) change over time. Thus, quality of life is not defined by physical, psychological, and social health alone, but also by, e.g., the spiritual health dimension.

\section{DETERMINANTS OF RESPONSE SHIFT}

Factors influencing response shift, which in turn might affect perceived healthrelated quality of life, have been integrated in a theoretical model. ${ }^{32}$ This theoretical model, devellaped by Sprangers and Schwartz, ${ }^{32}$ describes three major components that might explain response shift. The first component is a catalyst and refers to health states (or changes in health states), health-related events, treatment interventions or other events that impact on health-related quality of life. The second component, the antecedents, refers to stable or dispositional characteristics such as demographic characteristics or personality characteristics (e.g. self-esteem and treatment outcome). The third component involves mechanisms which refer to behavioral, cognitive, and affective processes to accommodate the catalyst. Mechanisms involved include coping behavior strategies, reframing future expectations, social support strategies, social comparison strategies, and strategies to reorder goals.

\section{METHODS FOR MEASURING RESPONSE SHIFT}

Several methods can be used to measure whether response shift occurs. These methods can be categorized into individualized methods, preference-based methods, successive comparison approaches, design approaches, statistical 
methods and qualitative methods. Each method measures different aspects of response shift. To assess changes in internal standards, the first aspect of response shift, Schwartz and Sprangers ${ }^{33,34}$ presented one individualized method and two design approaches: the ideal scale approach and the then-test approach. The ideal scale approach measures all aspects of response shift. It requires doubling the questionnaire to assess the current HRQoL and the 'ideal' HRQoL. The difficulty with this approach lies in the definition of the concept of "ideal' for HRQoL. While in a conventional pretest-posttest design, preference measurement incorporates changes in values, the then-test approach seems to be an appropriate method to establish scale recalibration. ${ }^{35}$ The ideal scale approach is most often used in studies examining organizational change, whereas the then-test approach is used in quality-of-life research and research examining response shift in preferences. ${ }^{36-38}$

\section{THEN-TEST APPROACH}

The then-test approach establishes recalibration response shift. ${ }^{35}$ To the conventional pretest-posttest design, it adds a retrospective pre-test, which is called a then-test. At the post-test, patients report self-assessed preferences twice. First they are asked to assess preferences for their current health state (the conventional post-test). The then-test is then administered immediately after the post-test, by asking patients to evaluate their preferences at the time of the pretest. Patients thus give a renewed evaluation of the situation before the treatment. The then-test assumes equal internal standards of measurement for the retrospective pre-test and the post-test. In other words, it assumes that the reference scale for the retrospective pre-test and the post-test do not differ. The comparison of retrospective pre-test scores, measured directly after the post-test, with the post-test scores themselves yields a preference change reflecting the same internal standards of measurement. ${ }^{35,39}$

\section{EMPIRICAL RESEARCH ON RESPONSE SHIFT}

Recent research has described the presence and importance of response shift in treatment outcome research and longitudinal observations of HRQoL. Recalibration response shift in preferences has been assessed in chronically ill patients suffering from diabetes mellitus and end-stage renal disease, who received a combined 
pancreas-kidney transplantation. ${ }^{36}$ This study concluded that patients underestimated their pre-treatment quality of life, and explained this by adaptation to illness during the pre-transplant period and a change in health status. However, these explanations were not empirically tested. Recalibration response shift has also been assessed in early-stage breast cancer patients undergoing radiotherapy. ${ }^{37}$ Prospectively assessed quality of life differed significantly from the retrospectively assessed quality of life of these seriously ill patients. The authors of the study questioned whether the retrospectively assessed quality of life scores underestimate the capacity of ill patients to adapt to their illness. Furthermore, response shift in disease-specific preferences has been established in hearing impaired patients. ${ }^{38}$ The conclusion of this study was that patients underestimated their pre-intervention hearing impairment. The study also recommended further research into factors initiating response shift effects.

The theoretical model suggests that coping might influence response shift effects. Coping and its influence on response shift have been illustrated, using qualitative data, among bereaved caregivers of men with AIDS. ${ }^{40}$ Response shift is achieved and maintained through meaning-based coping processes after initial problem-based coping behavior or emotionally focused coping behavior.

In a longitudinal study, Rapkin ${ }^{41}$ examined how the impact of illness and the accompanying life events were subject to response shift effects and whether they were associated with goal reordering. The results provided evidence that individual goals and concerns continue to evolve during illness. However, research into the mechanisms that might explain response shift in patient preferences is lacking.

This thesis reports on research to asses preferences with regard to cataract and cataract surgery, the most commonly performed type of surgery in the Netherlands. The next sections describe the etiology of senile cataract and preference studies in cataract.

\section{ETIOLOGY OF SENILE CATARACT}

Senile cataract is an age-related vision problem and is defined as an opacity in the crystalline lens of the eye. ${ }^{42}$ The most recent prevalence and incidence figures date from 2000. At that time, the prevalence of cataract among men aged over 50 in the Netherlands was approximately $3 \%$ and that for women $5 \%$. The incidence in the over-50 category was approximately $0.5 \%$ for men and $0.9 \%$ for women. ${ }^{43}$ The only 
treatment for senile cataract is surgery. In the Netherlands, 80,000 to 90,000 cataract operations are performed each year. ${ }^{44}$

During surgery, the opaque lens is removed and replaced by an artificial implant lens. Different types of artificial implant lenses are used in cataract surgery. The most common type is a monofocal intraocular lens with a fixed lens power that produces sharp vision at a far distance without correction. However, reading glasses (or contact lenses) are needed for near vision activities. The other artificial implant lens provides the patient with multifocal vision, ${ }^{45.46}$ which means sharp vision at near, intermediate, and far distances, without the need for glasses or contact lenses.

\section{PREFERENCE STUDIES ON CATARACT}

Preference studies on cataract have been scarce. The only study that was found presenting preferences with regard to cataract is a study that associated healthrelated quality of life with preferences. ${ }^{47}$ Preferences were assessed with the Standard Gamble method (SG) and a Verbal Rating Scale (VR) technique. The verbal technique was used instead of the visual technique because the patients were visually impaired. The mean preference score assessed with the SG was 0.78 , while the VR yielded a mean preference score of 0.71 . SG and VR were very highly correlated $(r=0.73, p<.01){ }^{47}$

Although the number of preference studies on cataract is limited, there have been studies presenting Time Trade-Off preference scores for visual acuity in the better seeing eye. ${ }^{48,49}$ Preferences vary from 0.92 if a patient's visual acuity is $20 / 20$ to 0.26 if patients are blind defined as "no light perception". Since cataract patients before surgery mostly fall into the category with visual acuity between $20 / 50$ and $20 / 40$, the mean preference score for the cataract patients before surgery varies between 0.74 and 0.77 .

Health economics applied to ophthalmology has recently received increased attention. ${ }^{50-52}$ The literature search yielded three cost-effectiveness studies on cataract surgery. ${ }^{53-55}$ Two were computer-based econometric modeling studies, and the third study used registry data to assess the cost-effectiveness of cataract surgery. One cost-effectiveness study compared monofocal intraocular lenses with multifocal lenses. This study used the health care payer perspective. ${ }^{56}$ Direct medical costs associated with bilateral cataract surgery on an outpatient basis were calculated. The costs and charges of drug therapy, consultations, diagnostic 
and therapeutic procedures, and surgery were included. This study used visionrelated outcome measures from a retrospective case-control study in the literature. The cost-effectiveness of cataract surgery was measured in cost per spectacle-free patient, cost per spectacle-free patient without limitation in vision-related function, cost per spectacle-free patient without limited night vision and cost per spectaclefree patient without glare. This cost-effectiveness study showed that the multifocal lens dominated. This result was associated with greater satisfaction about the quality of distance and near vision than the reduction in spectacle dependency. However, it also shows that the multifocal lens may not be the most cost-effective option for patients who require excellent night vision or who would not tolerate visual disturbances such as glare and halos.

\section{OBJECTIVE AND OUTLINE OF THIS DISSERTATION}

The main objective of the research reported on in this dissertation was to analyze bias in patient and population preferences.

Chapter 2 presents an example of a traditional cost-effectiveness analysis performed from a societal perspective. Preferences, however, were measured at the patient level.

Instead of patient preferences, population preferences should be used in cost-effectiveness analysis from a societal perspective. Chapter 3 reports on the measurement of population preferences obtained from a survey among a randomly drawn population sample. However, bias with regard to the representativeness of the study sample hampered the use of these preferences in cost-effectiveness analysis.

It is largely unknown whether it matters to use patient or population preferences. Chapter 4 summarizes and quantifies the mean differences in patient and population preferences from the literature and determines factors influencing these differences. However, patient preferences in the literature are biased by adaptation and response shift.

Chapter 5 presents the assessment of response shift in patient preferences, whereas Chapter 6 addresses individual specific factors influencing response shift in patient preferences using a random effects model. 


\section{REFERENCES}

1. Drummond MF, OBBien BJ, Stoddart GL, Torrance GW. Methods for the economic evaluation of health care programmes. Second ed. Oxford: Oxford University Press; 1997.

2. Ng Y. Welfare Economics. Introduction and development of basic concepts. First ed. London: The Macmillan Press Ltd:; 1979.

3. Garber AM. Advances in cost-effectiveness analysis of health interventions. In: Culyer A.J, Newhouse JP, eds. Handbook of Health Economics. Vol 1A. Amsterdam, London, New York, Oxford, Paris, Shannon, Tokyo: Elsevier Science B. V.; 2000:181221.

4. Hurley J. An overview of the normative economics of the health sector. In: Culyer AJ, Newhouse JP, eds. Handbook of Health Economics. Vol 1A. Amsterdam, London, New York, Oxford, Paris, Shannon, Tokyo: Elsevier Science B.V.; 2000:55-118.

5. Dolan $\mathrm{P}$. The measurement of individual utility and social welfare. I Health Econ $1998 ; 17: 39-52$

6. Dolan P. The measurement of health-related quality of life for use in resource allocation decisions in health care. In: Culyer AJ, Newhouse JP, eds. Handbook of Health Economics. Vol 1B. Amsterdam, London, New York, Oxford, Paris, Shannon, Tokyo: Elsevier Science B.V.; 2000:1723-1760.

7. Gold MR, Siegel JE, Russell LB, Weinstein MC. Cost-effectiveness in health and medicine. New York, Oxford: Oxford University Press; 1996.

8. Boyd NF, Sutherland $H J$, Heasman $K Z$, Tritchler DL, Cummings $B J$. Whose utilities for decision analysis? Med Decis Making 1990;10:58-67.

9. De Wit GA, Busschbach $\mathrm{JJ}$, de Charro FT. Sensitivity and perspective in the valuation of health status: whose values count? Health Econ 2000;9:109-126.

10. Poisky D, Richard JW, Wolke RJ. Scott K, Schulman KA, Glick HA. A comparison of scoring weights for the EuroQol derived from patients and the general public. Health Econ 2001:10:27-37.

11. Sackett $\mathrm{DL}$, Torrance $\mathrm{GW}$. The utility of different health states as perceived by the general public. J Chronic Dis 1978;31:697-704.

12. Fryback DG. Whose quality of life? or whose decision? Qual Life Res 2003;12:609. 610.

13. Ubel PA, Loewenstein $G_{n}$ Jepson $C$. Whose quality of life? A commentary exploring discrepancies between health state evaluations of patients and the general public. Qual Life Res 2003:12:599-607.

14. Torrance GW. Measurement of health state utilities for economic appraisal. $J$ Health Econ 1986;5:4-30.

15. Von Neumann J, Morgenstern O. Theory of games and economic behavior. Princeton: Princeton University Press; 1947. 
16. Torrance GW. Social preferences for health states: an empirical evaluation of three measurement techniques. Socio-Econ Plan Sci 1976:10:129-136.

17. Kaplan RM, Anderson JP. A general health policy model: update and applications. Health Serv Res 1988;23:203-235.

18. Torrance GW, Furlong W, Feeny D, Boyle M. Multi-attribute preference functions. Health Utilities Index. PharmacoEconomics 1995;7:503-520.

19. The EuroQol Group. EuroQol--a new facility for the measurement of health-related quality of life. Health Policy 1990;16:199-208.

20. Fryback DG, Dasbach El, Klein R, Klein BE, Dorn N, Peterson K, et al. The Beaver Dam Health Outcomes Study: initial catalog of health-state quality factors. Med Decis Making 1993;13:89-102.

21. Kaplan RM, Bush JW, Berry CC. Health status: types of validity and the index of wellbeing. Health Serv Res 1976;11:478-507.

22. Brooks R. EuroQdi: the current state of play. Health Policy 1996;37:53-72.

23. Dolan P, Gudex C, Kind P, Williams A. The time trade-off method: results from a general population study. Health Econ 1996;5:141-154.

24. Dolan P. Modeling valuations for EuroQol health states. Med Care 1997;35:10951108.

25. Twersky A, Kahneman D. The framing of decisions and the psychology of choice. Science 1981;211:453-458.

26. Kuehberger $\mathrm{A}$. The Influence of framing on risky decisions: A meta-analysis. Organ Behav Hum Dec 1998;75:23-55.

27. Miguel FS, Ryan M, Scott A. Are preferences stable? The case of health care. J Econ Behav Organ 2002;48:1-14.

28. Allison PJ, Locker D, Feine JS. Quality of life: a dynamic construct. Sac Sci Med 1997;45:221-230.

29. Golembiewski RT, Billingsley $K$, Yeager $S$. Measuring change and persistence in human affairs: Types of change glenerated by OD designs. I Appl Behav Sci 1975; 12:133-157.

30. Heyink J. Adaptation and well-being. Psychol Rep 1993;73(3 Pt 2):1331-1342.

31. Schwartz CE, Sprangers MAG. Adaptation to changing health: response shift in quality-of-life research. Washington, DC US: American Psychological Association; 2000.

32. Sprangers MA, Schwartz CE. Integrating response shift into health-related quality of life research: a theoretical model. Soc Sci Med 1999;48:1507-1515.

33. Schwartz CE, Sprangers MAG. Methodological approaches for assessing response shift in longitudinal health-related quality-of-life research. In: Schwartz CE, Sprangers MAG, eds. Adaptation to changing health: response shift in qualify-of-Nife research. Washington, DC, US: American Psychological Association; 2000:81-107. 
34. Schwartz CE, Sprangers MA. Methodological approaches for assessing response shift in longitudinal health-related quality-of-life research. Soc Sci Med 1999;48:15311548.

35. Howard GS, Ralph KM, Gulanick NA, Maxwell SE, Nance DW, Gerber SK. Internal invalidity in pretest-posttest self-report evaluations and a re-evaluation of retrospective pretests. App/ Psychol Meas 1979;3:1-23.

36. Adang EM, Kootstra $G$, Engel $G L$, van Hooff JP, Merckelbach HL. Do retrospective and prospective quality of life assessments differ for pancreas-kidney transplant recipients? Transp/ Int 1998;11:11-15.

37. Jansen SJ, Stiggelbout AM, Nooij MA, Noordijk EM, Kievit ل. Response shift in quality of life measurement in early-stage breast cancer patients undergoing radiotherapy. Qual Life Res 2000;9:603-615.

38. Joore MA, Potjewijd J, Timmerman AA, Anteunis LJ. Response shift in the measurement of quality of life in hearing impaired adults after hearing aid fitting. Qual Life Res 2002;11:299-307.

39. Bray $J H$, Maxwell SE, Howard GS. Methods of analysis with response-shift bias. Educ Psychol Meas 1984;44:781-804.

40. Richards TA, Folkman S. Response shift: a coping perspective. In: Schwartz CE, Sprangers MAG, eds. Adaptation to changing health: response shift in quality of life research. Washington, DC, US: American Psychological Association; 2000:25-36.

41. Rapkin BD. Personal goals and response shifts: understanding the impact of illness and events on the quality of life of people living with AIDS. In: Schwartz CE, Sprangers $\mathrm{MAG}_{1}$ eds. Adaptation to changing health: response shift in quality of life research. Washington, DC, US: American Psychological Association; 2000:53-71.

42. Khaw PT, Hughes DS, Keightley SJ "Walters. RF. Ophthaimology revision aid: BMJ Publishing Group; 1996.

43. Prevalence and incidence of cataract. Available at: http://www.rivm.nl/vtv/data/kompas/gezondheidstoestand/ziekte/gezichtsstoomis/ gezichtsstoornis_omvang_har.htm. Accessed October 27, 2004.

44. Yearly performed cataract surgeries. Availlable at: http:/wmw.rivm.ni//vtv/data/kompas/gezondheidstoestand/ziekte/gezichtsstoornis/ gezichtsstoornis_diagn_behand.htm. Accessed October 27, 2004

45. Javitt JC, Wang F. Trentacost DJ, Rowe M, Tarantino N. Outcomes of cataract extraction with multifocal intraocular lens implantation: functional status and quality of life. Ophthalmology 1997;104:589-599.

46. Nijkamp MD. Determinants of patient satisfaction after cataract surgery. Maastricht: Unigrapthic Maastricht; 2003.

47. Lee JE, Fos PJ, Zuniga MA, Kastl PR, Sung JH. Assessing health-related quality of life in cataract patients: the relationship between utility and health-related quality of life measurement. Qual Life Res 2000:9:1127-1135. 
48. Brown MM, Brown GC, Sharma S, Kistler J, Brown $H$. Utility values associated with blindness in an adult population. Br J Ophthalmor 2001,85:327-331.

49. Brown MM, Brown GC, Sharma S, Landy J, Bakal J. Quality of life with visual acuity loss from diabetic retinopathy and age-related macular degeneration. Arch Ophthalmol 2002; 120:481-484.

50. Brown MM, Brown GC, Sharma S, Garrett S. Evidence-based medicine, utilities, and quality of life. Curr Opin Ophthalmol 1999;10:221-226.

51. Brown MM. Health care economic analyses. Curr Opin Ophthalmol 2003:14:117-121.

52. Brown GC, Brown MM, Sharma S. Health care economic analyses. Retina 2004:24:139-146.

53. Busbee BG, Brown MM, Brown GC, Sharma S. Incremental cost-effectiveness of initial cataract surgery. Ophthalmology 2002;109:606-612.

54. Busbee BG, Brown MM, Brown GC, Sharma S. Cost-utility analysis of cataract surgery in the second eye. Ophthalmology 2003;110:2310-2317.

55. Kobelt G, Lundstrom M, Stenevi U. Cost-effectiveness of cataract surgery. Method to assess cost-effectiveness using registry data. J'Cataract Refr Surg 2002;28:17421749.

56. Orme ME, Paine AC, Teale CW, Kennedy LM. Cost-effectiveness of the AMOArray multifocal intraocular lens in cataract surgery. J Refr Surg 2002"18:162-168. 
COST-EFFECTIVENESS OF FOLDABLE MULTIFOCAL INTRAOCULAR LENSES COMPARED TO FOLDABLE MONOFOCAL INTRAOCULAR LENSES FOR CATARACT SURGERY

\author{
M. Dolders, M. Nijkamp, R. Nuijts, B. van den Borne, \\ F. Hendrikse, A. Ament, W. Groot \\ British Journal of Ophthalmology 2004;88:1163-1168
}

\begin{abstract}
Aim: To analyze the cost-effectiveness of foldable monofocal intraocular lenses (IOLs) compared to foldable multifocal $10 \mathrm{Ls}$ in cataract surgery alongside a prospective, multi center randomized clinical trial (RCT).

Methods: Patients underwent cataract surgery with bilateral monofocal $(n=97)$ or multifocal $(n=93)$ IOL implantation. Cost data and patient preferences, using the Visual Analogue Scale (VAS), the Time Trade-Off (TTO) and the Standard Gamble (SG) technique were obtained pre- and postoperatively by structured interviews. The incremental costs (multifocall minus monofocal), mean costs per patient, and differences in preferences were computed. Results: Mean costs for glasses per patient in the monofocal group were $€ 241.67$ and in the multifocal group $€ 149.58$. The difference in costs between the multifocal and monofocal group was $€-92.09$ and was statistically significant $(p=0.008)$. No significant differences were found in total costs or in effectiveness between the monofocal and multifocal IOL group.

Conclusion: The cost-effectiveness of multifocal 10Ls is reduced to a cost-minimization analysis, due to the inability to demonstrate significant differences in effects. The use of multifocal IOLs in cataract surgery resulted in a significant reduction in costs for patient's postoperative spectacles.
\end{abstract}


Modern cataract surgery enables treatment of cataract and (oncoming) presbyopia in cataract patients. ${ }^{1}$ An ideal intraocular lens ( $\mathrm{OOL}$ ) would simulate the original function of the crystalline lens and provide the patient with multifocal vision. ${ }^{1-3}$

Clinical studies have shown improved uncorrected near visual acuity and a decreased spectacle dependency for patients with a multifocal IOL compared to patients with monofocal lens implantation. ${ }^{4}$ It is hypothesized that this decreased spectacle dependency results in vision related and generic Health Related Quality of Life (HRQOL) differences between patients with monofocal and multifocal IOLs. ${ }^{5-7}$ Differences in the effectiveness can be related to the possible differences in costs, resulting in a cost-effectiveness analysis.

Until today there is one cost-effectiveness study that compares cataract surgery with implantation of bilateral monofocal and multifocal IOLs. ${ }^{8}$ This study reported the cost-effectiveness of each treatment using the health care payer perspective and divided the average cost per patient by the proportion of patients experiencing a particular vision related outcome, such as costs per spectacle-free patient.

A specific type of a cost effectiveness analysis (CEA) is a cost-utility analysis (CUA) ${ }^{9}$ In a CUA consequences are measured in Quality Adjusted Life Years (QALYs). A QALY combines quantity of life (in years) with quality of life (expressed in utilities/preferences) in one measure. A utility is a preference for a certain health state expressed in a cardinal number between 0 (death/worst imaginable health status) and 1 (perfect health/best imaginable health status). The term utility and preference will be used interchangeable in this chapter. The results of a CUA are reported as costs per QALY gained. By using this standard, CUAs in ophthalmology can be compared to CUAs in other health care fields. CUAs are particularly useful for decision-making about the allocation of scarce resources to maximize social welfare."

The aim of the present study was to conduct a cost-utility analysis of monofocal and multifocal IOLs in cataract surgery, following a societal perspective. ${ }^{9.10}$ 


\section{PATIENTS AND METHODS}

\section{PARTICIPANTS}

The medical files of 1218 consecutive cataract patients awaiting surgery were screened for inclusion in a randomized controlled trial (RCT) determinks patsen satisfaction after surgery. ${ }^{11}$ The inclusion criteria were: bilateral senlle catartad, preoperative keratometric astigmatism $\leq 1.5$ Diopters (D), axial lengh beween $19.5 \mathrm{~mm}$ and $26 \mathrm{~mm}$, preoperative sphere between $-6 \mathrm{D}$ and $+4 \mathrm{D}$. Exclugton criteria were: professional night driving, ocular co-morbidity, mental retardaton. inability to complete the questionnaire in Dutch and pseudophakia. Additonatys patients with perioperative or postoperative complications were excluded.

Figure 2.1 represents the flow of patients through the trial. The surgery was performed at one of the following outpatient centers: Atrium Medical Center Heerlen (AMCH), University Hospital Maastricht (UHM), and Medical Center Maastricht Annadal (MCMA). The nature and purpose of this study, including (side) effects of the treatment were explained to each patient by the ophthalmologist in attendance. A patient information brochure and an informed consent form were sent to all selected patients awalting surgery. The ethical committees of the tral centers approved this research protocol. Enrolment of 190 patients occurred from August 1999 until January 2001.

Patients were masked for their treatment condition until the first postoperative visit. Preoperatively, ophthalmologists and interviewers were unaware of the decision which type of lens a patient received. Since there were observable differences between both lenses masking of ophthalmologists and interviewers until study completion was not feasible. " Patients were randomized one week before surgery (when the power of the implant lens was computed) and after receiving informed consent.

Group 1 patients received bilateral monofocal 1OLs; group 2 bilateral multifocal IOLs. The patients were interviewed one to two weeks before first eyesurgery $\left(T_{1}\right)$, three months after first eye-surgery $\left(T_{2}\right)$ up to three months postoperatively after second eye-surgery $\left(T_{3}\right)$. The interval between first and second eye-surgery was approximately 16 weeks.

The surgical procedure was standardized (see Figure 2.2). Phacoemulsification using a monofocal foldable IOL (AMOPhacoFlexI' $\mathrm{B}$ (40 NB, Allergan, Irvine, CA, USA) or a multifocal foldable IOL (AMOArray ${ }^{\circ} 40 \mathrm{~N}$, 
Allergan, Irvine, CA, USA) was performed. Both IOLs were structurally identical differing only in the contour of the front surface of the optic.

Structured interviews took place at the UHM department of ophthalmology by two experienced interviewers.

Figure 2.1. Trial Profile

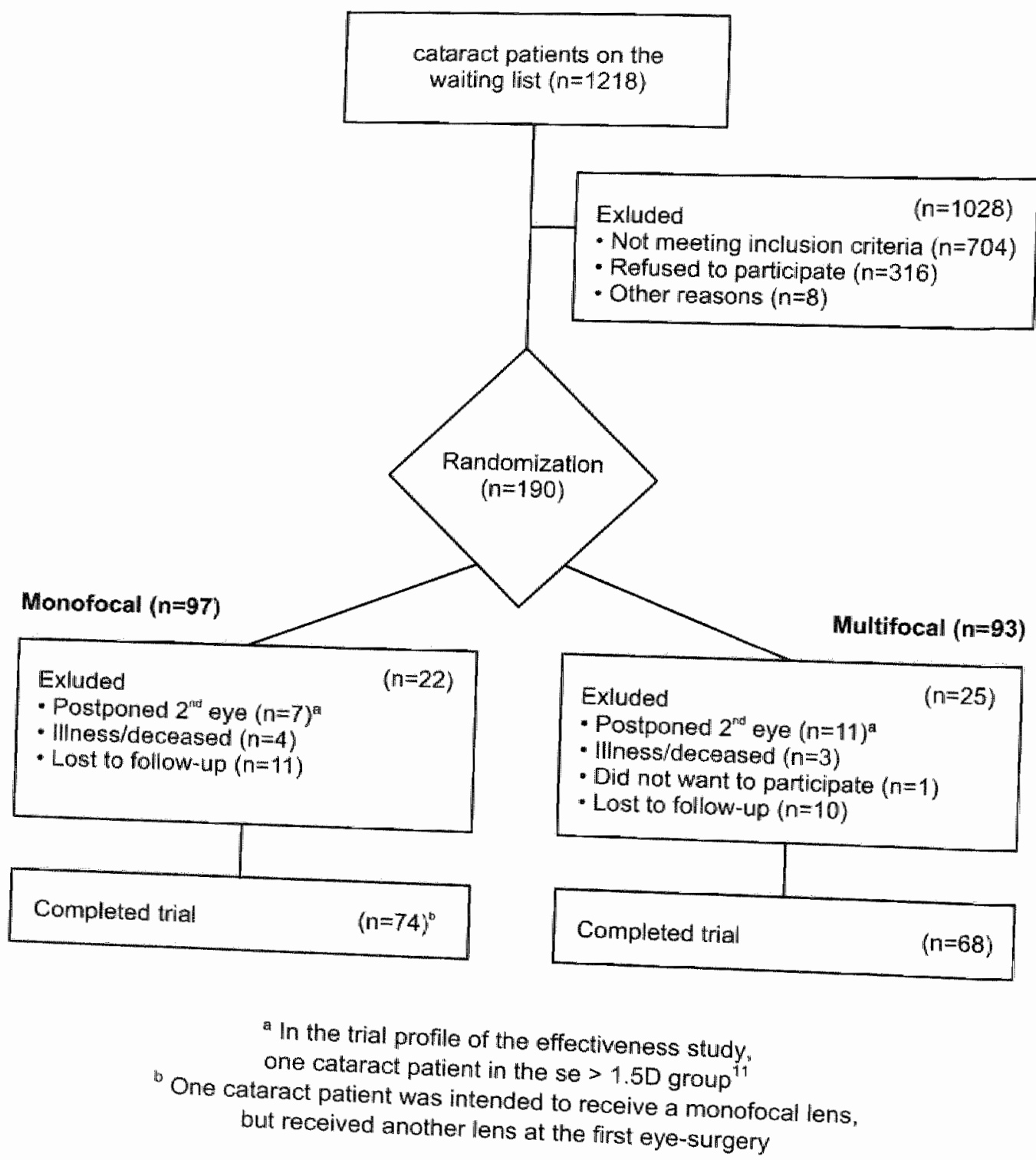


Figure 2.2. Standlardized surgical procedure

- Small $3.2 \mathrm{~mm}$ posterior limbal incision

- Subtenon retrobulbar anesthesia

- No-stitch technique in wound closure

- Postoperative topical steroids and antibiotics

- Postoperative refraction aimed at emmetropia

\section{COSTS}

The direct health and non-health care costs and the indirect costs were considered in the economic analysis. The costs for the IOLs were derived from the hospital administration. Since the surgical procedure was similar all patients, and the surgeons were exchangeable between the three centers, the costs of surgery were assumed equal for both IOLs. Drummond, O'Brien, Stoddart and Torrance ${ }^{10}$ suggest ignoring the costs that are common to both treatments compared because $^{2}$ they will not affect the choice between the given treatments. Therefore, the costs of the surgical procedure and other clinical relevant costs (e.g. diagnosis , postoperative tests, and consultation costs) were excluded from the economic analysis. ${ }^{8}$ Direct non-health care costs (e.g. transportation costs) were assumed to be equally distributed between the two $1 O L$ groups $^{8}$, excluding these costs from the analysis. $^{10}$ Indirect health care costs (e.g. disability for work) were assumed to be distributed equally between the two groups, and were therefore also excluded from the analysis.

\section{EFFECTIVENESS}

The effectiveness of the surgery was measured by means of patient preferences, which reflect the utilities or values assigned to a patients' self-reported health state. ${ }^{10}$ Self-reported health state was measured with the EuroQol-5D (EQ-5D) and categorized into three levels of severity: healthy, (very) mill. (very) severe. ${ }^{12,13}$

Measurement of patient preferences, used non-preference based (Visual Analogue Scale) and preference based instruments (Time Trade-Off and Standard Gamble). ${ }^{14}$ The Visual Analogue Scale (VAS) is a horizontal $10 \mathrm{~cm}$ line on which patients can mark their current generic health state. A Report Mark (RM) was used instead of the VAS if patients were unable to see the $10 \mathrm{~cm}$ line. VAS and RM ranged from 0 to 10 and directly equal their preference. Although both preferences were measured on the same scale, we transformed both to a $0-1$ scale 


\section{CHAPTEF 2}

representing the worst HRQOL state (0) or the best HRQOL state (1) to allow comparison of non-preference based values with preference based values or utilities. VAS and RM-scores correlated highly $\left(T_{1}: r=.63, T_{2}: r=.71, T_{3}: r=.66\right.$, all significant at the 0.001 level). To avoid multicollinearity, the VAS was used in the statistical analyses, because it represents a continuous scale and is more commonly used in the economic literature.

The Time Trade-Off (TTO) was defined as a choice between two alternatives. In the present study, the first alternative was "living 10 years with cataract", the second "living 10 years in full health". The second alternative was then changed from 10 to 9 years, from 9 to 8 years and so on, until the patient was indifferent about the two alternatives. To compute the preference for cataract, 0-10 scales were transformed to 0-1 scales using the formula: cataract=number of years in full health/10.

The standard Gamble (SG) is a technique in which choices are offered to patients between living with cataract for the remainder of their lives or undergoing surgery with a chance of returning to perfect health ( $p$ ) or a chance that the surgery results in bindness $(1-p)$. The probability of surgery success is varied until the patient is indifferent between remaining in the cataract state and risking surgery. At this indifference point the utility equals $p$. The probabilities are measured as proportions. In economic evaluations the utility scale is a $0-1$ scale with endpoints perfect health and death. In the present study the endpoint was blindness. Utilities were recalculated to a $0-1$ scale with endpoints perfect health and death by multiplying chance (1-p) by the mean utility for blindness (No Light Perception) ${ }^{15}$ and adding chance ( $p$ ). Visual aids were used to enhance the comprehensibility of the probabilities for TTO and SG. ${ }^{16}$

\section{STATISTICAL ANAL YSES}

Power calculations were performed to determine the sample size necessary to draw reliable statistical conclusions on clinical parameters. Economic criteria ${ }^{17}$ could not be applied, since this was the first cost-effectiveness study comparing IOLs from a societal perspective. Patients measured at $T_{1}, T_{2}$ and $T_{3}$ were analyzed $(N=143)$ on an intention-to-treat base. Independent $t$-tests and Chisquare tests for proportions were applied to assess selection caused by dropout and to assess differences in baseline characteristics between mono- and multifocal IOL patients. The distribution of the data was tested for normality with the Kolgomorov-Smirnov test. Since costs were non-normally distributed the non- 
parametric Mann-Whitney U-test was used to analyze the differences in costs for spectacles between both $1 O L$ groups. Logistic regression analysis was used to determine differences in preferences and change in general health status between both IOL groups. Pretest differences were controlled for by entering general health status and preferences at $T_{1}$ in the first step of the analysis. In the dropout analysis, dropouts were compared to patients who completed the interviews regarding the following variables: demographic characteristics, type of $I O L$, type of preoperative glasses, general health status, and preferences. Whenever possible, the reasons for dropout were traced. Furthermore, the same variables and the presence or absence of general co-morbidity were used to compare baseline characteristics between monofocal and multifocal IOL groups. The level of significance was $p<0.05$. Analyses were performed using SPSS 10.0 (Chicago, II).

Patients reported the costs of glasses in Dutch guilders. In the period 19992002 the conversion from Dutch guilders to euros was fixed. The recalculation was: 1 Euro $=2.20374$ Dutch guilders. Euros can be converted into US Dollars by using the exchange rate in the period that patients were included. This exchange rate varies from 1 Euro $=0.85$ US Dollars to 1 Euro $=1.07$ US Dollars. ${ }^{18}$

\section{RESULTS}

\section{REPRESENTATIVENESS OF STUDY GROUP}

Eligibility criteria were met for 514 cataract patients (42.2\%) (Figure 2.1). The main reason for ineligibility was pseudophakia. Further information regarding differences in representativeness of the study group is explained in the effectiveness study by Nijkamp et al. ${ }^{11}$

No significant differences were found in the dropout analysis, indicating that there was no selection bias. Known reasons for dropout were: (acquired) ocular comorbidity $(N=6)$, other illnesses or deceased $(N=7)$, unwilling to continue participation $(N=1)$, and unreachable patients $(N=10)$. Twenty-one cataract patients postponed second eye-surgery of which two with multifocal IOL implantation, whom reported halos at night.

\section{BASELINE CHARACTERISTICS}

Table 2.1 presents the baseline characteristics of the monofocal and multifocal group completing all measurements. Demographics, vision-related characteristics and co-morbidity were similar for both groups. 
Table 2.1. Baseline characteristics of cataract patients participating in all measurements $(n=143)$

\begin{tabular}{|c|c|c|c|}
\hline & $\begin{array}{l}\text { Monofocal IOL }(0) \\
\qquad(n=75)\end{array}$ & $\begin{array}{l}\text { Multifocal } \| \mathrm{OL}(1) \\
\qquad(\mathrm{n}=68)\end{array}$ & $\begin{array}{c}\text { P-value } \\
\#\end{array}$ \\
\hline \multicolumn{4}{|c|}{ Demographic characteristics $(\%)^{m:}$} \\
\hline Age (mean, SD) & $72.2 \pm 7.9$ & $72.9 \pm 7.0$ & 0.59 \\
\hline Female male ratio & $56.0: 44.0$ & $64.7: 35.3$ & 0.29 \\
\hline \multicolumn{4}{|l|}{ Marital status: } \\
\hline - Married/living together $(0)$ & 61.3 & 60.3 & \multirow[t]{2}{*}{0.90} \\
\hline $\begin{array}{l}\text { - Single/divorced/widowed (1) } \\
\text { Education: }\end{array}$ & \multicolumn{2}{|c|}{ Education: } & \\
\hline - low (1) & 56.0 & 61.8 & \multirow[t]{3}{*}{0.67} \\
\hline - middle (2) & 34.7 & 32.3 & \\
\hline - high $(3)$ & 9.3 & 5.9 & \\
\hline \multicolumn{4}{|c|}{$\begin{array}{l}\text { Vision related characteristics }(\%)^{\mathrm{b}} \text { : } \\
\text { Type of glasses }\end{array}$} \\
\hline - reading (1) & 9.3 & 13.2 & \multirow[t]{3}{*}{0.18} \\
\hline - bifocal or multifocal (2) & 73.3 & 80.9 & \\
\hline - distance (3) & 10.7 & 4.4 & \\
\hline \multicolumn{4}{|c|}{$\begin{array}{l}\text { Health status characteristics }(\%)^{b} \text { : } \\
\text { General co-morbidity: }\end{array}$} \\
\hline * no & 41.3 & 42.6 & \multirow[t]{3}{*}{0.87} \\
\hline - yes & 58.7 & 57.4 & \\
\hline \multicolumn{3}{|l|}{$\begin{array}{l}\text { General Health status, EQ-5D: } \\
\text { - healthy (1) }\end{array}$} & \\
\hline - healthy (1) & 36.0 & 26.5 & \multirow{3}{*}{$<0.01$} \\
\hline (very) mild (2) & 60.0 & 47.0 & \\
\hline - (very) severe (3) & 4.0 & 26.5 & \\
\hline \multirow{2}{*}{\multicolumn{4}{|c|}{$\begin{array}{l}\text { Preferences (mean, SD) } \\
\text { VAS }^{\mathrm{g}}\end{array}$}} \\
\hline & $0.78 \pm 0.19$ & $0.66 \pm 0.22$ & $<0.01$ \\
\hline TTO & $0.68 \pm 0.28$ & $0.70 \pm 0.26$ & 0.83 \\
\hline & $0.94 \pm 0.06$ & $0.95 \pm 0.06$ & 0.06 \\
\hline \multicolumn{4}{|c|}{ 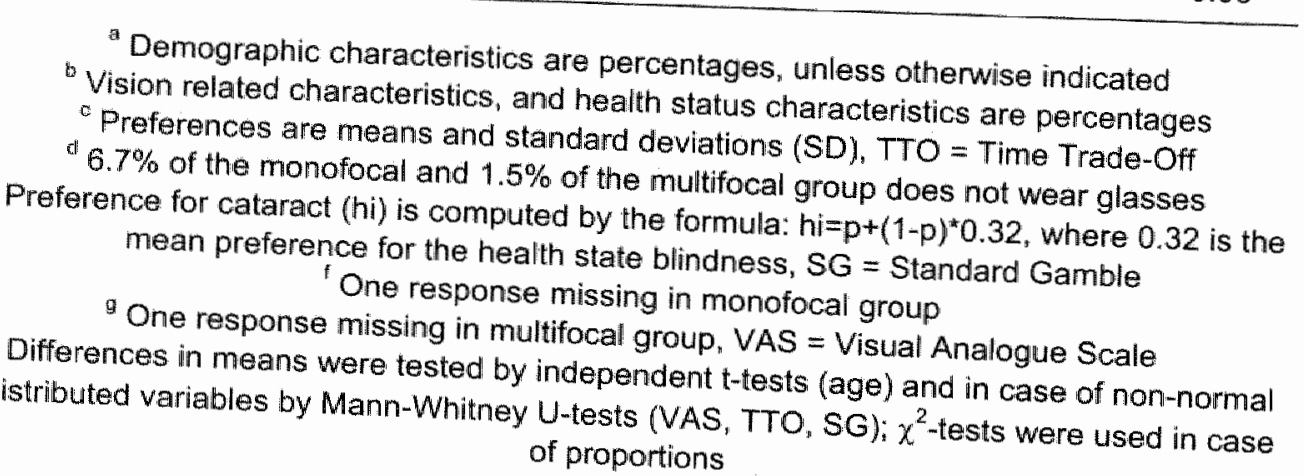 } \\
\hline
\end{tabular}


The general health status of patients differed significantly $(p<0.01)$ between the two groups. In the monofocal group $36.0 \%(n=27)$ were classified as healthy, $60.0 \%$ $(n=45)$ as having a mild disease and $4.0 \%(n=3)$ as severely ill. The percentages in the multifocal group were $26.5 \% \quad(n=18), 47.0 \% \quad(n=32)$ and $26.5 \% \quad(n=18)$, respectively. Severely ill patients were patients with different co-morbidity, which was reflected in the generic quality of life instrument. These patients have some difficulties to walk, bath and dress themselves and perform their daily activities. They also were likely to have some pain and have some problems in anxiety. According to Dolan ${ }^{13}$ these patients classify themselves as severely ill, which is not reflected in the general co-morbidity. In contrast to self-reported health status, cataract patients did not differ significantly in general co-morbidity $(p=0.87)$. Since the randomization was based on ocular co-morbidity, it was possible to find a significant difference between monofocal and multifocal patients for self-reported general health status. Thus, general health status is a known covariate and needs to be included in the statistical analyses. Statistical baseline differences between the monofocal and multifocal group were found regarding the VAS valuation of the general health status. The preference for the monofocal group, was $0.78 \pm 0.19$ and for the multifocal group $0.66 \pm 0.22$ ( $p<0.01)$. Controlling for these baseline differences by including them as covariates in the regression model was applied.

\section{CLINICAL OUTCOME PARAMETERS}

Table 2.2 presents the present corrected visual acuity (VA) in logMAR and postoperative refraction error in Spherical Equivalent (SE). VA was not significantly different between the two $1 O \mathrm{~L}$ groups. The monofocal group showed a myopic Spherical Equivalent compared to the multifocal group at $T_{1}(p<0.01)$ and at $T_{2}$ $(p<0.001)$.

\section{COSTS}

Table 2.3 presents the costs for monofocal and multifocal IOL for both eyes and the mean direct patient costs. No significant differences in total patient costs were found. Significant costs differences between the monofocal and multifocal IOL were found for the out-of-pocket expenses for multifocal glasses $(U=-2.406, p=0.016)$ and for nonrefractive glasses $(U=-2.838, p=0.005)$. 


\section{CHAPTER 2}

Table 2.2. Mean ( \pm SD) clinical outcomes of cataract patients by treatment group

\begin{tabular}{|c|c|c|c|c|c|c|c|c|}
\hline & \multicolumn{3}{|c|}{$\begin{array}{c}\text { Monofocal } 10 \mathrm{~L}(0) \\
\qquad(n=75)\end{array}$} & \multicolumn{3}{|c|}{$\begin{array}{l}\text { Multifocal IOL (1) } \\
\qquad(\mathrm{n}=68)\end{array}$} & \multirow[b]{2}{*}{$\begin{array}{c}\mathrm{p}- \\
\text { value } \\
\end{array}$} & \multirow[b]{2}{*}{$\begin{array}{c}\text { p- } \\
\text { value }\end{array}$} \\
\hline 8 & $T_{1}$ & $\mathrm{~T}_{2}$ & $T_{3}$ & $\mathrm{~T}_{1}$ & $T_{2}$ & $T_{3}$ & & \\
\hline VA $\left(1^{s t} \theta y e\right)^{m}$ & $\begin{array}{r}0.46 \\
\pm 0.27\end{array}$ & $\begin{array}{l}0.12 \\
\pm 0.22\end{array}$ & NA & $\begin{array}{c}0.49 \\
\pm 0.27\end{array}$ & $\begin{array}{c}0.13 \\
\pm 0.17\end{array}$ & NA & $\mathrm{ns}$ & ns \\
\hline VA $\left(2^{\text {nd }} \text { ever }\right)^{a}$ & $\begin{array}{c}0.31 \\
\pm 0.22\end{array}$ & NA & $\begin{array}{l}0.07 \\
\pm 0.14\end{array}$ & $\begin{array}{c}0.28 \\
\pm 0.19\end{array}$ & $N A$ & $\begin{array}{c}0.09 \\
\pm 0.16\end{array}$ & ns & ns \\
\hline$S E\left(1^{s t} \text { eye }\right)^{b}$ & $\begin{array}{l}-0.31 \\
\pm 2.14\end{array}$ & $\begin{array}{l}-0.31 \\
\pm 0.77\end{array}$ & NA & $\begin{array}{c}0.29 \\
\pm 2.08\end{array}$ & $\begin{array}{c}0.06 \\
\pm 0.66\end{array}$ & NA & $<0.01$ & NA \\
\hline$S E\left(2^{n d} \text { eye }\right)^{b}$ & $\begin{array}{r}-0.16 \\
\pm 2.21 \\
\end{array}$ & NA & $\begin{array}{r}-0.42 \\
\pm 0.77 \\
\end{array}$ & $\begin{array}{r}0.60 \\
\pm 1.95 \\
\end{array}$ & NA & $\begin{array}{c}0.14 \\
\pm 0.58\end{array}$ & NA & $<0.001$ \\
\hline
\end{tabular}

a VA $\left(1^{\text {st }}\right.$ eye) or VA $\left(2^{\text {nd }}\right.$ eye $)=$ Present Corrected Visual Acuity of the first eye (OD or OS) or Present Corrected Visual Acuity of the second eye (OD or OS) in mean logMAR (= logarithm of the minimal angle of resolution scale) and standard deviation (SD)

${ }^{b} S E\left(1^{\text {st }}\right.$ eye) or SE $\left(2^{\text {nd }}\right.$ eye $)=$ Refraction error of the first eye (OD or OS) or Refraction error of the second eye (OD or OS) in mean Spherical Equivalent and standard deviation (SD)

${ }^{c}$ Differences between monofocal and multifocal $1 O \mathrm{~L}$ groups at $\mathrm{T}_{2}$

Differences between monofocal and multifocal IOL groups at $T_{3}$ $\mathrm{NA}=$ not applicable, $\mathrm{ns}=$ not significant

The mean costs for multifocal or non-refractive glasses per patient in the monofocal group were $€ 128.19 \pm € 230.79$ and $€ 0.00$, and in the multifocal group $€ 46.40 \pm$ $€ 140.21$ and $€ 1.82 \pm € 5.76$, respectively. Cumulating all types of glasses a significant difference was found in the direct patient costs $(U=-2.670, p=008)$. The monofocal group spent more money on glasses ( $€ 241.67 \pm € 219.91)$ than the multifocal group ( $€ 149.58 \pm € 185.01$ ), due to the costs of the relatively expensive multifocal glasses. As some patients in the multifocal group were habitually used to wear glasses, they spent money on non-refractive glasses. 
Table 2.3. Mean costs per patient by treatment group (in Euros)

\begin{tabular}{|c|c|c|c|}
\hline & $\begin{array}{l}\text { Monofocal IOL } \\
\qquad(n=75)\end{array}$ & $\begin{array}{l}\text { Multifocal } \| \mathrm{OL} \\
\qquad(n=68)\end{array}$ & $\begin{array}{l}\text { Incremental } \\
\text { costs }\end{array}$ \\
\hline \multicolumn{4}{|l|}{ Direct hospital cosils: } \\
\hline Mono/Muitifocal IOL & $158.82^{2}$ & $249.58^{\circledR}$ & 90.76 \\
\hline \multicolumn{4}{|l|}{ Direct patient costs (mean, SD): } \\
\hline Reading glasses & $29.91 \pm 78.45$ & $32.17 \pm 64.01$ & 2.26 \\
\hline Bifocal glasses & $67.47 \pm 133.22$ & $64.02 \pm 147.07$ & -3.45 \\
\hline Multifocal glasses & $128.19 \pm 230.79$ & $46.40 \pm 140.21$ & $-81.79 *$ \\
\hline Distance glasses & $16.11 \pm 51.99$ & $5.17 \pm 24.61$ & -10.94 \\
\hline Nom-refractiveglasses & $0.00 \pm 0.00$ & $1.82 \pm 5.76$ & $1.82^{* *}$ \\
\hline $\begin{array}{l}\text { Subtotal direct patients costs } \\
\qquad(95 \% \mathrm{Cl})\end{array}$ & $241.67 \pm 219.91$ & $149.58 \pm 185.01$ & $\begin{array}{c}-92.09 * * \\
(-159.06,-25.12)\end{array}$ \\
\hline $\begin{array}{c}\text { Total costs per patient } \\
(95 \% \mathrm{Cl})\end{array}$ & $400.49 \pm 219.91$ & $399.16 \pm 185.01$ & $\begin{array}{c}-1.33 \\
(-68.30,65.34)\end{array}$ \\
\hline
\end{tabular}

\footnotetext{
* Mann-Whitney U-test: $U=-2.406, p=0.016$

** Mann-Whitney U-test: $U=-2.838, p=0.005$

*** Mann-Whitney U-test: $U=-2.670, p=0.008$

" standard deviation not applicable

$\mathrm{SD}=$ standard deviation

$95 \% \mathrm{Cl}=95 \%$ Confidence Interval
}

\section{EFFECTIVENESS}

Table 2.4 shows the mean utilities of monofocal and multifocal $10 \mathrm{~L}$ implanted patients after first $\left(T_{2}\right)$ and second $\left(T_{3}\right)$ eye-surgery. Although we controlled for the preoperative difference in VAS preferences between the two groups, significant differences in VAS preferences after first eye-surgery were not found. The significant Odds Ratio (OR=0.08, 95\% Confidence Interval $(\mathrm{CI})=0.01-0.56$ ) was explained by the preoperative difference in VAS preferences. At $T_{1}$ the mean VAS preference was $0.78 \pm 0.19$ for the monofocal group and $0.66 \pm 0.22$ for the multifocal group.

After second eye-surgery a significant Odds Ratio (OR $=0.10,95 \%$ $\mathrm{Cl}=0.02-0.64)$ was found between the monofocal and multifocal group. This difference was also explained by the preoperative difference in VAS preferences. Statistical differences in TTO and SG were not found between monofocal and multifocal $10 \mathrm{~L}$ patients. 
Table 2.4. Mean ( \pm SD) utilities of monofocal and multifocal IOL patients over time controlled for baseline differences $(n=143)$

\begin{tabular}{|c|c|c|c|c|c|c|c|c|}
\hline & \multicolumn{3}{|c|}{$\begin{array}{c}\text { Monofocal } 10 L(0) \\
(n=75)\end{array}$} & \multicolumn{3}{|c|}{$\begin{array}{c}\text { Multifocal IOL (1) } \\
(n=68)\end{array}$} & \multirow[b]{2}{*}{$\begin{array}{l}\text { Odds Ratio } \\
(95 \% \text { Cl })^{2}\end{array}$} & \multirow[b]{2}{*}{$\begin{array}{l}\text { Odds Ratio } \\
(95 \% \mathrm{Cl})^{\mathrm{b}}\end{array}$} \\
\hline & $T_{i}$ & $T_{2}$ & $T_{3}$ & $T_{i}$ & $T_{2}$ & $T_{3}$ & & \\
\hline VAS & $\begin{array}{r}0.78 \\
\pm 0.19\end{array}$ & $\begin{array}{r}0.80 \\
\pm 0.19\end{array}$ & $\begin{array}{c}0.79 \\
\pm 0.17\end{array}$ & $\begin{array}{c}0.66 \\
\pm 0.22\end{array}$ & $\begin{array}{r}0.76 \\
\pm 0.22\end{array}$ & $\begin{array}{c}0.70 \\
\pm 0.24\end{array}$ & $\begin{array}{c}0.08^{x} \\
(0.01-0.56)\end{array}$ & $\begin{array}{c}0.10^{*} \\
(0.02-0.64)\end{array}$ \\
\hline TTO & $\begin{array}{r}0.68 \\
+0.28\end{array}$ & $\begin{array}{l}0.74 \\
\pm 0.28\end{array}$ & $\begin{array}{c}0.67 \\
\pm 0.29\end{array}$ & $\begin{array}{r}0.70 \\
\pm 0.26\end{array}$ & $\begin{array}{c}0.70 \\
\pm 0.30\end{array}$ & $\begin{array}{c}0.62 \\
\pm 0.28\end{array}$ & ns & $\mathrm{ns}$ \\
\hline$S G$ & $\begin{array}{r}0.94 \\
+0.06\end{array}$ & $\begin{array}{c}0.95 \\
\pm 0.06\end{array}$ & $\begin{aligned} & 0.94 \\
+ & 0.05\end{aligned}$ & $\begin{array}{r}0.95 \\
\pm 0.06\end{array}$ & $\begin{array}{r}0.94 \\
\pm 0.06\end{array}$ & $\begin{array}{r}0.93 \\
\pm 0.07\end{array}$ & ns & ns \\
\hline
\end{tabular}

$95 \% \mathrm{Cl}=95 \%$ Confidence interval, $\mathrm{ns}=$ not significant

VAS $=$ Visual Analogue Scale, TTO = Time Trade-Off, SG = Standard Gamble

Odds Ratios calculated between $T_{2}$ and $T_{1}$

${ }^{b}$ Odds Ratios calculated between $T_{3}$ and $T_{1}$

* $p<0.05$

\section{DISCUSSION}

This paper described a cost-utility analysis of foldable multifocal and monofocal IOLs in cataract surgery applying a societal perspective. Contradictory to the study of Orme et al. ${ }^{8}$ this study revealed that cataract surgery implanting a monofocal or multifocal IOL is equally cost-effective. The present study used prospectively collected effectiveness data and measured costs alongside an RCT. Since an RCT is the "gold standard" to obtain unbiased, reliable data we have reason to believe that our data are more representative for the actual reality. ${ }^{1}$

The present study was performed without financial interest and offers an unbiased representation of the cost-effectiveness of multifocal IOLs. ${ }^{19-21}$

Effectiveness in the present study was measured in terms of generic HRQoL. We assumed a relationship between visual acuity loss and HRQOL for cataract based on a study comparing the quality of life in patients with visual acuity loss due to diabetic retinopathy and visual acuity loss due to age-related macular degeneration. ${ }^{22}$

Generic HRQOL was measured with the EQ-5D. This instrument was used to describe a patients' health state. The aim of this study was to perform a cost-utility 
analysis, not to discriminate between levels of health status. Therefore, preferences were not assessed for the dimensions of the EQ-5D."

Furthermore, this study showed that the savings in the direct patients costs compensate for the additional direct health care costs for the multifocal $10 \mathrm{~L}$. Although policy makers may not welcome the fact that costs in the health care sector will be saved outside the health care sector, from a patient perspective this is a positive result.

Some remarks about the present study can be made. First, patient preferences were used as outcome measure. To fully carry through the societal perspective, societal preferences should be used. Secondly, significant differences in effectiveness in this prospective study were not found. This could be attributed to an adaptation effect ${ }^{23-25}$ or to a problem with construct validity. Patients adapt to their condition and as a consequence they value the pre-treatment quality of life generally higher than one would expect given their condition. Post-treatment, patients value their pre-treatment quality of life generally lower, due to a change in internal standards. This phenomenon is known as response-shift. ${ }^{23}$ VAS, TTO and $S G$ correlated significantly $(p<0.01)$. Correlations varied from 0.40 to 0.43 , indicating that the underlying construct is similar.

Different elicitation methods obtain different preferences. Numerous studies report higher Standard Gamble scores than TTO scores and also higher TTO scores than VAS scores. ${ }^{26-31}$ In this study TTO scores are lower than VAS preferences, which we are not able to explain."

In view of our results we believe that a reduction in costs for multifocal glasses for patients with a multifocal $\| O L$, is beyond the goal of resource allocation in the health care sector. However, seen from a societal perspective, this should be included in the decision-making process, since a reduction in costs for patients maximizes social welfare, which is the goal of resource allocation. ${ }^{19}$ Nevertheless, individual decisions are not only based on costs but on patients' acceptance of nighttime halos in exchange for decreased spectacle dependence for near.

\footnotetext{
"The above sections were added for this thesis
} 


\section{REFERENCES}

1. Javitt JC, Wang $F$, Trentacost DJ, Rowe $M$, Tarantino $N$. Outcomes of cataract extraction with mullifocal intraocular lens implantation: functional status and quality of life. Ophthalmology 1997;104:589-599.

2. Post CT, Jr. Comparison of depth of focus and low-contrast acuities for monofocal versus multifocal intraocular lens patients at 1 year. Ophthalmology 1992;99:16581663 .

3. Steinert RF, Post CT, Jr., Brint SF, Fritch CD, Hall DL, Wilder LW, et al. A prospective, randomized, double-masked comparison of a zonal-progressive multifocal intraocular lens and a monofocal intraocular lens. Ophthalmology 1992,99:853-860.

4. Leyland $M_{1}$ Zinicola E. Multifocal versus monofocal intraocular lenses after cataract extraction (Cochrane review). J Am Coll Surg 2002;195:685.

5. Javitt $d_{\sharp}$ Brauweiler HP, Jacobi KW, Klemen U, Kohnen $S$, Qentin $C$, et al. Cataract extraction with multifocal intraocular lens implantation: clinical, functional, and qualityof-life outcomes. Multicenter clinical trial in Germany and Austria. $J$ Cataract Refr Surg 2000;26:1356-1366.

6. Javitt JC, Steinert RF. Cataract extraction with multifocal intraocular lens implantation: a multinational clinical trial evaluating clinical, functional, and quality-oflife outcomes. Ophthalmology 2000;107:2040-2048.

7. Desai P, Reidy A, Minassian DC, Vafidis G, Bolger J. Gains from cataract surgery: visual function and quality of life. Br J Ophthalmol 1996;80:868-873.

8. Orme ME, Paine AC, Teale CW, Kennedy LM. Cost-effectiveness of the AMOArray multifocal intraocular lens in cataract surgery. J Refr Surg 2002;18:162-168.

9. Gold MR, Siegel JE, Russell LB, Weinstein MC. Cost-effectiveness in health and medicine. New York, Oxford: Oxford University Press; 1996.

10. Drummond MF, O'Brien BJ, Stoddart GL, Torrance GW. Methods for the economic evaluation of health care programmes. Second ed. Oxford: Oxford University Press: 1997.

11. Nikamp M. Determinants of patient satisfaction after cataract surgery. Maastricht: Unigraphic Maastricht; 2003.

12. The EuroQol Group. EuroQol--a new facility for the measurement of health-related quality of life. Health Policy 1990;16:199-208.

13. Dolan P. Modeling valuations for EuroQol health states. Med Care 1997:35:10951108.

14. Torrance GW. Measurement of health state utilities for economic appraisal. $J$ Health Econ 1986;5:1-30.

15. Brown MM, Brown GC, Sharma S, Kistler J, Brown H. Utility values associated with blindness in an adult population. Br, Ophthalmo/ 2001;85:327-331. 
16. Torrance GW. Social preferences for health states: an empirical evaluation of three measurement techniques. Socio-Econ Plan Sci 4976;10:129-136.

17. Torgerson D.J, Campbell MK. Economics notes: cost effectiveness calculations and sample size. BMJ 2000;321:697.

18. Exchange rates. Available at: http://www.statistics.dnb.ni//ndex.html. Accessed September 27, 2003.

19. Azimi NA, Welch HG. The effectiveness of cost-effectiveness analysis in containing costs. J Gen Intern Med 1998;13:664-669.

20. Friedberg $M$, Saffran $B$, Stinson $T J$, Nelson $W$, Bennett CL. Evaluation of conflict of interest in economic analyses of new drugs used in oncology. JAMA 1999:282:14531457.

21. Krimsky S. Conflict of interest and cost-effectiveness analysis. JAMA 1999;282:14741475.

22. Brown MM. Brown GC, Sharma S, Landy J, Bakal J. Quality of life with visual acuity loss from diabetic retinopathy and age-related macular degeneration. Arch Ophthalmol 2002;120:481-484.

23. Groot W. Adaptation and scale of reference bias in self-assessments of quality of life. $J$ Health Econ 2000;19:403-420.

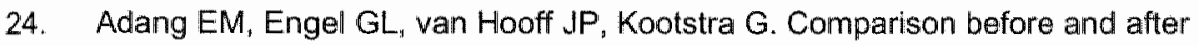
transplantation of pancreas-kidney and pancreas-kidney with loss of pancreas--a prospective controlled quality of life study. Transp/ 1996;62:754-758.

25. Postulart D, Adang EM. Response shift and adaptation in chronically ill patients. Med Decis Making 2000;20;186-193.

26. Hornberger JC, Redelmeier DA, Petersen J. Variability among methods to assess patients" well-being and consequent effect on a cost-effectiveness analysis. $J \mathrm{Clin}$ Epidemiol 1992;45:505-512.

27. Bleichrodt $H_{1}$ Johannesson $M$. An experimental test of a theoretical foundation for rating-scalle valuations. Med Decis Making 1997;17:208-216.

28. Nease RF, Jr., Brooks WB. Patient desire for information and decision making in health care decisions: the Autonomy Preference Index and the Health Opinion Survey. J Gen Intern Med 1995; 10:593-600.

29. O'Leary JF, Fairclough DL, Jankowski MK, Weeks JIC. Comparison of time-tradeoff utilities and rating scale values of cancer patients and their relatives: evidence for a possible plateau relationship. Med Decis Making 1995;15:132-137.

30. Read $J L$, Quinn RJ, Berwick DM, Fineberg HV, Weinstein MC. Preferences for health outcomes. Comparison of assessment methods. Med Decis Making 1984;4:315-329.

31. van Wijck EE, Bosch JL, Hunink MG. Time-tradeoff values and standard-gamble utilities assessed during telephone interviews wersus face-to-face interviews. Med Decis Making 1998;18:400-405. 



\title{
BIASED AND UNBIASED PREFERENCES IN A REFERENCE CASE SCENARIO FOR SENILE CATARACT IN THE NETHERLANDS
}

\author{
M. Dolders, E. Adang, A. Ament, W. Groot \\ Submitted for publication
}

\begin{abstract}
Aim: To analyze potential bias in obtaining population preferences for senile cataract and the health states after cataract surgery, using a Reference Case scenario.

Methods: A random sample $(\mathrm{N}=1000)$ of the Dutch population was surveyed using a mailed questionnaire. Preferences were measured with the Visual Analogue Scale, the Time TradeOff and the Standard Gamble.

Results: The response rate was $12 \%$ and was non-randomly distributed. Respondents aged between 40 and 59 years, married and highly educated respondents and those having a job were over-represented. Respondents not wearing spectacles were underrepresented. The sample was representative with respect to morbidity. Female respondents valued the health status of "cataract" significantly higher than male respondents. However, valuation differences between individuals more inclined to respond were not found.

Conclusion: Obtaining preferences from a survey among a random sample of the population might result in unbiased population preferences, even if the sample is not representative for the population.
\end{abstract}




\section{INTRODUCTION}

According to the US Panel on Cost-Effectiveness, it is desirable to use a Reference Case scenario in cost-effectiveness analysis to determine resource allocation at the macro-level. ${ }^{1}$ A Reference Case is a standard set of methodological practices to enhance the comparability of cost-effectiveness studies. One of these methodological practices is the perspective of the analysis. An analysis aimed at the general allocation of health resources needs to consider not only who gains in health but also who has to pay for it. The Panel therefore recommended a societal perspective for both costs and effects. In this chapter, we restrict ourselves to the effects. A societal perspective for effects results in the measurement of population preferences. Population preferences regarding a particular health state should, theoretically, be gathered from a representative and unbiased sample of the population. Random sampling increases the likelihood of obtaining a sample that is representative of the population. ${ }^{2}$ However, it may be questioned whether drawing a sample from the community at random will indeed result in a representative sample. If the response is non-random, a randomly drawn sample can ultimately result in a selective sample. Conclusions on the valuation of the health benefits of an intervention drawn from a non-random sample may lead to biased population preferences, if the likelihood of participating in the survey is correlated with the valuation of health benefits.

Even if the sample is randomly drawn, the response may contain an overrepresentation of individuals that have greater affinity with or knowledge about the specific disease or handicap and its treatment(s) than others. Consequently, some people may be more inclined to respond to such survey questions than others. The present study aimed to obtain population preferences regarding senile cataract and cataract surgery. From age 50 onwards, the incidence and prevalence of "near visual functioning limitations, without correction" and the diagnosis of "cataract" increase. Thus, age is an important variable in valuing the visionimpaired health states of "cataract" and "wearing reading glasses". The health state of "wearing reading glasses" can be assumed to be valued differently by respondents wearing (reading) glasses or contact lenses than by respondents who do not wear these sight corrections. Thus, if the sample contains more patients or elderly persons than expected from their prevalence in the general population, preferences may not reflect population preferences and may give biased information. The purpose of the present study was to analyze whether addressing 
a random sample of the Dutch population would result in a non-selective sample that could yield reliable information on population preferences regarding senile cataract.

Senile cataract is an age-related vision problem and is defined as an opacity in the crystalline lens of the eye. ${ }^{3}$ In 1994, the prevalence of cataract among people over 50 in the Netherlands was approximately 3\% among men and 5\% among women. The incidence in the over 50 age category was approximately $0.5 \%$ for men and $0.9 \%$ for women., 4 The only treatment for senile cataract is surgery. During surgery, the opaque lens is removed and replaced by an artificial implant lens. Different types of artificial implant lenses are used in cataract surgery "the most common type being a monofocal intra-ocular lens with fixed lens power that gives sharp vision at far distance without correction. Nevertheless, reading glasses (or contact lenses) are needed for near-vision activities. The other type of artificial implant lens, a multifocal implant lens, provides the patient with multifocal vision, ${ }^{6}$ that is, sharp vision at near, intermediate, and far distances, without glasses or contact lenses. ${ }^{7}$

\section{METHODS}

\section{SAMPLE}

A cross-sectional anonymous random sample of the Dutch population aged 18 and over was only once sent a questionnaire by mail $(N=1000)$. A letter explaining the purposes of the study and a postage-free return envelope were included. The sample size in this study was calculated from the guidelines on studies among the general population using the EuroQol-5D (EQ-5D) index for population preferences. ${ }^{8}$ The sample was based on private telephone addresses in the Netherlands, selected by zip-code. Based on the literature, the response-rate was expected to be at least $30 \%{ }^{9}$

\section{SCENARIO FOR THE REFERENCE CASE STUDY}

The Panel on Cost-Effectiveness identified six steps to calculate the difference in effectiveness between a health state assuming a particular disease (e.g. cataract) and the health states after an assumed intervention and the alternative(s) for that particular disease (e.g. reading glasses). This paper concentrates on the first three steps, because they are related to population preferences. The first recommended step is to identify the relevant outcomes in terms of generic health states (including 
death). The second step involves describing the elements of health states and their possible course over time for individuals receiving the intervention and for those who receive an alternative. The third step involves combining the elements of the health state into a single number reflecting the value assigned to that health state.' Alongside the survey reported on in the present article, a multi-center randomized controlled trial on the effectiveness and efficiency of multifocal intra-ocular implant lenses was undertaken by the Maastricht Eye Research Institute. ${ }^{10}$ This is why we chose the health states relating to senile cataract and cataract surgery for our attempt to obtain population preferences.

\section{QUESTIONNAIRE}

The questionnaire included the EQ-5D self-classifier to assess the respondents' self-reported health status. This descriptive classification system defines generic Health Related Quality of Life in terms of five dimensions (mobility, self-care, usual activities, pain/discomfort and anxiety/depression). Each dimension is recorded at three levels of severity: $1=$ no problems, $2=$ moderate problems and $3=$ severe problems. The result of selecting one level for each of the 5 dimensions is a fivedigit code, representing an individual's current EQ-5D health state. For example, the health state 11231 indicates no problems with mobility, no problems with selfcare, moderate problems with usual activities, severe problems of pain/discomfort and no problems of anxiety/depression. For the purpose of the statistical analysis, this five-digit code, representing the current health state of an individual, was recoded into three levels of severity: healthy, mild and severe. ${ }^{11}$ The EQ-VAS, defined as a standard vertical $20 \mathrm{~cm}$ visual analogue scale (comparable to a thermometer), was used to measure respondents' rating of their current Health Related Quality of Life state. ${ }^{12,13}$ To measure the health states before and after cataract surgery, this thermometer was extended to measure the following states as well: cataract, wearing reading glasses, health and death. This was our specification of step 1 in the Reference Case scenario described above.

Cataract was described in detail using visual aids and a description in terms of the five dimensions on the EQ-5D (see Figure 3.1). This represented our specification of step 2 in the Reference Case scenario. 
Figure 3.1. Visualizing the health state of "cataract"

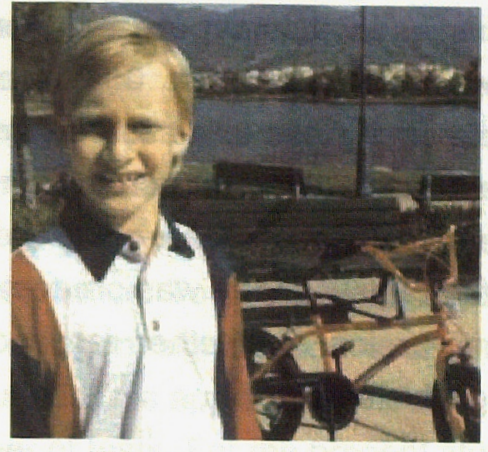

Normal vision

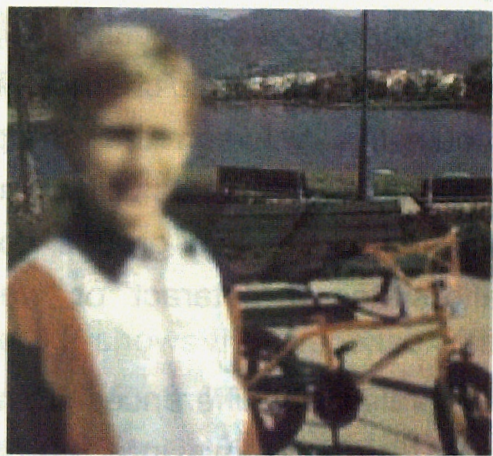

Vision with monofocal lens

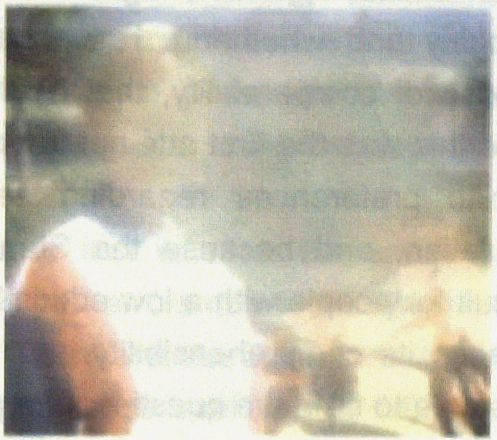

Vision with cataract

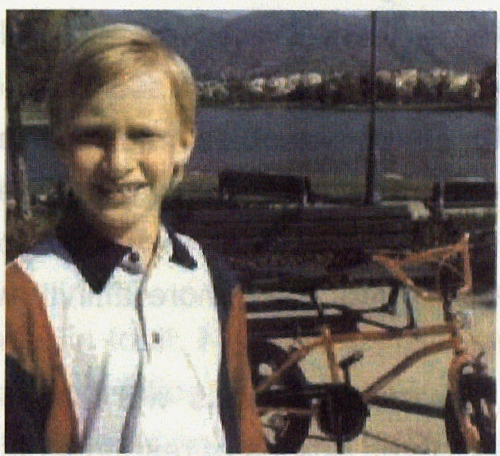

Vision with multifocal lens

To measure preferences for the various health states (step 3 of the Reference Case scenario) we used three different scales: a Visual Analogue Scale, that is, a straight $10 \mathrm{~cm}$ line with endpoints representing the best imaginable health state and the worst imaginable health state, ${ }^{14}$ the Time Trade-Off ${ }^{1,15,16}$ technique and the Standard Gamble technique. ${ }^{17}$ Since the Standard Gamble technique has been reported to be difficult to use in a mailed questionnaire and might result in missing observations or an incomplete Standard Gamble technique, the other valuation methods were also included in the questionnaire. ${ }^{18} \mathrm{~A}$ grade between zero and ten, with zero representing the worst imaginable health state and ten the best imaginable health state, was used for respondents who were unable to fill in the VAS because of their visual impairment. 
The questionnaire also included questions on socio-demographic characteristics (gender, age, marital status, level of education, occupation) morbidity and whether a respondent wore glasses or contact lenses. For the purpose of comparability, the VAS and TTO were transformed to $0-1$ scales. Since this was the first attempt to conduct a Reference Case to measure diseasespecific preferences regarding senile cataract and cataract surgery in the population, and because the Standard Gamble method is believed to be too difficult for people with a low educational level, the questionnaire was pre-tested to enhance its comprehensibility and to get an impression of whether respondents were able to fill in the questionnaire (to avoid cognitive overload).

\section{STATISTICAL ANALYSIS}

A missing values analysis was performed to analyze the pattern of missing data. If the missing values were scattered randomly this would cause less serious problems than if the missing values were scattered systematically. Logistic regression analysis was used to assess differences in demographic characteristics, health status variables and eye-related characteristics between the groups of respondents with randomly distributed missing data and respondents with complete data. Differences that might be found, show whether the two groups contain individuals that have more affinity with the health states of "cataract" or "wearing reading glasses".

Parametric t-tests were applied to assess valuation differences in health states for the groups of respondents with randomly distributed missing data or with non-missing data and to assess valuation differences for the health states of "cataract" and "wearing reading glasses" in (a) men versus women, (b) respondents younger than 50 years versus respondents aged 50 years or over, (c) respondents who were married, never married, widowed or divorced, (d) respondents with lower education, middle education or higher education, (e) respondents having or not having a job (including retired persons), (f) respondents wearing glasses or contact lenses versus respondents without sight corrections, (g) respondents suffering from one or more of the following diseases: rheumatism, chronic cough, heart disease, cancer, hypertension, consequences of a stroke, diabetes mellitus, anemia, asthma, consequences of an accident and cataract versus healthy respondents, (h) female respondents wearing reading
glasses versus male respondents wearing reading glasses. 
These two parametric techniques test whether two populations that are independent are identical. The null hypothesis states that there is no difference between the two populations, whereas the alternative hypothesis is that they are different. The sample was compared with the Dutch population in terms of demographic, health status and eye-related characteristics, using the classification described above.

A $\chi^{2}$-goodness-of-fit test was performed to test whether the sample was representative. To avoid the increasing risk of Type I errors due to multiple testing, more stringent significance levels were applied. Therefore, the Bonferroni approach was used. This approach divides the chosen significance level (mostly 0.05 ) by the number of tests. For the present study, this resulted in a significance level of 0.007 .

Pearson coefficients were used to assess the correlation between grades and VAS scores. A significant correlation between grade and VAS was found for the current health state $(\alpha=.71, p=.000)$, the health state of "cataract" ( $\alpha=.82$, $p>.000)$ and the health state of "wearing reading glasses" $(\alpha=.79, p>.000)$. Based on these correlations, the VAS scores were used in the analyses described below.

\section{RESULTS}

\section{RESPONSE}

Figure 3.2 shows the response rate of this study. In total, $N=1000$ questionnaires were send to a random sample of the Dutch population. There was an initial response rate of $19 \%(n=189)$. Of these 189 questionnaires, $148(78 \%)$ were returned in the answering envelope. Forty-one questionnaires were undeliverable and were returned unopened. These 41 questionnaires had not been delivered because people had either moved $(n=17)$, were deceased $(n=11)$ or their address was unknown $(n=13)$. Of the 148 returned questionnaires, $123(83 \%)$ had been filled in. The reasons stated for not filling in the questionnaire $(n=25)$ were: respondent deceased $(n=9)$, respondent angry $(n=2)$, questionnaire too difficult $(n=1)$, or insufficient command of Dutch $(n=1)$ and age in combination with suffering from cataract $(n=1)$. For 11 respondents, the reason was unknown. This resulted in a response rate of approximately $12 \%$. 
Figure 3.2. Response of Study

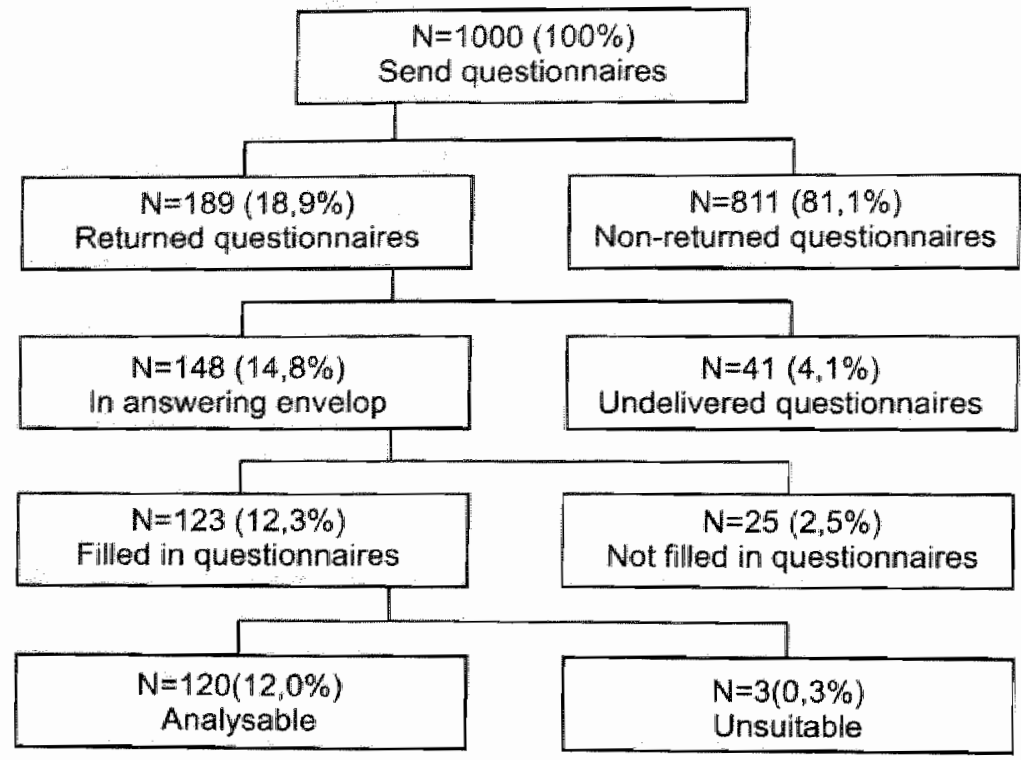

MISSING VALUES ANALYSIS

Of the 123 questionnaires, 80 had been filled in completely, whereas three questionnaires had too many missing values to be used in the analyses. The remaining 40 incomplete questionnaires lacked the valuation for at least one of the five health states on the thermometer. Five of these 40 incomplete questionnaires missed the valuations of the different health states and one missed the demographic characteristics. The pattern indicated that missing values were not randomly distributed. Furthermore, these respondents had affinity with cataract. Based on the missing values pattern 114 questionnaires remained for further analyses. Health status valuations and differences in health status valuations between the group with randomly distributed missing data $(n=34)$ and the group with non-missing data $(n=80)$ are presented in Table 3.1.

The valuations on the VAS for the health state of "cataract" differed significantly between the groups with randomly distributed missing data and without missing data. Respondents with complete data valued the health state of "cataract" more highly than respondents with randomly distributed missing data. 
Table 3.1. Differences in health status valuations between groups of respondents with randomly missing data and non-missing data

\begin{tabular}{|c|c|c|c|}
\hline & $\begin{array}{c}\text { Randomly missing } \\
\text { data }(n=34)^{a}\end{array}$ & $\begin{array}{l}\text { Non-missing } \\
\text { data }(n=80)^{a}\end{array}$ & $p$-value ${ }^{\mathrm{c}}$ \\
\hline \multicolumn{4}{|l|}{ Valuations } \\
\hline - current health status & $0.74(0.20)$ & $0.80(0.13)$ & ns \\
\hline - cataract & $0.39(0.26)$ & $0.53(0.19)$ & .005 \\
\hline $\begin{array}{l}\text { - wearing reading glasses } \\
\text { TTO }\end{array}$ & $0.78(0.14)$ & $0.82(0.11)$ & ns \\
\hline - cataract & $0.72(0.21)$ & $0.74(0.18)$ & ns \\
\hline $\begin{array}{l}\text { - wearing reading glasses } \\
\mathrm{SG}^{\mathrm{b}} \text { : }\end{array}$ & $0.70(0.21)$ & $0.73(0.18)$ & $\mathrm{ns}$ \\
\hline - cataract & $0.90(0.06)$ & $0.90(0.06)$ & ms \\
\hline - wearing reading glasses & $0.90(0.06)$ & $0.89(0.06)$ & ns \\
\hline
\end{tabular}

\footnotetext{
${ }^{a}$ Data are presented as means and standard deviations

- Visual Analogue Scale, Time Trade-Off, Standard Gamble

"p-values based on $t$-tests

$\mathrm{ns}=$ not significant
}

\section{LOGISTIC REGRESSSION ANALYSIS}

Table 3.2 presents the differences in demographic, health status and eye-related characteristics, the -observable characteristics-, between groups with randomly distributed data and complete data. The group with randomly distributed data did not differ significantly from the group with complete data on the above mentioned observabie characteristics. Hence, individuals having more affinity with the health state of "cataract" or the health state of "wearing reading glasses" were not more inclined to respond. Based on this result 114 respondents were used in the remaining analyses. 
CHAPTER 3

Table 3.2. Differences in demographic, health status and eye-related characteristics between groups of respondents with randomly missing data and complete data

\begin{tabular}{|c|c|c|c|}
\hline & $\begin{array}{l}\text { Randomly missing } \\
\text { data }(0) \\
(n=34)\end{array}$ & $\begin{array}{l}\text { Complete } \\
\text { data (1) } \\
(\mathrm{n}=80)\end{array}$ & $\begin{array}{c}\text { Oddls Ratio } \\
(95 \% \mathrm{Cl})\end{array}$ \\
\hline \multicolumn{4}{|c|}{ Demographic characteristics } \\
\hline Age (mean, sd) & $51.1(\mathrm{sd} 12.7)$ & $47.4($ sd 10.7) & $0.94(0.87-1.02)$ \\
\hline \multicolumn{4}{|l|}{ Gender: } \\
\hline - Female (0) & $59 \%$ & $65 \%$ & $0.35(0.09-1.24)$ \\
\hline - Male (1) & $41 \%$ & $35 \%$ & \\
\hline \multicolumn{4}{|l|}{ Marital status: } \\
\hline - Married $(0)^{a}$ & $82 \%$ & $86 \%$ & $1.85(0.3 \|-10.88)$ \\
\hline - Single $(1)^{6}$ & $18 \%$ & $14 \%$ & \\
\hline \multicolumn{4}{|l|}{ Education: } \\
\hline - lower & $41 \%$ & $26 \%$ & 1.00 \\
\hline - middle & $27 \%$ & $21 \%$ & $0.46(0.13-1.61)$ \\
\hline - high & $32 \%$ & $53 \%$ & $1.11(0.27-4.59)$ \\
\hline \multicolumn{4}{|l|}{ Occupation: } \\
\hline - not having a job & $20 \%$ & $10 \%$ & 1.00 \\
\hline - having a job & $62 \%$ & $78 \%$ & $0.70(0.07-7.06)$ \\
\hline - retired & $18 \%$ & $12 \%$ & $0.52(0.07-3.85)$ \\
\hline \multicolumn{4}{|c|}{ Health status characteristics } \\
\hline \multicolumn{4}{|c|}{ Morbidity: } \\
\hline$\cdot$ no & $53 \%$ & $69 \%$ & $0.50(0.17-1.50)$ \\
\hline - $\geq$ one chronic disease & $47 \%$ & $31 \%$ & \\
\hline \multicolumn{4}{|l|}{ Health status severity: } \\
\hline - healthy & $45 \%$ & $61 \%$ & 1.00 \\
\hline - mild & $14 \%$ & $23 \%$ & $2.41(0.63-9.29)$ \\
\hline - severe & $41 \%$ & $16 \%$ & $3.01(0.51-17.93)$ \\
\hline \multirow{2}{*}{\multicolumn{4}{|c|}{$\begin{array}{l}\text { Eyearelated } \\
\text { characteristics } \\
\text { Types of glasses or lenses: }\end{array}$}} \\
\hline Types of glasses or lenses: & & & \\
\hline - near distance & $12 \%$ & $33 \%$ & $0.06(0.12-0.33)$ \\
\hline - far distance & $29 \%$ & $29 \%$ & $0.34(0.06-1.81)$ \\
\hline - both & $24 \%$ & $19 \%$ & $1.16(0.19-7.02)$ \\
\hline - none & $35 \%$ & $20 \%$ & 1.00 \\
\hline \multicolumn{4}{|l|}{ Affinity with cataract: } \\
\hline$\cdot$ no $(0)$ & $100 \%$ & $97 \%$ & $0.00(0.00-0.00)$ \\
\hline - yes (1) & $0 \%$ & $3 \%$ & \\
\hline
\end{tabular}

ancluding living together

bingle includes never married, widowed or divorced 


\section{DIFFERENCES BETWEEN THE SAMPLE AND THE ADULT DUTCH POPULATION}

The 114 analyzable questionnaires of the sample were compared with the Dutch adult population in terms of socio-demographics, morbidity and wearing glasses or contact lenses. The results are presented in Table 3.3. The sample turned out to be significantly different from the adult Dutch population with regard to gender, age, marital status, education, occupation and type of glasses. Female respondents and respondents between 40 and 59 years of age, married respondents, highly educated respondents, and respondents having a job were over-represented, whereas respondents without glasses were underrepresented. The sample was representative for the adult Dutch population with regard to morbidity.

\section{VALUATION DIFFERENCES IN HEALTH STATES}

The results of the t-tests to assess valuation differences for the health state of "cataract" and the health state of "wearing reading glasses" are reported in Table 3.4. Female respondents valued the health state of "cataract" significantly higher than male respondents. However, female respondents were not more likely to wear near-sight corrections $(60 \%)$ than male respondents (64\%). Additionally, female and male respondents equally suffered from cataract $(n=2)$. Respondents younger than 50 years did not differ significantly in their valuations for the two health states than respondents aged 50 years and over. There were no significant differences in the valuations of the health states between respondents who were married and those who were never married, widowed or divorced. Nor were there any significant differences in the valuations of the two health states when the sample was stratified by level of education. Respondents who had a job did not have significantly different judgments on the health states than those without a job (including respondents who were retired). No significant difference in valuation of the health states was found between respondents wearing glasses or contact lenses and those who did not wear eye corrections. Nor did respondents suffering from one or more chronic diseases differ significantly from healthy respondents in their valuations of the health state of "cataract" and "wearing reading glasses". Furthermore, the interaction between gender and wearing reading glasses shows that female respondents who wear reading glasses did not differ significantly in their valuations of the two health states from male respondents who wear nearsight corrections. 
Table 3.3: Distribution of characteristics of the Reference Case sample (n=114) compared to the Dutch adult population $(n=12,372,552)$ at 1 January $2000^{119}$

\begin{tabular}{|c|c|c|c|}
\hline & $\begin{array}{c}\text { RC-sample } \\
(\%)\end{array}$ & $\begin{array}{l}\text { Dutch adult } \\
\text { population }(\%)\end{array}$ & $x^{2}$-value \\
\hline \multicolumn{4}{|l|}{ Demographic characteristics } \\
\hline - femalle & 63 & 51 & \multirow[t]{2}{*}{6.88} \\
\hline - male & 37 & 49 & \\
\hline \multicolumn{4}{|l|}{ Age (10-year categories) ${ }^{a}$ : } \\
\hline $18-19$ & 0 & 3.1 & \multirow{9}{*}{57.08} \\
\hline$\cdot 20-29$ & 1.8 & 17.2 & \\
\hline - $30-39$ & 23.6 & 21.3 & \\
\hline$\cdot 40-49$ & 29.1 & 19.0 & \\
\hline$\cdot 50-59$ & 34.5 & 16.2 & \\
\hline - $60-69$ & 6.4 & 11.1 & \\
\hline$\cdot 70-79$ & 2.7 & 8.1 & \\
\hline - $80-89$ & 1.8 & 3.5 & \\
\hline - $90+$ & 0 & 0.5 & \\
\hline \multicolumn{4}{|l|}{ Marital status: } \\
\hline - married ${ }^{b}$ & 85.1 & 57.2 & \multirow{4}{*}{37.82} \\
\hline - never married & 7.0 & 28.8 & \\
\hline - widowed & 3.5 & 7.1 & \\
\hline - divorced & 4.4 & 6.9 & \\
\hline \multicolumn{4}{|l|}{ Education: } \\
\hline - lower & 30.7 & 48.9 & \multirow{3}{*}{59.91} \\
\hline middle & 22.8 & 32.6 & \\
\hline - high & 46.5 & 18.5 & \\
\hline \multicolumn{4}{|l|}{ Occupation: } \\
\hline - having a job & 72.8 & 53.2 & \multirow[t]{3}{*}{17.07} \\
\hline - not having a job ${ }^{c}$ & 27.2 & 46.8 & \\
\hline \multicolumn{3}{|l|}{$\begin{array}{l}\text { Health status characteristics } \\
\text { Morbidity: }\end{array}$} & \\
\hline * no & 64.0 & 60.4 & \multirow[t]{3}{*}{0.59} \\
\hline Z one chronic disease & 36.0 & 39.6 & \\
\hline Eye related characteristics ${ }^{20}$ & & & \\
\hline \multicolumn{4}{|l|}{ Type of glasses: } \\
\hline - near distance & 26.3 & 14.1 & \multirow{4}{*}{34.75} \\
\hline - far distance & 28.9 & 17.9 & \\
\hline both & 20.2 & 19.0 & \\
\hline none & 24.6 & 49.0 & \\
\hline
\end{tabular}

${ }^{2}$ For the $\chi^{2}$-test the age groups of $18-19$ and $20-29$ were comprised to the age group of $18-29$. The same was done for respondents $\geq 70$ years

${ }^{b}$ Including living together

Including retired individuals

${ }^{19}$ Statistics Netherlands, 2000

${ }^{20}$ Van Gessel-Dabekaussen. 1996 
Table 3.4. Valuations (mean and standard deviations) for the health states of "cataract" and "wearing reading glasses"

\begin{tabular}{|c|c|c|c|}
\hline & VAS cataract & TTO cataract & SG cataract \\
\hline Whole sample $(n=114)$ & $0.49(0.22)$ & $0.73(0.19)$ & $0.90(0.06)$ \\
\hline \multicolumn{4}{|l|}{$\begin{array}{l}\text { Sociodemographic } \\
\text { characteristics } \\
\text { Gender: }\end{array}$} \\
\hline - female & $0.54(0.22)^{*}$ & $0.76(0.19)$ & $0.90(0.06)$ \\
\hline - malle & $0.41(0.20) *$ & $0.69(0.18)$ & $0.89(0.06)$ \\
\hline \multicolumn{4}{|l|}{ Age: } \\
\hline - $<50$ years & $0.47(0.19)$ & $0.72(0.17)$ & $0.89(0.06)$ \\
\hline$\geq 50$ years & $0.54(0.25)$ & $0.76(0.21)$ & $0.90(0.06)$ \\
\hline \multicolumn{4}{|l|}{ Marital status: } \\
\hline married $^{\mathrm{a}}$ & $0.48(0.22)$ & $0.73(0.19)$ & $0.89(0.06)$ \\
\hline - never married ${ }^{b}$ & $0.57(0.22)$ & $0.76(0.18)$ & $0.92(0.06)$ \\
\hline \multicolumn{4}{|l|}{ Occupation: } \\
\hline - hawing a job & $0.49(0.28)$ & $0.76(0.21)$ & $0.92(0.06)$ \\
\hline - not having a job ${ }^{\mathrm{c}}$ & $0.49(0.20)$ & $0.72(0.18)$ & $0.89(0.06)$ \\
\hline \multicolumn{4}{|l|}{ Education: } \\
\hline - lower & $0.47(0.26)$ & $0.72(0.23)$ & $0.89(0.07)$ \\
\hline - middle & $0.52(0.22)$ & $0.74(0.17)$ & $0.88(0.06)$ \\
\hline - high & $0.50(0.20)$ & $0.74(0.17)$ & $0.91(0.06)$ \\
\hline \multicolumn{4}{|l|}{$\begin{array}{l}\text { Health status } \\
\text { characteristics } \\
\text { Morbidity: }\end{array}$} \\
\hline - yes & $0.48(0.25)$ & $0.74(0.19)$ & $0.90(0.06)$ \\
\hline - no & $0.50(0.21)$ & $0.73(0.19)$ & $0.90(0.06)$ \\
\hline \multicolumn{4}{|l|}{$\begin{array}{l}\text { Interaction terms } \\
\text { Interaction: }\end{array}$} \\
\hline - glender by wrg d & $0.46(0.20)$ & $0.75(0.18)$ & $0.92(0.06)$ \\
\hline - gender by not wrg & $0.51(0.22)$ & $0.74(0.19)$ & $0.89(0.06)$ \\
\hline
\end{tabular}

\begin{tabular}{lccc}
\hline & $\begin{array}{c}\text { VAS wearing } \\
\text { reading glasses }\end{array}$ & $\begin{array}{c}\text { TTO wearing } \\
\text { reading glasses }\end{array}$ & $\begin{array}{c}\text { SG wearing } \\
\text { reading glasses }\end{array}$ \\
\hline $\begin{array}{l}\text { Whole sample }(n=114) \\
\text { Sociodemographic } \\
\text { characteristics }\end{array}$ & $0.81(0.12)$ & $0.72(0.19)$ & $0.90(0.06)$ \\
$\begin{array}{l}\text { Gender: } \\
\text { - female }\end{array}$ & & & \\
- male & $0.81(0.11)$ & $0.74(0.19)$ & $0.90(0.06)$ \\
Age: & $0.80(0.14)$ & $0.68(0.18)$ & $0.89(0.06)$ \\
* $<50$ years & $0.78(0.12)$ & $0.70(0.17)$ & $0.89(0.06)$ \\
$* 250$ years & $0.84(0.11)$ & $0.75(0.20)$ & $0.90(0.06)$
\end{tabular}




\begin{tabular}{|c|c|c|c|}
\hline & $\begin{array}{l}\text { VAS wearing } \\
\text { reading glasses }\end{array}$ & $\begin{array}{l}\text { To wearing } \\
\text { reading glasses }\end{array}$ & $\begin{array}{l}\text { SG wearing } \\
\text { reading glasses }\end{array}$ \\
\hline Whole sample $(n=114)$ & $0.81(0.12)$ & $0.72(0.19)$ & $0.90(0.06)$ \\
\hline \multicolumn{4}{|l|}{ Marital status: } \\
\hline - married ${ }^{a}$ & $0.81(0.12)$ & $0.71(0.19)$ & $0.89(0.06)$ \\
\hline - never married & $0.77(0.13)$ & $0.76(0.18)$ & $0.93(0.06)$ \\
\hline \multicolumn{4}{|l|}{ Occupation: } \\
\hline - having a job & $0.81(0.14)$ & $0.76(0.20)$ & $0.91(0.06)$ \\
\hline - not having a job & $0.81(0.11)$ & $0.70(0.18)$ & $0.89(0.06)$ \\
\hline \multicolumn{4}{|l|}{ Education: } \\
\hline - lower & $0.82(0.14)$ & $0.70(0.22)$ & $0.89(0.07)$ \\
\hline - middle & $0.80(0.13)$ & $0.71(0.19)$ & $0.88(0.06)$ \\
\hline - high & $0.80(0.10)$ & $0.74(0.17)$ & $0.91(0.06)$ \\
\hline \multicolumn{4}{|l|}{$\begin{array}{l}\text { Health status } \\
\text { characteristics }\end{array}$} \\
\hline yes & $0.79(0.13)$ & $0.74(0.18)$ & $0.89(0.06)$ \\
\hline - no & $0.81(0.12)$ & $0.71(0.19)$ & $0.90(0.06)$ \\
\hline \multicolumn{4}{|l|}{ Interaction terms } \\
\hline \multicolumn{4}{|l|}{ Interaction: } \\
\hline - gender by wrg & $0.83(0.11)$ & $0.75(0.17)$ & $0.92(0.06)$ \\
\hline - gender by not wrg & $0.80(0.12)$ & $0.71(0.19)$ & $0.89(0.06)$ \\
\hline
\end{tabular}

\section{CONCLUSION AND DISCUSSION}

A Reference Case scenario was applied to senile cataract. The recommended population preferences were measured in a survey conducted among a random sample of the adult Dutch population. The response rate was approximately $12 \%$. The analyzable sample resulted in a selective sample in terms of sociodemographic characteristics and eye-related characteristics. People wearing sight corrections were more likely to respond than people without sight corrections. Consequently, individuals who have greater affinity with or knowledge about the consequences of cataract surgery were over-represented. Despite the unrepresentativeness of the sample, the valuations for the two health states did not differ between persons having or not having affinity with visual impairment. 
Furthermore, the sample was representative with respect to morbidity, in that people with chronic diseases were not more likely to respond than people without chronic diseases. Based on these results we conclude that preferences obtained from a survey among a random sample of the population might result in reliable population preferences, even if the sample is not representative for the population.

Torrance et al. ${ }^{21}$ found a mean preference value for blindness, measured with the VAS, of $0.33(\mathrm{sd}=0.26)$. We found a mean preference value for cataract, a health status slightly better than blindness, of 0.49 ( $\mathrm{sd}=0.22$ ), aiso measured with the VAS. Fryback et al. ${ }^{22}$ found a mean TTO preference value for cataract, valued by persons unaffected by the disease, of 0.874 ( $s d=0.0075)$. We found a mean TTO preference of $0.73(\mathrm{sd}=0.19)$. Since our study had some limitations, the mean preferences found by Fryback et al. ${ }^{22}$ are not comparable to those found in our study. Since cataract results in mobility problems, the mean preference value in our research can be compared with that for mobility problems in the research by Torrance et al. ${ }^{21}$ They reported a mean preference value for mobility of 0.54 ( $s d=0.26$ ), which is comparable to the mean preference value found in our study.

Although the sample obtained in the present study was non-random in terms of gender, age, marital status, education and occupation, the question remains whether this causes the valuation for the different health states to be biased. Female respondents gave a higher valuation to the health state of "cataract" than male respondents. However, near eye corrections were not more frequently worn by female respondents than by male respondents. The finding that being in a particular health state led to equal valuations indicates that the results found in our study are reliable and similar to the results found elsewhere in the literature. ${ }^{23.24}$ Unlike other studies using the EQ-5D in samples of the general population, we did not find valuation differences between age categories. ${ }^{25-27}$ The valuations for the health state of "wearing reading giasses" and the health state of "cataract" do not undermine the external validity of the results with regard to the health state of "cataract" and the health states after cataract surgery. However, the outcomes of this study do not support the common thought that patients adapt to their situation. Cataract is a mild health condition, thus the discriminative power between health states might be less than in a severe health condition like cancer. The quality of the data might be insufficient. In this study only measurable observable characteristics were taken into account. There are however, also un-observable characteristics that might lead to bias. 
Some options have been suggested to obtain a more representative sample. One technique to obtain a representative sample would be to delete respondents from groups that are over-represented. In the present study, however, applying this technique would seriously affect the power of the study sample. Another technique which can be used when respondents are underrepresented is to stratify the sample. In the present study, elderly respondents and respondents not wearing glasses were underrepresented. Thus, stratifying the sample by age groups and groups wearing or not wearing spectacles is a possible solution to obtain a more representative sample.

Besides the lack of representativeness of the sample, two additional sampling problems may have led to bias in the reported preferences. These two problems relate to the definition and the size of the sample. The random sample in this study was drawn on the basis of private telephone numbers by zip-code. Private telephone numbers reflect a selection of the adult population, in that the institutionalized elderly people are less likely to be selected. Many institutionalized persons in the Netherlands do not have their own private telephone number, with only the number of the institution being listed. Thus, the under-representation of elderly people may have a serious effect on the assessment of population preferences regarding the health states of "cataract" and "wearing reading glasses". Therefore, methods to ensure the selection of institutionalized elderly people should be considered.

The second problem -sample size calculation in a survey-is more difficult to correct. Sample sizes are calculated on the basis of the ability to detect differences in preferences for two alternative therapies. This requires specification of the effect size of the outcome variable. The effect size is generally defined as the standardized measure of change in a group or a difference in measurements between two groups. ${ }^{28}$ According to Roset et al. ${ }^{8}$ a wide range of possible effect sizes are used to calculate the sample size to detect the smallest change in general health status. A sample size of 1000 individuals should be large enough (provided the response rate is at least $30 \%$ ) to be representative of the Dutch population, indicating that biased preferences in the present study cannot be explained by the sample size. However, biased preferences still can be explained by a sample containing more knowledgeable or more involved individuals or respondents having greater affinity with the disease or treatment outcomes asked about in the questionnaire. Only two questions in our questionnaire referred to this 
factor, namely the question whether the respondents suffered from cataract and the question whether they wore reading glasses.

Two respondents mentioned that they found it difficult to value the health states mentioned in the questionnaire. The parents of one respondent suffered from cataract and this respondent "saw their upheaval". The other respondent suffered from a disease which required frequent hospitalization, resulting in a poorer quality of life. In future research on population preferences with regard to diseases, we recommend adding more questions about the personal involvement of the respondents in the subject of the study. In addition, questions on the respondents' knowledge about the subject should be included. This will allow respondents to be divided into groups having only basic knowledge of the disease, based on the description of the disease in the questionnaire, and respondents who are more knowledgeable because they have experienced the consequences of having the disease.

Another comment on the present study is that population-based preferences were obtained by a mailed questionnaire, which used the Standard Gamble technique. Although Torrance ${ }^{18}$ claims that the Standard Gamble technique can only be used in an interview and requires well-trained interviewers, the present research showed that the SG might also be suitable in a mailed questionnaire. There were no missing observations or incomplete SG-technique. Furthermore, no differences in Standard Gamble valuation were found between respondents with high, intermediate and low educational levels, also indicating that the SG technique might be suitable for use in a mailed questionnaire.

\section{POLICY IMPLICATIONS}

The present study was based on the recommendations of the US Panel on CostEffectiveness. "The preferences found in this study might be suitable for costeffectiveness analyses with regard to cataract and cataract surgery involving implantation of a monofocal or multifocal lens. This policy implication should be interpreted very cautiously due to the low response rate. Furthermore, this policy implication can not be generalized to other diseases. 


\section{REFERENCES}

1. Gold MR, Slegel JE, Russell LB, Weinstein MC. Cost-effectiveness in health and medicine. New York, Oxford: Oxford University Press; 1996.

2. Miller DC. Handbook of research design and social measurement. Fifth ed. Newbury Park, London, New Delhi: Sage Publications, Inc; 1991.

3. Khaw PT, Hughes DS, Keightley SJ, Walters RF. Ophthalmology rewision aid: BMJ Publishing Group; 1996 .

4. Statistics Netherlands. Population statistics. Voorburg/Heerlen; 1994.

5. Prevalence and incidence of cataract. Available at http://www.rivm.nl.vtv/data/kompas/gezondheidstoestand/ziekte/gezichtsstoomis/ gezichtsstoornis_omvang_har.htm. Accessed October 27, 2004.

6. Javitt $\mathrm{JC}_{\mathrm{N}}$ Wang $\mathrm{F}$, Trentacost $\mathrm{D} J$, Rowe $\mathrm{M}$, Tarantino $\mathrm{N}$. Outcomes of cataract extraction with multifocal intraocular lens implantation: functional status and quality of life. Ophthalmology 1997; 104:589-599.

7. Boyd BF. Section V-B: Cataract and intraocular lens surgery. In: Boyd BF, ed. Highlights of ophthalmology. World atlas series of ophthalmic surgery. El Dorado, Panama: Highlights of Ophthalmology It.; 1996:104-132.

8. Roset M, Badia $X$, Mayo NE. Sample size calculations in studies using the EuroQol5D. Qual Life Res 1999:8:539-549.

9. Brinkman J. De Vragenlijst. Groningen: Wolters-Noordhoff; 1994. [The questionnaire. Groningen: Wolters-Noordhof, The Netherlands, 1994].

10. Nijkamp MD. Determinants of patient satisfaction after cataract surgery. Maastricht: Unigraphic Maastricht; 2003.

11. Dolan P. Modeling valuations for EuroQol health states. Med Care 1997;35:10951108.

12. The EuroQol Group. EuroQol--a new facility for the measurement of health-related quality of life. Heath Policy 1990;16."199-208.

13. Brooks R. EuroQol: the current state of play. Health Policy 1996;37:53-72.

14. Froberg DG, Kane RL. Methodology for measuring health-state preferences--II: Scaling methods. J Cin Epictemiol 1989;42:459-471.

15. Torrance GW. Measurement of health state utilities for economic appraisal. J Health Econ 1986:5:1-30.

16. Drummond MF, O'Brien BJ, Stoddart GL, Torrance GW. Methods for the economic evaluation of health care programmes. Second ed. Oxford: Oxford University Press: 1997.

17. Von Neumann $J$, Morgenstern $O$. Theory of games and economic behavior. Princeton: Princeton University Press; 1947.

18. Torrance GW. Social preferences for health states: an empirical evaluation of three measurement techniques. Socio-Econ Plan Sci 1976;10:129-136. 
19. Statistics Netherlands. Population statistics, Voorburg/Heerlen; 2000.

20. Van Gessel-Dabekaussen $G$. Health Interview Survey. Persons wearing glasses or contact llenses in the Netherlands, 1985-1995. Statistics Nethertands. Montley health statistics, November 1996. Voorburg/Heerlen; 1996:15.

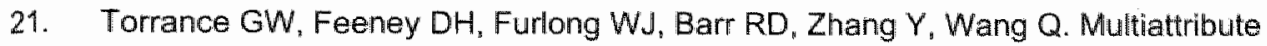
utility function for a comprehensive health status classification system. Health Utility Index Mark 2. Medical Care. 1996;34:702-722.

22. Fryback DG, Dasbach EJ, Klein R, Kein BE, Dorn N, Peterson K, et al. The Beaver Dam Health Outcomes Study: initial catalog of health-state quality factors. Med Decis Making. 1993;13:89-102.

23. Hadorn DC, Uebersax J. Large-scale health outcomes evaluation: how should quality of life be measured? Part 1-Calibration of a brief questionnaire and a search for preference subgroups. J Clin Epidemiol 1995;48:607-618.

24. De Wit GA, Busschbach JJ, de Charro $\mathrm{FT}$. Sensitivity and perspective in the valuation of health status: whose values count? Health Econ $2000 ; 9: 109-126$.

25. Dolan P, Gudex C, Kind P, Williams A. The Time Trade-Off Method: results from a general population study. Health Econ 1996;5:141-154.

26. Gudex C, Dolan P, Kind P, Williams A. Health state valuations from the general public using the visual analogue scale. Qual Life Res 1996;5:521-531.

27. Badia X, Schiaffino A, Alonso J, Herdman M. Using the EQ-5D in the Catalan general population: feasibility and construct validity. Qual Life Res 1998;7:311-322.

28. Kazis LE, Jennifer JA, Meenan RF. Effect sizes for interpreting changes in health status. Med Care 1989;3:S178-S189. 
. 


\title{
4 \\ WHOSE VALUES COUNT? \\ A Meta-analysis of Patient and Population Preferences
}

\author{
M. Dolders, M. Zeegers, W. Groot, A. Ament \\ Submitted for publication
}

\begin{abstract}
Aim: To summarize and quantify mean differences between patient and population health state evaluations (=preferences) and to identify factors explaining these differences.

Methods: Three meta-analyses of observational studies comparing patient and population preferences for stratified health state classifications: actual/actual, actual/hypothetical and hypothetical/hypothetical health states.

Results: Twenty-six articles comparing patient and population preferences were included, generating 243 independent patient/population preference combination estimations. Data were extracted on health state assessments, elicitation methods, assessment method and population characteristics by one reviewer, monitored by an experienced independent rewiewer.

Overall, patient preferences were significantly lower than population preferences for actual health status (Summary Mean Difference $(S M D)=-0.06,95 \%$ confidence interval $(95 \% \mathrm{Cl})=$ $-0.07,-0.05)$. Patients' actual health status preferences were not significantly higher than populations' hypothetical health status prefierences (SMD $=-0.01,95 \% \mathrm{Cl}=-0.01,0.03$ ). Preferences for hypothetical health states did not differ significantly between patients and population $(\mathrm{SMD}=-0.00,95 \% \mathrm{Cl}=-0.03,0.02)$. Most parameters substantially influencerd the SMD, although the magnitude and direction differed for the three strata used (all pvalues <.05).

Conclusion: Patient preferences are lower than population preferences for actual health status. The actual/hypothetical and hypothetical/hypothetical meta-analyses demonstrated no significant differences between patient and population preferences. Patient and population preferences can both be used to allocate resources.
\end{abstract}




\section{INTRODUCTION}

Cost-effectiveness and cost-utility analyses of health care interventions are increasingly used as instruments in allocating scarce resources in health care. The results of these analyses are summarized in Qaly League Tables (QLTS). Whether these tables are appropriate decision-making tools has been extensively discussed in the literature. ${ }^{1-3}$ One of the main shortcomings of these QLTs is that it is not always clear whether preferences are elicited from patients or from the general population. In addition, it is largely unknown whether it matters if one uses patient or population preferences. 4.5

In the present study we applied a framework ${ }^{6}$ to distinguish systematically the goals of the decision-making processes. The first goal was quantifying the burden of disease. The relevant preferences used were the actual health status of patients (experiencing the disease) and the general population (i.e., those who are healthy or at least not experiencing the disease). The second goal was to guide the decision-making process used to allocate resources. The relevant preferences were classified into the actual preferences of the patient and the hypothetical preferences of the general population. The third goal was related to the bias of having experienced the disease. Therefore, the preferences for hypothetical health states of patients and population were compared.

Preferences are quantitative expressions for certain health states and are used to calculate Quality Adjusted Life Years (QALYs). They reflect the desirability of certain health states. ${ }^{7}$ Methods for assigning preferences to health states may be choice-based (e.g. Standard Gamble (SG). Time Trade-Off (TTO)) or nonchoice-based (e.g. Visual Analogue Scale (VAS), Rating Scale (RS)). The Health Utility Index (HUl), the Quality of Well-Being Scale (QWB) and the EuroQol-5D (EQ-5D) are multi-attribute descriptive classification systems for generic health states with preference scores. ${ }^{8-10}$ These instruments are suitable for economic evaluations. 7.11

Preferences to evaluate a health state can be elicited from the patient him/herself. For some diseases, where the patient may be unable to answer questions (e.g. dementia or stroke) the judgments of physicians, other health care professionals or caregivers, so-called proxies, are used to elicit preferences. Since the Panel on Cost-Effectiveness recommended using the societal perspective for costs and effects, the general population is also used. ${ }^{11}$ However, the literature is ambiguous about the question whose preferences count. ${ }^{11,12}$ 
The conclusion that patient preferences are higher than ${ }^{13,14}$ or equal ${ }^{15.16}$ wo population preferences is mostly derived from single articles or narrative reviews. ${ }^{16,77}$ They report mixed findings and are confusing to those seeking guidance in decision-making. ${ }^{18}$ A meta-analytic approach may help to overcome this problem. To our knowledge, there have so far not been any attempts to summarize the literature quantitatively.

The goal of the present review was to analyze the difference between patient preferences and preferences from the general population. Since preference studies are mostly observational studies, it is important to account for potential sources of heterogeneity. ${ }^{19}$ As mentioned above, various methods can be used to elicit preferences. These methods are used to explain the differences between patient and population preferences. Preferences can be attached to disease-specific or generic health states, or health state profiles. Hence, an assessment of the health state was included as a possible source of heterogeneity. The way preferences are assessed was also taken into account as a potential source of heterogeneity. External factors, such as gender, age, educational level and type of disease (chronic, contagious, or high-risk factors for disease) were added. ${ }^{12,16,20,21}$ The second goal of this review was to assess the effects of different sources off heterogeneity on patient and population preferences.

\section{METHODS}

\section{DATA SOURCES}

The literature search by the principal investigator covered the computerized databases MEDLINE and ECONLIT over the period 1966 to September 2003, but was restricted to adults ( $~ \geq 18$ years). References cited in published original and review papers were examined until no further studies were identified. Relevant journals were hand-searched. No language restrictions were applied.

The search procedure involved a combination of the keywords health state preference* ${ }^{*}$, Time Trade-Off, Standard Gamble, Visual Analogue Scale, and Rating Scale. The following keywords were added to the search procedure: Health Utility Index, Quality of Well-Being, EuroQol, and a combination of SF-36, Visual Analogue Scale, Standard Gamble, Time Trade-Off and Rating Scale to suppress the number of studies found by using $S F-36$ as a single keyword. Duplicates $(N=9)$ from ECONLIT or articles retrieved by more than one criterion were excluded. 
Articles were reviewed by relevance on the basis of their abstracts $(N=115)$, and 30 articles were supplemented from the bibliographic information in the relevant articles, yielding 145 full-text publications (see Figure 4.1 ).

\section{STUDY SELECTION}

Of the 145 full-text publications, $58^{\text {al }}$ were excluded, because they presented population norms. This process left 87 articles eligible for data entry. Of these articles, 31 were excluded because they reported only patient preferences $(n=14)^{22-35}$ or population preferences $(n=14)^{36-49}$ or proxy preferences $(n=3) .^{50-52}$ Two articles reported mixed patient and proxy preferences and compared these with population preferences. ${ }^{53,54}$ One article presented preferences based on the Rosser index. ${ }^{55}$ These 34 articles were excluded, leaving 53 articles that compared patient and population preferences. Next, 27 articles were rejected because they reported insufficient data. ${ }^{15,18,43,56-79}$ In the end, therefore, 26 articles $^{12-14,79-101}$ remained, which generated 280 patient/population preference combination estimates.

\section{QUANTITATIVE DATA EXTRACTION}

The principal investigator (MD) extracted quantitative and qualitative data from the articles. This procedure was monitored by an experienced independent reviewer (MZ). Disagreements between the two reviewers were discussed until consensus had been reached. In compiling the database, a distinction was made between articles and independent preference combination estimates, which are referred to in this chapter as studies.

An independent study comprises all the preferences of a given group of research subjects. Several of these studies may be described in one article. If more than one study was referred to in the same article, they were regarded as part of a single comparison study. If the preference elicitation methods for the outcome parameter in the original article differed, we still assumed that the underlying theoretical concept of preferences was equal. This resulted in independent preference studies, which were used as the units of analysis.

\footnotetext{
The excluded references are listed in Appendix $A$
} 
Figure 4. 1. Flow diagram for inclusion and exclusion of articles and studies

\begin{tabular}{|c|c|c|}
\hline $\begin{array}{l}\text { Articlles Retrieved } \\
\qquad(n=540)\end{array}$ & & \\
\hline 5 & \multicolumn{2}{|c|}{ Excluded articles $(n=395)$} \\
\hline $\begin{array}{l}\text { Eligible Articles } \\
\qquad(n=145)\end{array}$ & & \\
\hline 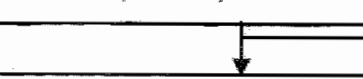 & \multicolumn{2}{|c|}{$\begin{array}{l}\text { Excluded articles }(n=58) \\
\text { - Population norms }\end{array}$} \\
\hline $\begin{array}{l}\text { Preference Articles } \\
\qquad(n=87)\end{array}$ & & \\
\hline$y$ & \multicolumn{2}{|c|}{$\begin{array}{l}\text { Excluded articles }(n=34) \\
\text { - Only patient preferences }(n=14) \\
\text { - Only population preferences }(n=14) \\
\text { - Only proxy preferences }(n=3) \\
\text { - Patient/proxy combined preferences }(n=2) \\
\text { - Population preference based on } \\
\text { Rosser Index }(n=1)\end{array}$} \\
\hline $\begin{array}{l}\text { Patient/Population } \\
\text { Comparison Articles } \\
\qquad(n=53)\end{array}$ & & $x^{2}$ \\
\hline & \multicolumn{2}{|c|}{$\begin{array}{l}\text { Excluded articles }(n=27) \\
\text { - Social tariff }(n=13) \\
\text { - Regression or algorithm }(n=5) \\
\text { - Missing standard deviation }(n=9)\end{array}$} \\
\hline \multirow{2}{*}{$\begin{array}{c}\text { Included Articles }(n=26) \\
\text { Generating } 280 \\
\text { preference studies }\end{array}$} & & \\
\hline & \multirow{2}{*}{\multicolumn{2}{|c|}{$\begin{array}{l}\text { Excluded studies }(n=37) \\
\text { - Population defined as students }(n=10) \\
\text { - Pooled preferences }(n=19) \\
\text { - Unadjusted preferences for co- } \\
\text { morbidity }(n=3) \\
\text { - Un-pooled for duration of the disease }(n=5)\end{array}$}} \\
\hline & & \\
\hline $\begin{array}{l}\text { Included preference } \\
\text { studies }(n=243)\end{array}$ & & \\
\hline$\mp$ & $\mp$ & 7 \\
\hline $\begin{array}{l}\text { Included preference } \\
\text { studies stratified into } \\
\text { actual health state for } \\
\text { patients and population } \\
\qquad(n=161)\end{array}$ & $\begin{array}{l}\text { Included preference } \\
\text { studies stratified into } \\
\text { hypothetical health } \\
\text { state for patients and } \\
\text { population } \\
\quad(n=58)\end{array}$ & $\begin{array}{l}\text { Included preference } \\
\text { studies stratiffed into } \\
\text { actual patient and } \\
\text { hypothetical population } \\
\text { health states } \\
(n=24)\end{array}$ \\
\hline
\end{tabular}


Since the independent studies represented continuous data, we extracted mean preferences and the standard deviations for each mean. If standard errors were reported, the sample size was needed to calculate the standard deviation. Thus both, standard error and sample size were extracted. These parameters were used to calculate the mean difference and the standard error of the mean difference. The mean difference, defined on a $0-1$ scale, with 0 representing death and 1 representing perfect health, was calculated by subtracting the mean preference of the population from the mean preference of the patients. The standard error of the mean difference was calculated by the following equation:

$$
\text { se }(\mathrm{MD})=\sqrt{\left.[\operatorname{se}(\text { patients })]^{2}+[\operatorname{se}(\text { population })]^{2}\right]}
$$

\section{QUALITATIVE DATA EXTRACTION}

The qualitative data extracted from the articles was classified by preference elicitation method (VAS, TTO, SG, EQ-5D, HUI, QWB), health state assessment (profile, disease-specific, generic) and study assessment method (interviewadministered or self-administered). General information (e.g. date of publication and author), patient and population characteristics (e.g. sample size), and type of health states, classified as actual versus hypothetical, were added.

\section{STATISTICAL ANALYSIS}

All statistical analyses were stratified according to health state classification actual or hypothetical - in patients and population, leading to three separately conducted meta-analyses, which assessed actual/actual, actual/hypothetical, and hypothetical/hypothetical health states, respectively, in patients and population. We tested for publication bias by using Egger's un-weighted regression asymmetry test, which is the intercept from regression of normal standard deviates against precision. ${ }^{102}$ We estimated the SMD and the corresponding $95 \%$ confidence intervals ( $\mathrm{Cls}$ ) with random effects meta-regression analysis using the Stata statistical software. ${ }^{103}$ In this method, the inverse of the standard error of the MD, together with an estimation of the between-study standard error, is used as a weighting factor. The between-study variance was estimated by a non-iterative procedure using a method of moments estimator. To expiore reasons for the observed heterogeneity, we performed sensitivity analyses on the study characteristics and tested their influence on the pooled effect estimates. 


\section{RESULTS}

\section{STUDY CHARACTERISTICS}

Each of the 280 generated patientpopulation preference combination estimates was included in the data file as a separate study, thus distinguishing articles from studies. Thirty-seven studies were excluded, ${ }^{12-14,82,85,96}$ because their population was defined as students $(n=10),{ }^{12,14}$ or because pooled preferences were reported $(n=19) .{ }^{82,96}$ Eight studies were excluded because they indicated dependency of preferences between patients and population. ${ }^{13,85}$ Three of these studies were excluded because they reported unadjusted preferences for co-morbidity ${ }^{85}$ and five studies because they presented un-pooled estimates for disease duration. ${ }^{13}$ After these studies had been excluded, 243 independent preference studies remained for further statistical meta-analyses (Figure 4.1).

Table 4.1 shows the characteristics of the 243 independent studies. VAS was used to assess preferences in $25.1 \%$ of the studies, while TTO was used in $28.4 \%$ of the studies, EQ-5D in $27.2 \%$, HUI in $12.3 \%$ and QWB in $22.2 \%$. Studies using SG $(6.6 \%)$ were excluded from our analysis because of sparse data. ${ }^{14,81,85,86,90,97}$ Two studies assessed discordant preferences, in that patient preferences were assessed with VAS and population preferences with TTO. ${ }^{91}$ These studies were also excluded from the further analyses (Table 2).

To assess the severity of the health states, $21.8 \%$ of the studies used disease-specific instruments, whereas $16.5 \%$ used generic instruments and $60.1 \%$ used a health state profile.

Most studies were interview-administered $(72 \%)$, while $27.1 \%$ were selfadministered (including mailed (1.2\%) and computer-based questionnaires $(6.6 \%)$ ).

Less than $6 \%$ of the studies reported a mean age between 18 and 45 years, while $49.1 \%$ reported a mean age between 45 and 65 years and $18.4 \%$ reported a mean age above 65 years. More than a quarter $(26.7 \%)$ of the studies reported discordant ages between patients and population. ${ }^{12,14,80,81,92,94}$ 


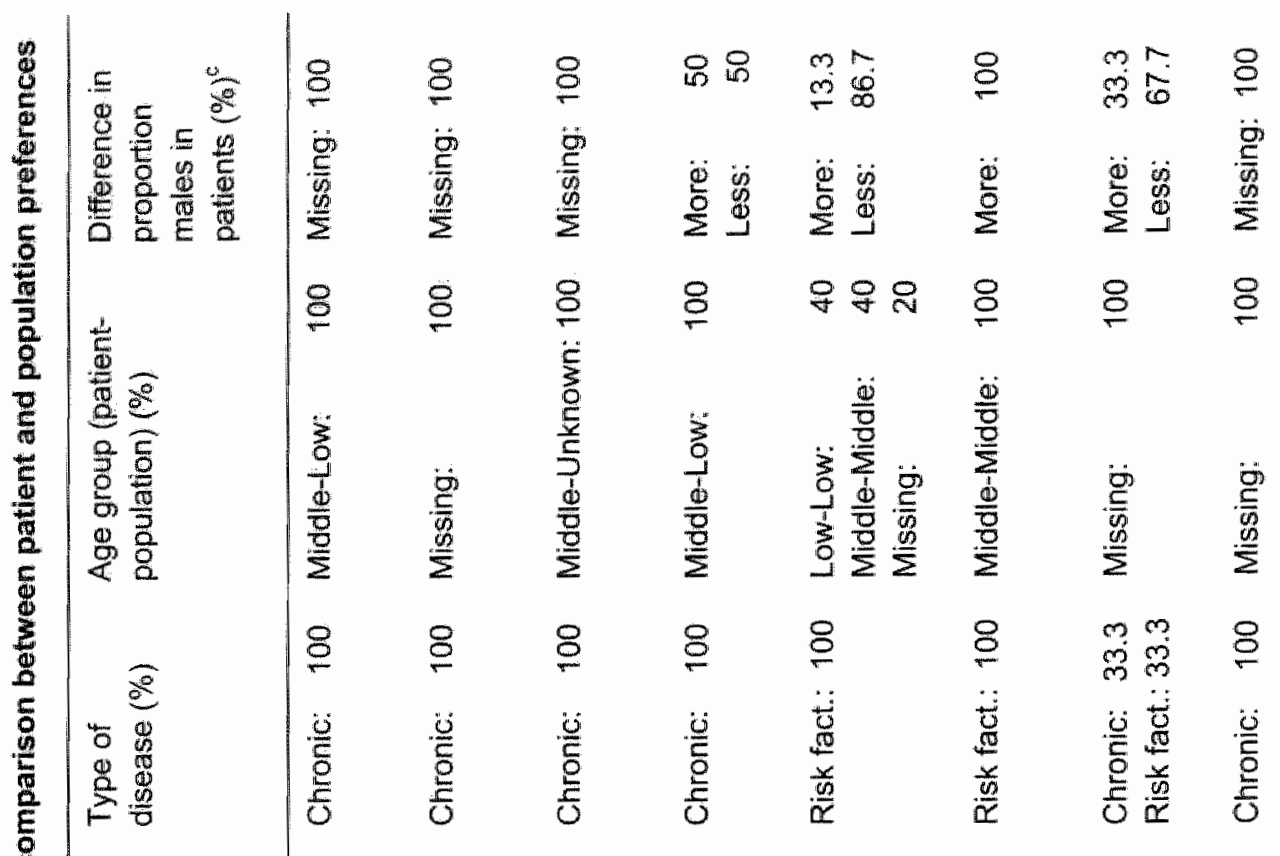

\begin{tabular}{|c|c|c|c|c|c|c|c|c|}
\hline 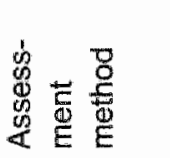 & 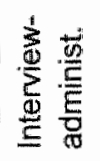 & 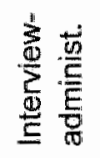 & 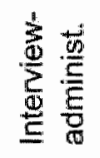 & 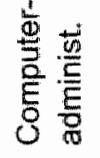 & 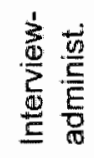 & 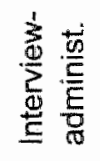 & 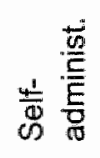 & 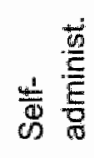 \\
\hline 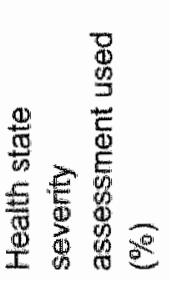 & $\begin{array}{l}\frac{0}{0} \\
\frac{\mathbb{1}}{1} \\
\frac{0}{0} \\
\frac{0}{2} \\
\frac{0}{Z}\end{array}$ & $\begin{array}{l}8 \\
8 \\
0 \\
8 \\
0 \\
0 \\
0 \\
0 \\
0 \\
0 \\
0 \\
0 \\
0\end{array}$ & 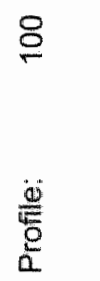 & $\begin{array}{l}10 \\
\infty \\
0 \\
0 \\
8 \\
0 \\
0 \\
0 \\
0 \\
0 \\
0 \\
0 \\
0\end{array}$ & 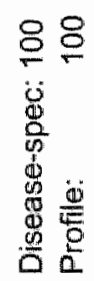 & 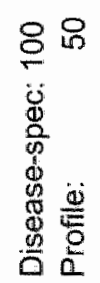 & 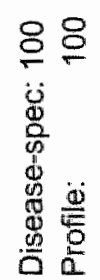 & $\begin{array}{l}\frac{0}{c} \\
\frac{2}{2}\end{array}$ \\
\hline 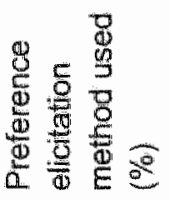 & $\ddot{0}$ & $\ddot{Q}$ & 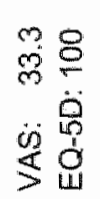 & 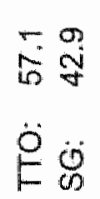 & $\stackrel{\ddot{\Xi}}{\underline{I}}$ & $\ddot{\circ} \dot{0}$ & $\begin{array}{l}8 \\
\dot{0} \\
\dot{0}\end{array}$ & $\begin{array}{l}80 \\
\dot{0} \\
\dot{0} \\
\dot{0} \\
\dot{0}\end{array}$ \\
\hline 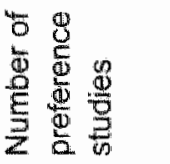 & ov & $N$ & $\stackrel{c}{\sim}$ & \pm & m & $N$ & $\mathrm{~m}$ & $N$ \\
\hline 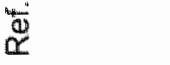 & 8 & $\cong$ & $\sim$ & $+\infty$ & $\approx$ & $\mathbb{M}_{\mathfrak{M}}$ & 声 & $g$ \\
\hline
\end{tabular}


Meta-analysis of Population and Patient Preferences

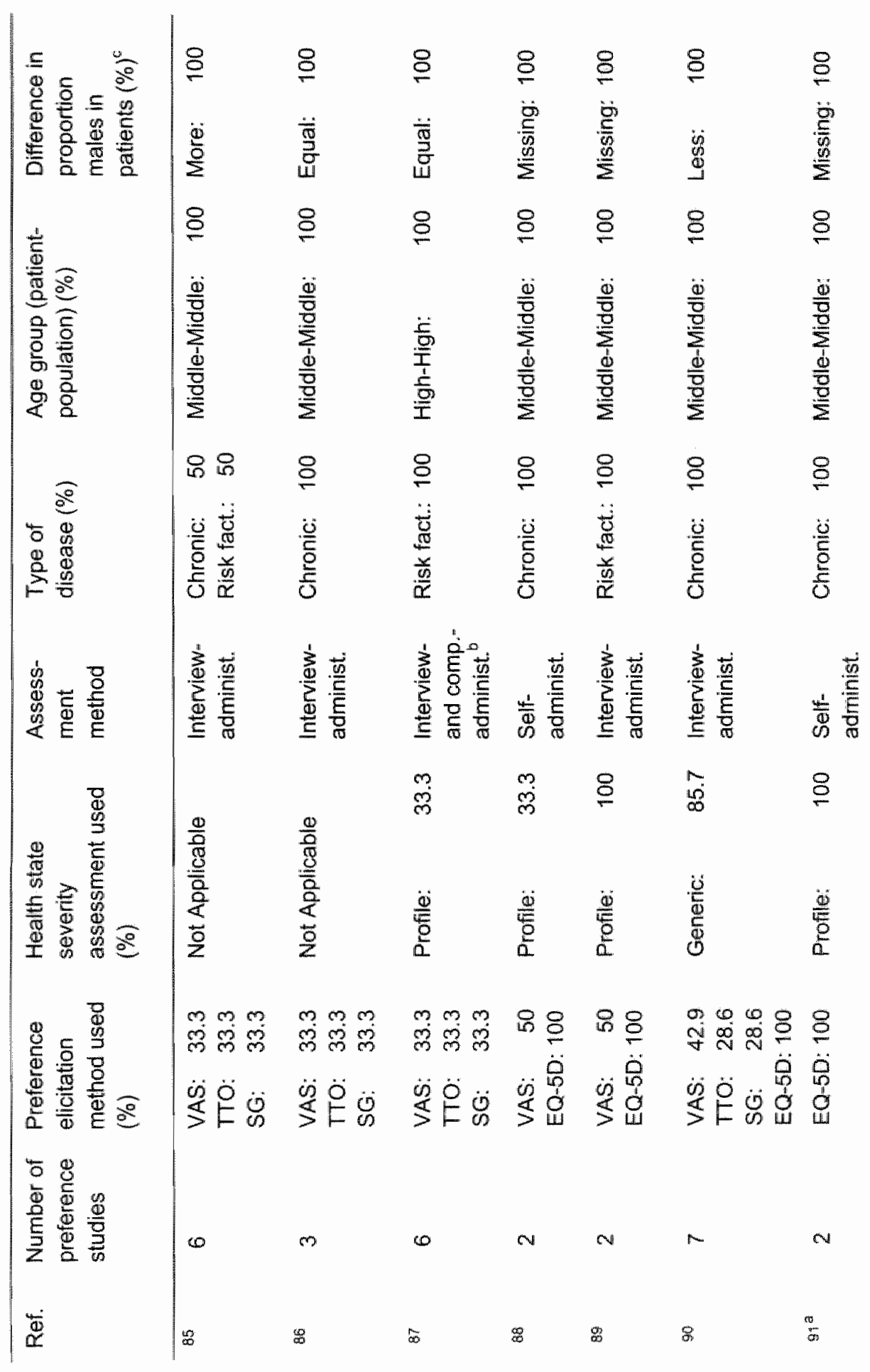




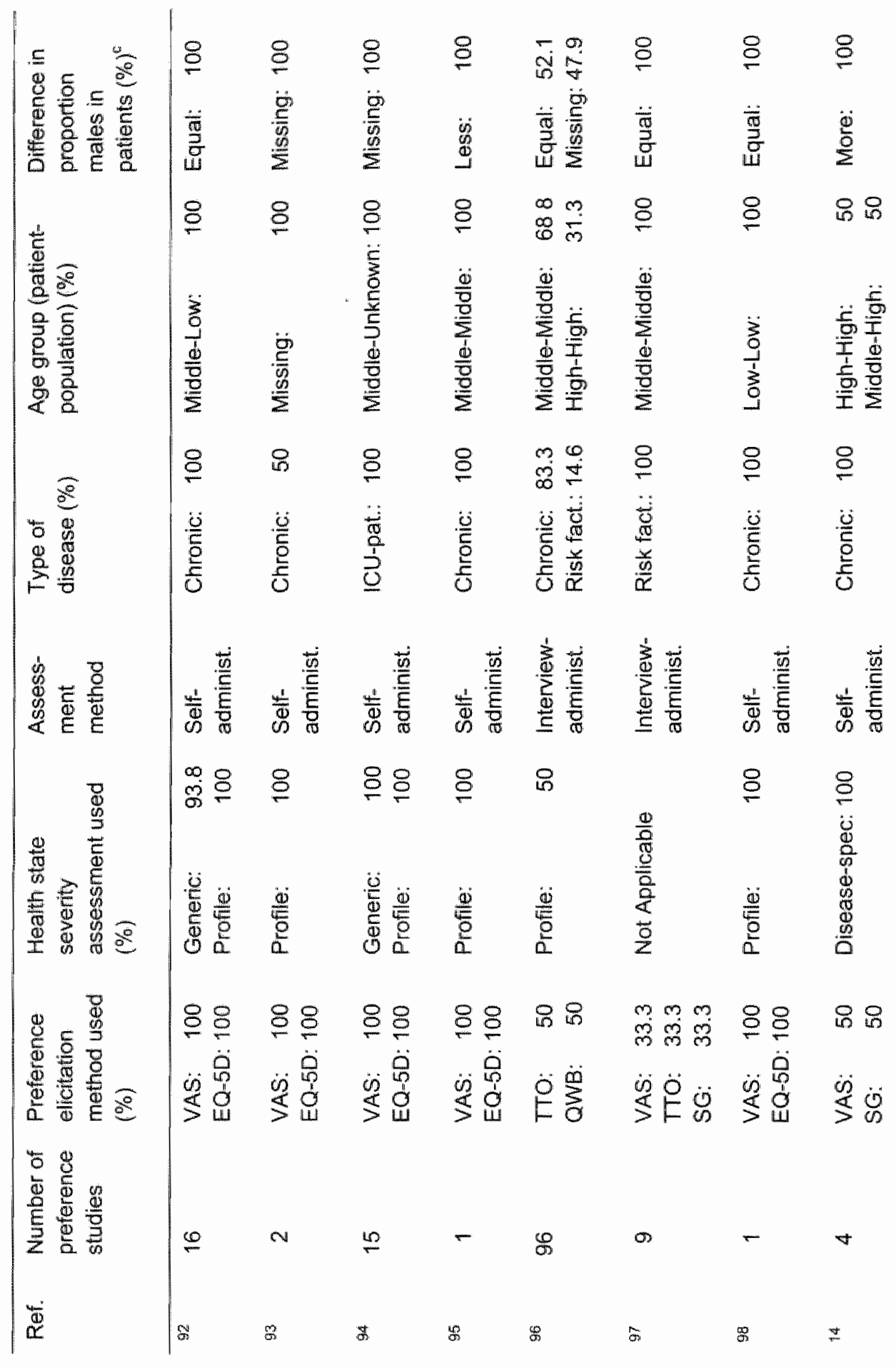




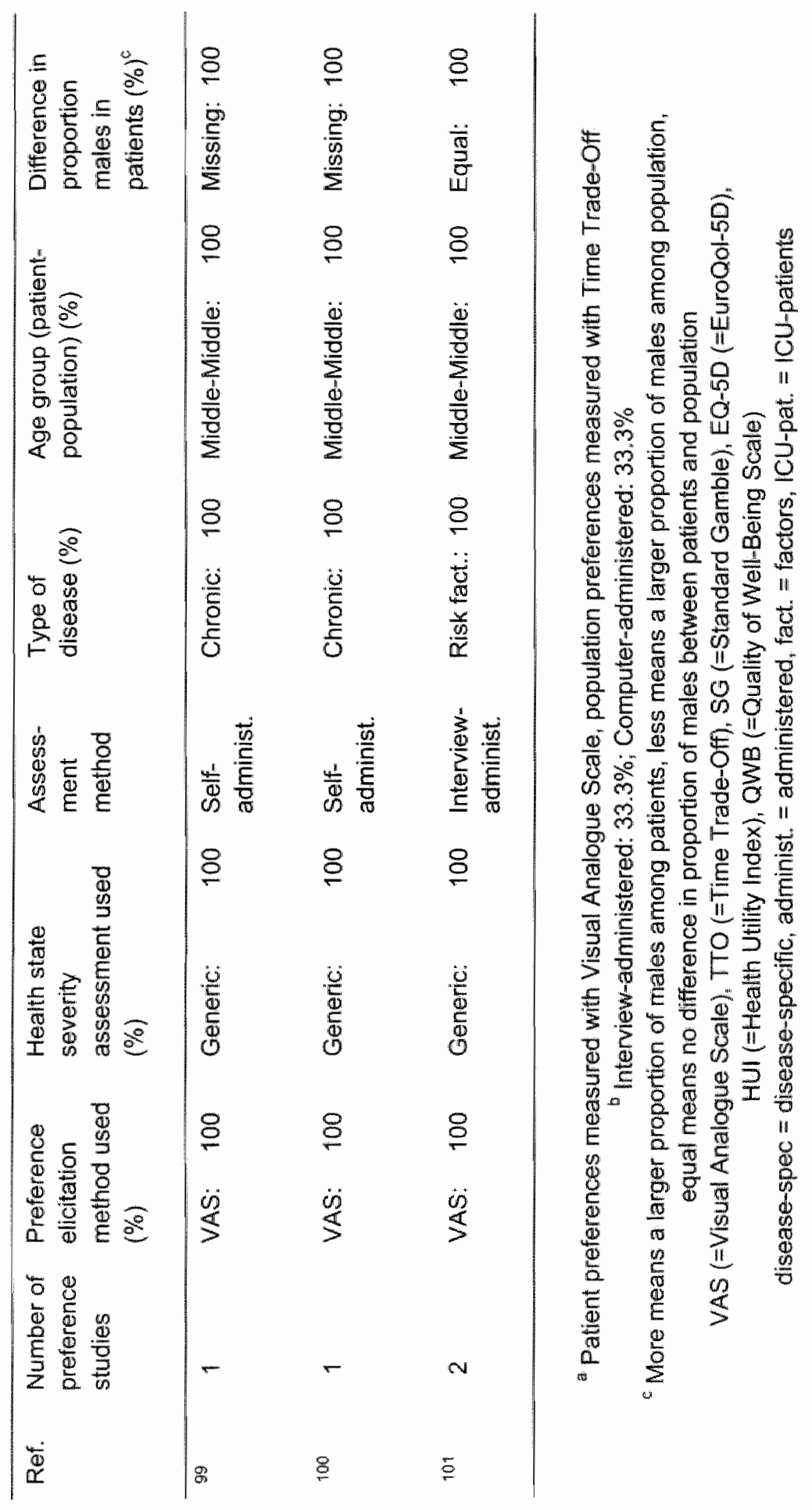


Thirty-one studies (12.8\%) reported a larger proportion of males among patients than among the population, while $14.8 \%$ reported a smaller proportion of males in the patient group and $35.8 \%$ of the studies reported equal proportions of males among patients and population. Almost $75.3 \%$ of the studies failed to present data on educationall level, so this factor was excluded from the analysis.

Of the 243 studies included, $28.4 \%$ reported risk factors for diseases and $63.8 \%$ reported chronic diseases, whereas $7.8 \%$ reported contagious diseases, $\llbracket \mathrm{CU}$ patients and temporary diseases. This last group was excluded from our analyses (Table 2) ${ }^{84,93,94,96}$

\section{PUBLICATION BIAS}

Publication bias was tested visually (Figure 4.2) and statistically $(p=0.03)$ in funnel plots for the comparison of hypothetical patient and population health states. Funnel plots are plots of effect estimates against sample size. The degree of funnel plot asymmetry was measured by means of the intercept from regression of standard normal deviates against precision. The funnel plots revealed no publication bias for the comparison of actual patient and population health states or for the comparison of actual patient and hypothetical population health states, either visually (Figure 4.2) or statistically $(p=0.46, p=0.31$, respectively).

\section{SUMMARY MEAN DIFFERENCE SCORES}

Table 4.2 describes the three stratified meta-analyses. The first compared actual patient and population preferences $(\mathbb{N}=161)$. The random effect pooling revealed an SMD of $-0.06 \quad(\mathrm{Cl}=-0.07,-0.05)$, being statistically significant. Patient preferences for actual health status were $6 \%$ lower than population preferences. The second analysis compared actual patient preferences and hypothetical population preferences $(\mathrm{N}=24)$ and yielded an SMD of $0.01(\mathrm{Cl}=-0.01,0.03)$. The third meta-analysis compared hypothetical patient and population preferences $(\mathrm{N}=58)$ and yielded an SMD of $-0.00(\mathrm{Cl}=-0.03,0.02)$. These two meta-analyses revealed no significant difference between patient and population preferences. 


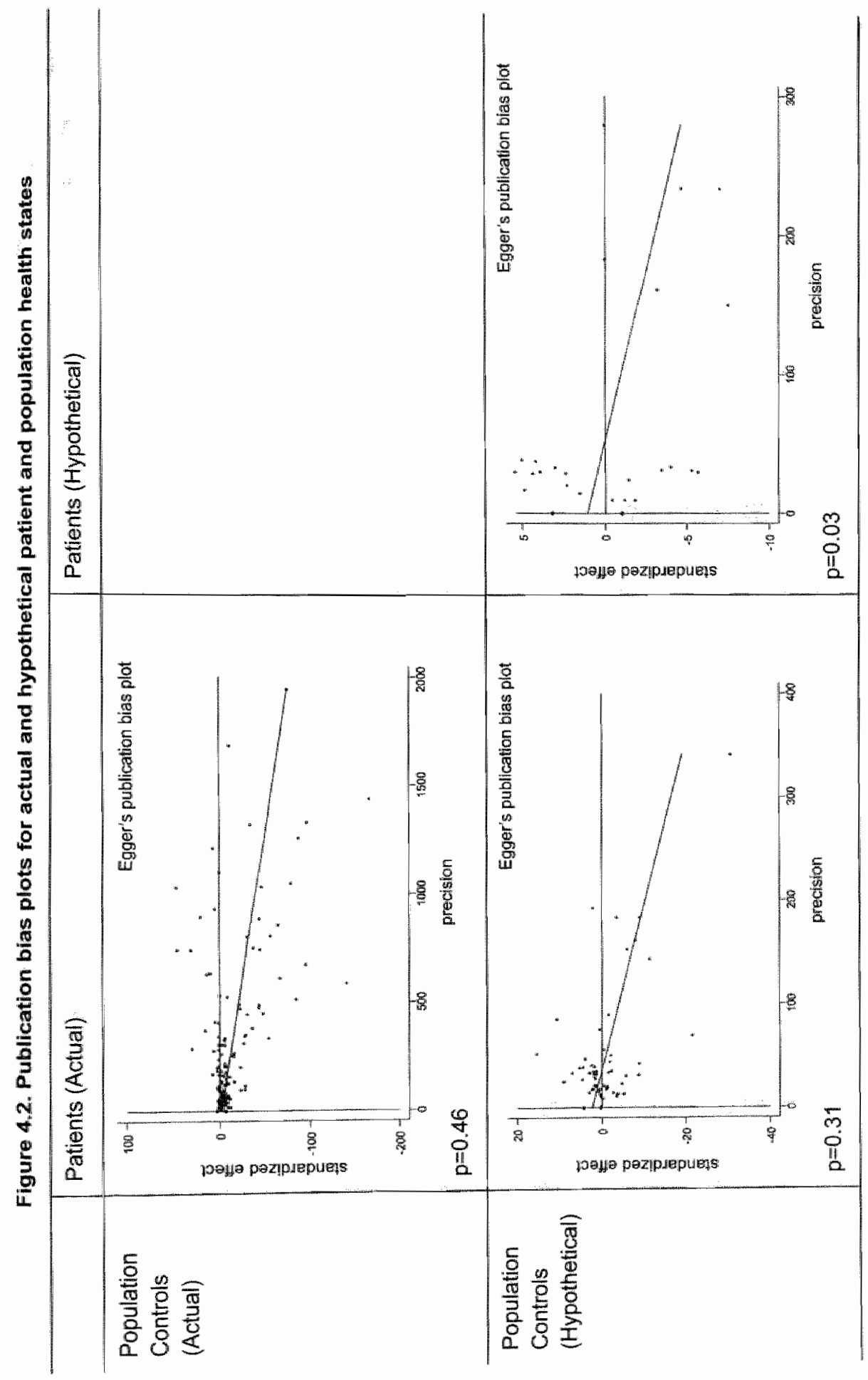




\section{CAMPTER}

Table 4 .2. Summary mean differences and sensitivity analyses for actual and hypothetical patient and population health states

Heallh State

\begin{tabular}{|c|c|c|c|c|c|c|}
\hline \multirow[t]{2}{*}{$\begin{array}{l}\text { Prwemus } \\
\text { Porulaton } \\
\text { Connols }\end{array}$} & \multicolumn{2}{|l|}{$\begin{array}{l}\text { Actual } \\
\text { Actual }\end{array}$} & \multicolumn{2}{|l|}{$\begin{array}{c}\text { Actual } \\
\text { Hypothetical }\end{array}$} & \multicolumn{2}{|l|}{$\begin{array}{l}\text { Hypothetical } \\
\text { Hypothetical }\end{array}$} \\
\hline & $M O(95 \% \mathrm{Cl})$ & $N$ & $\mathrm{MD}(95 \% \mathrm{Cl})$ & $\mathbb{N}$ & $\mathrm{MD}(95 \% \mathrm{Cl})$ & $\mathrm{N}$ \\
\hline Overa政 & $-0.06(-0.07,-0.05)$ & 161 & $0.01(-0.01,0.03)$ & 24 & $-0.00(-0.03,0.02)$ & 58 \\
\hline \multicolumn{7}{|l|}{$\begin{array}{l}\text { Prenerce } \\
\text { Wolnods }\end{array}$} \\
\hline VAS & $p=0.00$ & & $p=0.00$ & & $p=0.00$ & \\
\hline - Not Used & $-0.05(-0.06,-0.04)$ & 140 & $-0.02(-0.03,-0.00)$ & 11 & $-0.09(-0.11,-0.06)$ & 21 \\
\hline Used & $-0.12(-0.15,-0.09)$ & 20 & $-0.07(-0.18,0.04)$ & 5 & $0.05(0.02,0.09)$ & 36 \\
\hline TTO & $p=0.00$ & & $p=0.00$ & & $p=0.00$ & \\
\hline - Not Used & $-0.05(\omega .05,-0.04)$ & 104 & $-0.02(-0.04,0.01)$ & 16 & $0.02(-0.01,0.04)$ & 48 \\
\hline Used & $-0.08(-0.10,-0.06)$ & 56 & $-0.02(-0.05,0.01)$ & 4 & $-0.07(-0.11,-0.02)$ & 9 \\
\hline $\mathrm{EQ}-50$ & $p=0.00$ & & $p=0.22$ & & $p=0.00$ & \\
\hline - Not Used & $-0.05(-0.06,-0.04)$ & 147 & $-0.01(-0.03,0.01)$ & 12 & $-0.07(-0.10,-0.04)$ & 18 \\
\hline - Used & $-0.18(-0.23,-0.13)$ & 14 & $0.02(-0.06,0.10)$ & 12 & $0.03(-0.01,0.07)$ & 40 \\
\hline Hul & $p=0.00$ & & & & & \\
\hline - Not Used & $-0.07(-0.08,-0.06)$ & 131 & $0.01(-0.01,0.03)$ & 24 & $-0.00(-0.03,0.02)$ & 58 \\
\hline Used & $-0.01(-0.02,-0.01)$ & 30 & & 0 & & 0 \\
\hline QW & $p=0.02$ & & $p=0.04$ & & & \\
\hline - Not Used & $-0.07(-0.08,-0.06)$ & 110 & $0.01(-0.01,0.03)$ & 21 & $-0.00(-0.03,0.02)$ & 58 \\
\hline Used & $-0.04(-0.05,-0.03)$ & 51 & $-0.12(-0.23,-0.01)$ & 3 & & 0 \\
\hline
\end{tabular}

\section{Wealth state}

Assessment

Profilie

- Not Used

- Used

DSI

- Not Used

- Used

Gl

- Not Used

- Used

AM

- Interview

$p=0.00$

$-0.08(-0.09,-0.06)$

$-0.04(-0.05,-0.04)$ $p=0.00$

$-0.07(-0.08,-0.06)$

$-0.02(-0.02,-0.01)$ $p=0.00$

$-0.06(-0.06,-0.05)$

$-0.24(-0.39,-0.10)$ $p=0.00$

$-0.05(-0.06,-0.05)$

$-0.14(-0.19,-0.08)$

$$
p=0.56
$$

$70-0.01(-0.03,0.01)(9$

$91-0.00(-0.07,0$

$$
p=0.22
$$

129

32

$0.02(-0.06,0.10) \quad 12$

$-0.01(-0.03,0.01) 12$

$0.01(-0.01,0.03)$

$157 \quad 0.01(-0.01,0.03)$

$$
p=0.12
$$

145

14
$0.02(-0.05,0.10)$

$-0.01(-0.03,0.01)$ $\rho=0.00$
$-0.07(-0.10,-0.04) \quad 18$
$0.03(-0.01,0.07) \quad 40$
$\rho=0.55$

$-0.00(-0.04,0.03) \quad 49$

$-0.03(-0.06,-0.01) \quad 9$

$p=0.00$

$24-0.10(-0.13,-0.08) \quad 22$

$0 \quad 0.06(0.03,0.09) \quad 36$

$p=0.00$

$3-0.09(-0.15 x-0.03) \quad 17$

$110.02(-0.00,0.05) \quad 41$ 


\begin{tabular}{|c|c|c|c|c|c|c|}
\hline \multirow{4}{*}{$\begin{array}{l}\text { Patients } \\
\text { Population } \\
\text { Controls }\end{array}$} & \multicolumn{6}{|c|}{ Health State } \\
\hline & \multicolumn{2}{|l|}{ Actual } & \multicolumn{2}{|l|}{ Actual } & \multicolumn{2}{|l|}{ Hypothetical } \\
\hline & \multicolumn{2}{|l|}{ Actual } & \multicolumn{2}{|l|}{ Hypothetical } & \multicolumn{2}{|l|}{ Hypothetical } \\
\hline & MD $(95 \% \mathrm{Cl})$ & $\mathrm{N}$ & $\mathrm{MD}(95 \% \mathrm{Cl})$ & $N$ & $\mathrm{MD}(95 \% \mathrm{Cl})$ & $N$ \\
\hline \multicolumn{7}{|l|}{$\begin{array}{l}\text { Population } \\
\text { Charact. }\end{array}$} \\
\hline Age & $p=0.03$ & & & & $p=0.44$ & \\
\hline $.18-45 y r s$ & $-0.01(-0.01,0.00)$ & 13 & & 0 & & 0 \\
\hline$\cdot 45-65$ yrs & $-0.06(-0.07,-0.05)$ & 94 & & 0 & $-0.12(-0.19,-0.05)$ & 18 \\
\hline $.65^{4}$ yrs & $-0.06(-0.08,-0.04)$ & 40 & & 0 & $-0.02(-0.15,0.12)$ & 2 \\
\hline Sex Dif. & $p=0.11$ & & $p=0.05$ & & $p=0.13$ & \\
\hline - More in pop. & $-0.02(-0.03,-0.01)$ & 28 & $-0.16(-0.29,-0.02)$ & 2 & $0.00(-0.04,0.05)$ & 6 \\
\hline - Equal & $-0.05(-0.06,-0.04)$ & 63 & & 0 & $0.00(-0.05,0.05)$ & 24. \\
\hline - More in pat. & $-0.04(-0.06,-0.01)$ & 14 & $-0.01(-0.03,0.01)$ & 9 & $-0.04(-0.06,-0.01)$ & 8 \\
\hline Disease & $p=0.00$ & & $\rho=0.59$ & & $p=0.00$ & \\
\hline "Chronic & $-0.08(-0.09,-0.07)$ & 100 & $0.01(-0.01,0.03)$ & 22 & $0.02(-0.01,0.04)$ & 33 \\
\hline * HRG & $-0.02\left(-0.03_{n}-0.01\right)$ & 58 & $-0.05(-0.24,0.15)$ & 1 & $-0.17(-0.27,-0.08)$ & 10 \\
\hline
\end{tabular}

VAS $=$ Visual Analogue Scale, $T T O=$ Time Trade-Off, $E Q-5 D=$ EuroQol-5D HUI = Health Utility Index, QWB = Quality of Well-Being Scale

Profile = Health State Profile, DSI = Disease-Specific Instrument, GI = Generic Instrument,

$\mathrm{AM}=$ Assessment Method, Interview $=$ Interview-administered, Self $=$ Self administered,

Population Charact. $=$ Population Characteristics, $y r s=$ years,

Sex Dif. $=$ Sex Difference, More in pop. = More men in population,

Equal = Equal sex difference, More in pat. $=$ More men in patients, $H R G=$ High risk group

\section{SENSITIVITY ANALYSES}

Next "we examined the SMD by preference ellicitation method, health state assessment, assessment method and population characteristics for each metaanalysis in order to explore the influence of these parameters on the outcome estimates (Table 4.2). For the actual patient and population preferences, all parameters substantially influenced the SMD, except for the demographic characteristics of difference in proportion of males between patients and population and age and for the QWB preference elicitation method. The last two were not significantly different if the Bonferroni test was applied to avoid the increasing risk of Type I errors due to multiple testing. All influences were in the same direction, patient preferences being lower tham population preferences. The magnitude of the influences, however, showed significant differences. In studies that used VAS, TTO or EQ-5D, the differences between patient and population preferences were significantly larger than in studies using other methods. By contrast, the differences 
in patient and population preferences were significantly smaller in studies that used HUI or QWB. The difference in patient and population preferences was significantly smaller in studies assessing health state severity using a profile or a diseasespecific instrument, whereas the difference in patient and population preferences was significantly larger in studies assessing health state severity using generic instruments. Furthermore, the difference in patient and population preferences was significantly larger in studies using self-administered questionnaires than in studies using interview-administered questionnaires. Moreover, studies using younger age groups found significantly larger differences between patient and population preferences than those using older age groups. Finally, studies regarding high-risk factors found significantly smaller differences between patient and population preferences than studies regarding chronic disease groups.

The parameters that influenced the SMD for actual patient preferences and hypothetical population preferences (second column in Table 4.2) were VAS, TTO, QWB and the difference in the proportion of males between patients and population. The last two were not significantly different if Bonferroni was applied to avoid inflation of Type I errors. Studies using VAS or QWB found significantly larger differences between actual patient preferences and hypothetical population preferences than studies not using these preference elicitation methods. However, studies using QWB assessed significantly lower actual patient preferences than hypothetical population preferences. Studies not using QWB found significantly higher patient preferences than population preferences. The minor difference (due to rounding) between actual patient preferences and hypothetical population preferences was significant in studies assessing TTO preferences compared to studies using other methods. Finally, studies including a larger proportion of males in the patient group found significantly larger actual patient preferences than hypothetical population preferences compared to studies including a larger proportion of males in the population. Patient preferences were lower than population preferences.

Numerous parameters influenced the SMD for the hypothetical patient and population preferences (third column in Table 4.2). Studies using VAS or EQ-5D found significantly smaller differences between patient and population preferences than studies not using these instruments. However, patient preferences assessed with these instruments were significantly higher than population preferences: $5 \%$ and $3 \%$ respectively. Studies not using VAS or EQ-5D found patient preferences to be significantly lower than population preferences: $9 \%$ and $7 \%$ respectively. 
Studies assessing TTO preferences found significantly larger differences between patient and population preferences than studies using other methods. Using the TTO resulted in patient preferences, which were $7 \%$ lower than population preferences, whereas studies using other methods found higher $(2 \%)$ patient preferences. Studies assessing health state severity using a profile or generic instrument revealed significantly smaller differences between patient and population preferences than studies using disease-specific instruments. Studies using profiles or a generic instrument found higher patient preferences than population preferences: $3 \%$ and $6 \%$ respectively, while studies not using profiles or a generic instrument found lower patient preferences than population preferences. The difference between patient and population preferences was significantiy smaller using self-administered questionnaires than using interview-administered questionnaires. However, patient preferences were $2 \%$ higher than population preferences when self-administered questionnaires were used. By contrast, patient preferences were significantly $(9 \%)$ lower than population preferences when interview-administered questionnaires were used. Furthermore, studies regarding high-risk factors found significantly larger differences between patient and population preferences than studies regarding a chronic disease group. Patient preferences for high-risk factors for diseases were $17 \%$ lower than population preferences, whereas patient preferences for chronic diseases were significantly higher than population preferences for such diseases.

\section{COMMENT}

The difference between patient and population preferences was studied by reviewing the published literature and using meta-regression analysis for three health state comparisons. The first meta-analysis quantified the burden of disease. Of the 243 studies included, 161 compared actual patient and population preferences, while 24 compared actual patient preferences with hypothetical population preferences. The results of this meta-analysis are applicable to resource allocation. However, since these studies are biased in terms of disease experience, we compared 58 hypothetical patient and population combinations.

The studies that were reviewed used a variety of preference elicitation methods, health state severity instruments and assessment methods, and varied in demographic characteristics and disease typology. These are all potential sources of heterogeneity. Therefore, we assumed that the true effects would be sensitive to 
variation among studies as well as heterogeneity within studies. A random effects meta-regression analysis was used to account for both sources of variation, allowing for heterogeneity beyond sampling error. ${ }^{104}$

\section{PREFERENCES FOR ACTUAL HEALTH STATES OF PATIENTS AND POPULATION}

OVERALL

We found no evidence of publication bias in the studies selected for this metaanalysis. A comparison of preferences for actual health states revealed that patients' preferences were $6 \%$ (meaning 6 points on a $0-100$ scale) lower than population preferences. This is probably due to the difference between the health states of patients, who are ill, and those of the healthy population subjects. While the difference was significant, one may wonder whether it is also meaningful. The answer to this question depends on the seriousness of the disease. Unfortunately, the seriousness of the disease could not be taken into account as a source of heterogeneity, because data were unavailable in the original articles. Furthermore, unlike clinically meaningful changes, there is no gold standard of meaningful changes in preferences. We believe that more efforts should be made to identify meaningful changes in comparing patient and population preferences.

\section{PREFERENCE Elicitation Methods}

The results of the sensitivity analyses showed that all preference elicitation methods accounted for substantial differences between patient and population preferences for actual health states. Froberg and Kane ${ }^{17}$ already noted this "framing effect" in their review. The direction of the difference was equal for all preference elicitation methods used. When using VAS, TTO, EQ-5D, HUI or QWB, patients attached a lower value to their actual health state than the population. However, the magnitude of the difference differs for the various methods: $10 \%, 8 \%$, $16 \%, 1 \%$, and $4 \%$ respectively. These results do not indicate which method is most suitable to assess preferences. Technically, using SG to measure preferences is the gold standard, because these preferences are measured under conditions of risk and the method is supported by Von Neumann and Morgensterns' expected utility theory. 105 However, the present meta-analysis had to exclude studies using the SG method, because of lack of observations. 


\section{HEALTH STATE ASSESSMENT}

The sensitivity analysis further showed that patients attached a lower value to their actual health state than the population when health state profiles or diseasespecific instruments were used to assess the severity of the health states. Results of studies using a generic classification for health state severity showed that patients attached a $24 \%$ lower preference to their generic health related quality of life than the population. ${ }^{11}$ The magnitude of the difference between patient and population preferences did not differ very much between the two classifications ( $4 \%$ for profile and $2 \%$ for disease-specific).

Interview-administered patient preferences were 5\% lower than interviewadministered population preferences, while patient preferences assessed with a self-administered instrument were $10 \%$ lower than self-administered population preferences. This difference in magnitude might be attributed to the fact that explanations in self-administered questionnaires have to be clear and understandable by themselves, whereas in interviewer-administered questionnaires, the interviewer can explain unclear passages in tasks and in what is expected from the interviewee.

\section{POPULATHON CHARACTERISTICS}

Age contributed to the difference between patient and population preferences. Younger age groups attached higher preferences to health than older age groups, probably because older age groups suffer from co-morbidity. Differences in the proportion of males did not contribute to the difference between actual patient and population preferences.

Chronically ill patients assigned lower preferences to their actual health state than subjects from the population, the difference amounting to $8 \%$. Patients who belonged to high-risk groups but were not yet ill assigned a $1 \%$ lower preference to their health state than the population.

\section{PREFERENCES FOR ACTUAL PATIENT HEALTH STATUS AND HYPOTHETICAL POPULATION HEALTH STATUS}

\section{OVERALL}

No publication bias was found in this meta-analysis. The comparison of actual patient preferences and hypothetical population preferences showed that patients attached higher preferences to their actual health status than the population did to a hypothetical health status. One explanation for this difference is that patients 
experiencing a particular health status adapt to their (chronically) ill health state. 106,107

\section{PREFERENCE ELICITATION METHODS}

The sensitivity analyses showed that most preference elicitation methods contributed to the difference between patient and population preferences. Patients' preferences assessed using VAS and QWB were 7\% and 12\% lower than population preferences, respectively. Population preferences were found to be linked to the description of the hypothetical health state. On the one hand, if this description is comprehensive, it might not be understandable to the population. On the other hand, if the description does not give detailed information, the population will underestimate the severity of the disease relative to patients actually experiencing it. Both explanations can lead to higher preferences assigned by subjects in the population.

\section{HEALTH STATE ASSESSMENT}

Classifying the severity of the health state into profiles using disease-specific or generic instruments yielded no significant differences between patient and population preferences. Actual patient preferences and hypothetical population preferences were not significantly different using interview-administered or selfadministered questionnaires.

\section{POFULATION CHARACTERISTICS}

Age and disease under study did not contribute to the overall difference in preferences between patients' actual health state and populations' hypothetical health state. Patient preferences were lower if there was a larger proportion of males among either the patients or the population. Only the magnitude differed: if there were more males among the population, the difference in preferences was $16 \%$, while if there were more males among patients, the difference between patient and population preferences was $1 \%$. These results suggest that gender is a source of heterogeneity.

\section{PREFERENCES FOR HYPOTHETICAL HEALTH STATES OF PATIENTS AND POPULATION}

\section{OVERALL}

A comparison of hypothetical health states showed the preferences of patients to be almost identical to those of the population, probably because the same health states were compared at an equal level. However, since this comparison did show 
some publication bias, the results of this meta-analysis should be interpreted carefully. This result suggests that reports of hypothetical patient health states have a smaller chance of being published.

\section{PREFERENCE ELICITATION METHODS}

The sensitivity analysis comparing hypothetical health states of patients and population showed that all preference elicitation methods substantially contributed to the difference in preferences between patients and population. When using VAS or EQ-5D, patients assigned higher preferences than the population: $5 \%$ and $3 \%$, respectively. When using TTO, patient preferences were $7 \%$ lower than population preferences.

\section{HEALTH STATE ASSESSMENT}

Studies classifying health state severity by profiles or a generic instrument found significantly smaller differences between patient and population preferences than studies using other assessment methods. Patients assigned 3\% higher preferences than the population using profiles and $6 \%$ higher preferences using a generic instrument. These results suggest that it is important to know how the severity of health states has been classified.

Self-administered patient preferences for hypothetical health states were $2 \%$ higher than self-administered population preferences. Interview-administered patient preferences were found to be $9 \%$ lower than interview-administered population preferences.

\section{POPULATION CHARACTERISTICS}

Age and gender did not contribute significantly to the difference between hypothetical patient and population preferences. Patient preferences for hypothetical health states regarding high-risk factors were $17 \%$ lower than hypothetical population preferences for high-risk factors. It is not surprising that patients who are experiencing a chronic disease but are asked to value a hypothetical high risk of a disease attached a lower value to this high risk than the population who are not experiencing a disease and are asked to value the same hypothetical high risk. Patients valuing hypothetical chronic diseases assigned $2 \%$ higher preferences than the population valuing the same hypothetical diseases. These findings suggest that patients attach a higher value to a disease they are not actually experiencing than the disease they are currently experiencing. This psychological phenomenon is known as downward comparison. 


\section{CONCLUSION}

These meta-analyses demonstrate that patient preferences differ significantly from population preferences for actual health states, whereas patient preferences do not differ significantly from population preferences for hypothetical health states. Patient preferences for actual health status and population preferences for hypothetical health status do not differ significantly. The latter result suggests that patient and population preferences can both be used to allocate resources. Moreover, the meta-analyses revealed that a variety of parameters act as sources of heterogeneity, including preference elicitation methods, health state assessment methods, study assessment methods and population characteristics. However, the direction and magnitude of the difference between patient and population preferences depends on the type of health states compared.

\section{REFERENCES}

1. Drummond M, Torrance G, Mason J. Cost-effectiveness league tables: more harm than good? Soc Sci Med 1993;37:33-40.

2. Gerard K, Mooney G. QALY league tables: handle with care. Health Econ 1993;2:5964.

3. Mason J. Drummond M, Torrance G. Some guidelines on the use of cost effectiveness league tables. BMJ 1993;306:570-572.

4. Ubel PA, Loewenstein $G$, Jepson $C$. Whase quality of life? A commentary exploring discrepancies between health state evaluations of patients and the general public. Qual Life Res 2003;12:599-607.

5. Fryback DG. Whose quality of life? or whose decision? Qual Life Res $2003 ; 12: 609$ 610.

6. Tugwell P, Bennett KJ, Sackett DL, Haynes RB. The measurement itterative loop: a framework for the critical appraisal of need, benefits and costs of health interventions. $\checkmark$ Chronic Dis 1985:38:339-351.

7. Drummond MF, O'Brien BJ, Stoddart GL, Torrance GW. Methods for the economic evaluation of health care programmes. Second ed. Oxford: Oxford University Press; 1997.

8. Torrance GW. Measurement of health state utilities for economic appraisal. $J$ Health Econ 1986;5:1-30.

9. The EuroQoll Group. EuroQol--a new facility for the measurement of health-related quality of life. Health Policy 1990;16:199-208.

10. Kaplan RM, Anderson JP. A general health policy model: update and applications. Health Serv Res 1988;23:203-235. 
11. Gold MR, Siegel JE, Russell LB, Weinstein MC. Cost-effectiveness in health and medicine. New York, Oxford: Oxford University Press; 1996.

12. De Wit GA, Busschbach $J J$, de Charro FT. Sensitivity and perspective in the valuation of health status: whose values count? Health Econ 2000:9:109-126.

13. Sackett DL, Torrance GW. The utility of different health states as perceived by the general public. J Chron Dis 1978;31:697-704.

14. Boyd NF, Sutherland HJ, Heasman KZ, Tritchler DL, Cummings BJ. Whose utilities for decision analysis? Med Decis Making 1990;10:58-67.

15. Balaban DJ, Sagi PC. Goldfarb NI, Nettler S. Weights for scoring the quality of wellbeing instrument among rheumatoid arthritics. A comparison to general population weights. Med Care 1986;24:973-980.

16. Froberg DG, Kane RL. Methodology for measuring health-state preferences-111: population and context effects. J Clin Epidemiol 1989;42:585-592.

17. Froberg DG, Kane RL. Methodology for measuring health-state preferences- $\|$ : scaling methods. J Clin Epidemiol 1989;42:459-471.

18. Ashby $J$, O'Hanlon M, Buxton MJ. The time trade-off technique: how do the valuations of breast cancer patients compare to those of other groups? Qual Life Res $1994 ; 3: 257-265$.

19. Egger M, Schneider M, Davey Smith G. Spurious precision? Meta-analysis of observational studies. BMJ 1998;316:140-144.

20. Green C. Brazier J, Deverill M. Valuing health-related quality of life. A review of health state valuation techniques. PharmacoEconomics 2000;17:151-165.

21. Nord E. Methods for quality adjustment of life years. Soc Sci Med 1992;34:559-569.

22. Hurst NP, Jobanputra P, Hunter M, Lambert M, Lochhead A, Brown H. Validity of Euroqol--a generic health status instrument-in patients with rheumatoid arthritis. Economic and Health Outcomes Research Group. Br I Rheumato/ 1994;33:655-662.

23. Bartman BA, Rosen MJ, Bradham DD, Weissman J, Hochberg M, Revicki DA. Relationship between heaith status and wility measures in older claudicants. Qual Life Res 1998;7:67-73.

24. Patrick DL, Ramsey SD, Spencer AC, Kinne S, Belza B, Topolski TD. Economic evaluation of aquatic exercise for persons with osteoarthritis. Med Care 2001:39:413424 .

25. Shields RK, Enloe LJ, Leo KC. Health related quality of life in patients with total hip or knee replacement. Arch Phys Med Rehab 1999;80:572-579.

26. Wang $C$, Mayo NE, Fortin PR. The relationship between health related quality of life and disease activity and damage in systemic lupus erythematosus. I Rheumato $2001 ; 28: 525-532$.

27. Sage WM, Rosenthal MH "Silverman JF. Is intensive care worth it? An assessment of input and outcome for the critically ill. Crit Care Med 1986;14:777-782.

28. Nicholl CR, Lincoln NB, Francis VM, Stephan TF. Assessing quality of life in people with multiple sclerosis. Disabil Rehabil 2001;23:597-603. 
29. Donovan JL, Kay HE, Peters TJ, Abrams P, Coast J, Matos Ferreira A, et al. Using the ICSOOL to measure the impact of lower urinary tract symptoms on quality of life: evidence from the ICS-"BPH' Study. International Continence Society-Benign Prostatic Hyperplasia. Br U Urol 1997;80:712-721.

30. Selai C. Rosser R. Eliciting EuroQol descriptive data and utility scale values from inpatients. A feasibility study. PharmacoEconomics 1995;8:147-158.

31. Lai SM, Duncan PW. Stroke recovery profile and the Modified Rankin assessment. Neuroepidemiology 2001:20:26-30.

32. Merlino LA, Bagchi I, Taylor TN, Utrie $P$, Chrischilles $E$, Sumner II W, et al. Preference for fractures and other glucocorticoid-associated adverse effects among rheumatoid arthritis patients. Med Decis Making 2001:21:122-132.

33. Chapman GB, Elstein AS, Kuzel TM, Nadler RB, Sharifi R, Bennett CL. A multiattribute model of prostate cancer patient's preferences for health states. Qual Life Res 1999;8:171-180.

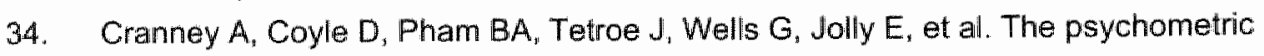
properties of patient preferences in osteoporosis. J Rheumatol 2001:28:132-137.

35. Jansen SJ, Stiggelbout AM, Wakker PP, Nooij MA, Noordijk EM, Kievit J. Unstable preferences: a shift in valuation or an effect of the elicitation procedure? Med Decis Making 2000;20:62-71.

36. Gold M, Franks P. Erickson P. Assessing the health of the nation. The predictive validity of a preference-based measure and self-rated health. Med Care 1996;34:163177.

37. Andresen EM, Patrick DL, Carter WB, Malmgren JA. Comparing the performance of health status measures for healthy older adults. J Am Geriatr Soc 1995;43:10301034.

38. Badia X, Roset M, Heroman M. Kind P. A comparison of United Kingdom and Spanish general population time trade-off values for EQ-5D health states. Med Decis Making 2001;21:7-16.

39. Devlin N, Hansen P. Herbison P. Variations in self-reported health status: results from a New Zealand survey. New Zeal Med J 2000;113:517-520.

40. Bjork $S$, Norinder A. The weighting exercise for the Swedish version of the EuroQol. Health Econ 1999;8:117-126.

41. Rizzo JA, Sindelar JL. Linking health-related quality-of-life indicators to large national data sets. Pharmaco Economics 1999;16:473-482.

42. Hisashige A, Mikasa H. Katayama T. Description and valuation of health-related quality of life among the general pubic in Japan by the EuroQol. JMI 1998;45:123129

43. Jenkinson $\mathrm{C}_{1}$ Stradling J, Petersen S. Comparison of three measures of quality of life outcome in the evaluation of continuous positive airways pressure therapy for sleep apnoea. J Sleop Res 1997;6:199-204. 
44. Gudex C, Dolan P, Kind P. Williams A. Health state valuations from the general public using the visual analogue scale. Qual Life Res 1996;5:521-531.

45. Elvik $R$. The validity of using health state indexes in measuring the consequences of traffic injury for public health. Soc Sici Med 1995;40:1385-1398.

46. Dolan P. Modeling valuations for EuroQol health states. Med Care 1997;35:10951108.

47. Kind $P$, Dolan $P$, Gudex $C$, Williams $A$. Variations in population health status: results from a United Kingdom national questionnaire survey. BMJ 1998;316:736-741.

48. Johnson JA, Coons SJ, Ergo A, Szava Kovats G. Valuation af EuroQOL (EQ-5D) health states in an adult US sample. Pharmaco Economics 1998;13:421-433.

49. Kirsch J, McGuire A. Establishing health state valuations for disease specific states: an example from heart disease. Health Econ 2000;9:149-158.

50. Neumann PJ, Kuntz KM, Leon J, Arakii SS, Hermann RC, Hsu MA, et al. Health utilities in Alzheimer's disease: a cross-sectional study of patients and caregivers. Med Care 1999;37:27-32.

51. Taylor WJ, Lord S, McPherson KM, MoNaughton HK. EuroQd EQ-5D may not adequately describe the health of people with disabilities. Disabil Rehabil $2001 ; 23: 281-285$.

52. Diaz Prieto A, Gorriz MT, Badia X, Torrado H, Farrero E, Amador لl, el al. Proxyperceived prior health status and hospital outcome among the critically ill: is there any relationship? Intens Care Med 1998;24:691-698.

53. Kerner DN, Patterson TL, Grant I, Kaplan RM. Validity of the quality of well-being scale for patients with Alzheimer's disease. J Aging Health 1998;10:44-61.

54. Coucill W, Bryan S, Bentham P, Buckley A, Laight A. EQ-5D in patients with dementia: an investigation of inter-rater agreement. Med Care 2001;39:760-771.

55. Hollingworth W. Mackenzie R, Todd CJ, Dixom AK. Measuring changes in quality of life following magnetic resonance imaging of the knee: SF-36, EuroQol or Rosser index? Qual Life Res 1995;4:325-334.

56. Zethraeus $N$, Johannesson M. A comparison of patient and social tariff values derived from the time trade-off method. Health Econ 1999;8:541-545.

57. Polsky D, Richard JW, Wilke RJ, Scott K, Schulman KA, Glick HA. A comparison of scoring weights for the EuroQol derived from patients and the general public. Health Econ 2001:10:27-37.

58. Hiollingworth W, Deyo RA, Sullivan SD, Emerson SS, Gray DT, Jarvik JG. The practicality and validity of directly elicited and SF-36 derived health state preferences in patients with low back pain. Health Econ 2002;11:71-85.

59. Schackman BR, Goldie SJ, Freedberg KA, Losina E. Brazier J, Weinstein MC. Comparison of health state utilities using community and patient preference weights derived from a survey of patients with HIVIAIDS. Med Decis Making 2002;22:27-38. 
60. Chen $\mathrm{S}$, Shaheen $\mathrm{A}$, Garber A. Cost-effectiveness and cost-benefit analysis of using methotrexate vs Goeckerman therapy for psoriasis. A pilot study. Arch Dermatol $1998 ; 134: 1602-1608$.

61. Hays RD, Siu AL, Keeler E, Marshall GN, Kaplan RM, Simmons S, et al. Long-term care residents' preferences for health states on the quality of well-being scale. Med Decis Making 1996;16:254-261.

62. Trippoli $S$, Valiani $M$. Lucioni $C$. Messori $A$. Quality of life and utility in patients with non-small cell lung cancer. Quality-of-life Study Group of the Master 2 Project in Pharmacoeconomics. PharmacoEconomics 2001;19:855-863.

63. Lalonde L, Clarke AE, Joseph L, Grover SA. Conventional and chained standard gambles in the assessment of coronary heart disease prevention and treatment. Med Decis Making 1999:19:149-156.

64. Redekop WK, Koopmanschap MA, Stolk RP, Rutten GE, Wolffenbuttel BH, Niessen LW. Health-related quality of life and treatment satisfaction in Dutch patients with type 2 diabetes. Diabetes Care 2002;25:458-463.

65. Van Agthoven M, Fokkens WJ, van de Merwe JP, wan Bolhuis E, Uyl-de Groot CA, Busschbach $J \mathbb{J}$. Quality of life of patients with refractory chronic rhinosinusitis: effects of filgrastim treatment. Am J Rhinol 2001;15:231-237.

66. Hilker R, Schischniaschwili M, Ghaemi M, Jacobs A, Rudolf J. Health related quality of life is improved by botulinum neurotoxin type $A$ in long term treated patients with focal dystonia. I Neurol Neurosurg Ps 2001;71:193-199.

67. Van Agthoven M, Vellenga E, Fibbe WE, Kingma T, Uyl-de Groot CA. Cost analysis and quality of life assessment comparing patients undergoing autologous peripheral blood stem cell transplantation or autologous bone marrow transplantation for refractory or relapsed non-Hodgkin's lymphoma or Hodgkin's disease. A prospective randomised triall. Eur J Cancer 2001;37:1781-1789.

68. Johnson. JA, Connolly M, Zuberbuhler P, Brown NE. Health-related quality of life for adults with cystic fibrosis: a regression approach to assessing the impact of recombinant human DNase. Pharmacotherapy 2000;20:1167-1174.

69. Schrag $A$, Jahanshahi $M$, Quinn $N$. How does Parkinson's disease affect quality of life? A comparison with quality of life in the general population. Movement Disord $2000 * 15: 1112-1118$.

70. Trueman P, Hood SC, Nayak US, Mrazek MF. Prewalence of Hower urinary tract symptons and self-reported diagnosed 'benign prostatic hyperplasia', and their effect on quality of life in a community-based survey of men in the UK. BJU 1999;83:410415.

71. Dolan P. Torgerson D, Kakarlapudi TK. Health-related quality of life of Colles' fracture patients. Osteoporosis 1999;9:196-199. 
72. Brazier JE, Harper R, Munro J, Walters SJ, Snaith ML. Generic and condition-specific outcome measures for people with osteoarthritis of the knee. Rheumatol 1999;38:870-877.

73. Bryan $\mathrm{S}$, Ratcliffe J, Neuberger JM, Burroughs AK, Gunson BK Buxton MJ. Healthrelated quality of life following liver transplantation. Qual Life Res 1998;7:115-120.

74. Jenkinson $C$, Stradling J, Petersen S. How should we evaluate health status? A comparison of three methods in patients presenting with obstructive sleep apnoea. Qual Life Res 1998; 7:95-100.

75. Richards DM, lrving MH. Assessing the quality of life of patients with intestinal failure on home parenteral nutrition. Gut 1997;40:218-222.

76. Hurst NP, Kind P, Ruta D, Hunter M, Stubbings A. Measuring health-related quality of life in rheumatoid arthritis: validity, responsiveness and reliability of EuroQol (EQ-5D). Br J Rheumatol 1997;36:551-559.

77. Tidermark J, Zethraeus N, Svensson O, Tornkvist H. Ponzer S. Femoral neck fractures in the elderly: functional outcome and quality of life according to EuroQol. Qual Life Res 2002;11:473-481.

78. Jansen AJ, Essink-Bot ML, Beckers EA, Hop WC, Schipperus MR, van Rhenen DJ. Quality of life measurement in patients with transfusion-dependent myelodysplastic syndromes. Br J Haematol 2003;121:270-274.

79. Ratcliffe J, Longworth $L$, Young T, Bryan S, Burroughs A, Buxton M. Assessing health-related quality of life pre- and post-liver transplantation: a prospective multicenter study. Liver Transplant 2002;8:263-270.

80. Van der Donk J, Levendag PC, Kuijpers AJ, Roest FH, Habbema JD, Meeuwis CA, et al. Patient participation in clinical decision-making for treatment of T3 laryngeal cancer: a comparison of state and process utilities. I Clin Oncol 1995;13:2369-2378.

81. Clarke AE, Goldstein MK, Michelson D, Garber AM, Lenert LA. The effect of assessment method and respondent population on utilities elicited for Gaucher disease. Qual Life Res 1997;6:169-184.

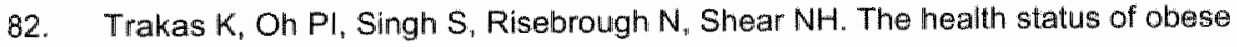
individuals in Canada. Int J Obesity Metab Disord 2001;25:662-668.

83. Lawrence WF, Fryback DG, Martin PA, Klein R, Klein BE. Health status and hypertension: a population-based study. J Clin Epidemiol 1996;49:1239-1245.

84. Kaplan RM, Anderson JP, Patterson TL, McCutchan JA, Weinrich JD, Heaton RK, et al. Validity of the quality of well-being scale for persons with human immunodeficiency virus infection. Psychosom Med 1995;57:138-147.

85. Lalonde L, Clarke AE, Joseph L, Mackenzie T, Grover SA. Health-related quality of life with coronary heart disease prevention and treatment. $J$ Ciin Epidemiol 2001:54:1011-1018.

86. Lalonde L, Clarke AE, Joseph L, Mackenzie T, Grover SA. Comparing the psychometric properties of preference-based and nonpreference-based healthrelated quality of life in coronary heart disease. Qual Life Res 1999;8:399-409. 
87. Tosteson AN, Gabriel SE, Kneeland TS, Moncur MM, Manganiello PD, Schiff I, et all. Has the impact of hormone replacement therapy on health-related quality of life been undervalued? J Women Health Gen-B 2000;9:119-130.

88. Miners AH, Sabin CA, Mocroft A, Youle M, Fisher M, Johnson M. Health-related quality of life in individuals infected with HIV in the era of HAART. HIV CIn Trials $2001 ; 2: 484-492$.

89. Van Cleemput P. Parry G. Health status of gypsy travellers. I Public Health Med $2001 ; 23: 129-134$.

90. Suarez-Almazor ME, Conner-Spady B. Rating of arthritis health states by patients, physicians, and the general public. Implications for cost-utility analyses. I Rheumatol 2001:28:648-656.

91. Schneider SM, Pouget I, Staccini P. Rampal P, Hebuterne X. Quality of life in longterm home enteral nutrition patients. Clin Nutr 2000;19:23-28.

92. Badia $X$, Herdman $M, K i n d P$. The influence of ill-thealth experience on the valuation of health. PharmacoEconomics 1998;13:687-696.

93. Gudex CM, Hawthorne MR, Butler AG, Duffey P. Effect of dystonia and botulinum toxin treatment on health-related quality of life. Movement Disord 1998;13:941-946.

94. Badia X, Diaz Prieto A, Rue $M_{4}$ Patrick DL. Measuring health and health state preferences among critically ill patients. Intens Care Med 1996;22:"1379-1384.

95. Essink-Bot ML, van Royen $L$, Krabbe P, Bonsell GJ, Rutten FF. The impact of unigraine on health status. Headache 1995;35:200-206.

96. Fryback DG, Dasbach EJ, Klein R, Klein BE, Dorn N, Peterson K, et all. The Beaver Dam Health Outcomes Study: initial catalog of health-state quality factors. Med Decis Making 1993:13:89-102.

97. Patrick DL, Starks HE, Cain KC, Uhlmann RF, Pearlman RA. Measuring preferences for health states worse than death. Med Decis Making 1994;14:9-18.

98. Badia $X_{.}$Fernandez $E$, Segura A. Influence of socio-dernographic and health status variables on evaluation of health states in a Spanish population. Eur J Public Health $1995: 5: 87-93$.

99. Terwee C, Wakelkamp I, Tan S, Dekker F, Prummel MF, Wiersinga W. Long-term effects of Graves' ophthalmopathy on health-related quality of life. Eur $J$ Endocrino 2002; 146:751-757.

100. Miners AH, Holmes A, Sherr L, Jenkinson C, MacDermot KD. Assessment of healthrelated quality-of-life in males with Anderson Fabry disease before therapeutic intervention. Qual Life Res 2002;11:127-133.

101. Collins ED, Kerrigan $\mathrm{CL}$, Kim M, Lowery $J C$, Striplin DT, Cunningham B, et al. The effectiveness of surgical and nonsurgical interventions in relieving the symptoms of macromastia. Plast Reconstr Surg 2002;109:1556-1566.

102. Egger $M$, Davey Smith $G$, Schneider M, Minder $C$. Bias in meta-analysis detected by a simple graphical test. BMJ 1997;3115:629-634. 
103. Corporation S. StataCorp Stata Statistical Software. Release 6.0 ed. College Station, TX: Stata Corporation; 1999.

104. Berkey CS, Hoaglin DC, Mosteller F, Colditz GA. A random-effects regression model for meta-analysis. Stat Med 1995;14:395-411.

105. Von Neumann $J$, Morgenstern $O$. Theory ol games and economic behavior. Princelon: Princeton University Press; 1947.

106. Adlang EM, Kootstra G, Baeten $C G$. Engel $G L$. Quality-of-life ratings in patients with chronic illnesses. JAMA 1997;277:1038,

107. Postulart D, Adang EM. Response shift and adaptation in chronically ill patients. Med Decis Making 2000;20:186-193. 
5

\title{
HEALTH RELATED QUALITY OF LIFE EVALUATIONS AND RESPONSE SHIFT. THE CASE OF CATARACT PATIENTS
}

\author{
M. Dolders, A. Ament, W. Groot \\ Submitted for publication
}

\begin{abstract}
Aim: To assess recalibration response shift in preferences among patients undergoing bilateral cataract surgery.

Methods: Cataract patients of three university medical centers were interviewed between August 1999 and January 2001, before and after first and second eye surgery using a structured questionnaire, measuring prospective and retrospective Visual Analogue Scale, Time Trade-Off and Standard Gamble preferences for overall health status and five health status dimensions, defined by the EuroQol-5D.

Results: No significant differences were found in prospectively assessed preferences (Wilcaxon Signed Rank Test, $p>.005$ ). Retrospectively assessed VAS preferences differed significantly from prospectively assessed VAS preferences (Wilcoxon Signed Rank test, $p<.001$ ). This then-test change can be explained by a recalibration response shift, meaning that then-test preferences were significantly lower than pre-test preferences (Wilcoxon Signed Rank test, $p<.001$ ). Significant differences were found between retrospectively assessed VAS preferences and post-test preferences in unchanged health state dimensions after first and second eye surgery (Wilcoxon Signed Rank test, $p<, 001$ ). These differences can be explained by a recalibration response shift.

Conclusion: Recalibration response shift is present in VAS preferences of cataract patients. After surgery, then-test scores were lower than pretest scores, which suggest that patients adapt to their visual impairment before surgery. Whether TTO and SG are feasible for thentesting is questionable.
\end{abstract}


Patient preferences, values or utilities are (self-reported) quantitative evaluations of health states.' Preferences are used to calculate quality-adjusted life years (QALYs), which are an outcome measure in cost-effectiveness (or cost-utility) analyses, and serve, combined with cost estimates, as input in clinical and health care decision-making. In this paper we refer to patients" self-assessed preferences using directly measured preferences for certain health states. This approach can use choice-based or non-choice-based methods. The Time Trade-Off (TTO) and Standard Gamble (SG) are choice-based preference methods, whereas the Visual Analogue Scale (VAS) and Rating Scale (RS) are non-choice-based preference methods.

The methodology used to measure preferences influences the outcomes of cost-effectiveness analyses. ${ }^{2}$ In a Pretest-Posttest design, preferences can be measured prospectively or retrospectively. Measuring them prospectively (in a conventional Pretest-Posttest design) may seriously threaten internal validity, a threat called response shift. A working definition of response shift is given by Schwartz \& Sprangers 3,4 :

"response shift refers to a change in the meaning of one's self-evaluation of a target construct as a result of: (a) a change in the respondent's internal standards of measurement (scale recalibration), (b) a change in the respondent's values (reprioritization), or (c) a redefinition of the target construct (i.e. reconceptualization)".

The first aspect of response shift is scale recalibration, which refers to a change in internalized perceptions (an internal standard of measurement) of the level of functioning on a given (health-related) dimension. Respondents understand what the points on the response scalle mean to them, based on their own particular experiences and perceptions. New experiences over time can alter this understanding. Thus, response scales stretch or condense to fit the experience continuum, resulting in different intemal standards of measurement. In the present study, scale recalibration was assessed using the then-test approach (see explanation below). Figure 5.1 graphically presents this scale recalibration effect as the change from $A$ (= pre-test) to $B$ (= then-test). The change from $B$ to $C$ (or $C^{\prime}=$ post-test) is the then-test change, whereas the change from $A$ to $C$ is the conventional (Pretest-Posttest) change. 
The second aspect of response shift is reprioritization, which occurs when respondents change their values over time. For example, respondents may value the physical dimension higher than the social dimension before surgery, whereas after surgery the social dimension becomes more important. The quality-of-life construct has not changed, but the importance respondents attach to the different dimensions has changed, causing the change in values.

The third aspect of response shift is a redefinition of the target construct (reconceptualization). Reconceptualization occurs when the dimensions of the target construct (i.e. the quality-of-life dimensions) change over time. Thus, qualityof-life is not defined by physical, psychological and social health alone, but also by, e.g., the spiritual health dimension.

Figure 5.1. Response-shift effect due to conventional change (AC' change), scale recalibration ( $A B$ change), and then-test change ( $B C$ " change) in a prospectiveretrospective Pretest-Posttest design

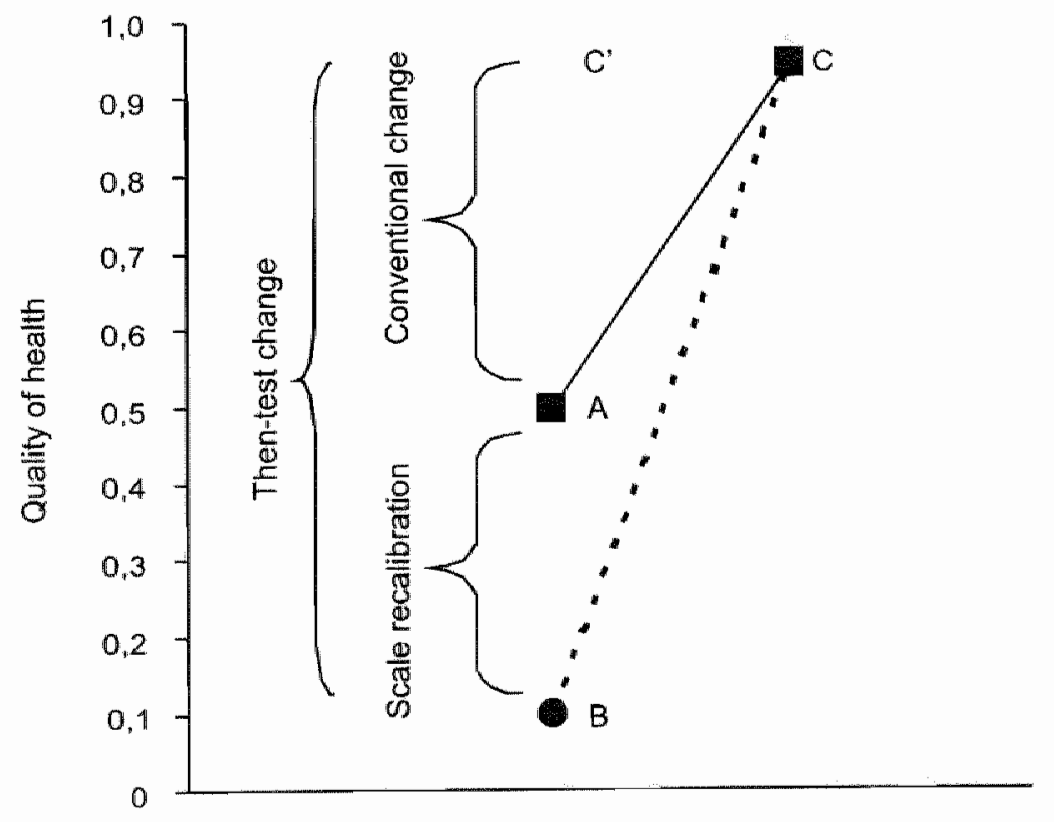

$A=$ Pre-test, $B=$ Then-test, $C=$ Post-test

- - $\quad B C^{\prime}$ change: Then-test change (difference $=.85$ )

$A C$ " change: Conventional change (difference $=.45$ )

$\mathrm{AB}$ change: Scale recalibration (difference $=.40$ ) 
Several methods can be used to examine whether response shift occurs. One method to measure scale recalibration is the then-test approach, originally described by Howard et al. ${ }^{5}$ To the conventional Pretest-Posttest design, a retrospective pre-test (then-test) is added, assuming equal internal standards of measurement for the retrospective pre-test and the post-test. At the post-test; patients report self-assessed preferences twice. First they are asked to assess preferences for their current health state (the conventional post-test). The then-test is then administered immediately after the post-test, by asking patients to evaluate their preferences at the time of the pre-test. Patients thus give a renewed evaluation of the situation before the treatment. The comparison of retrospective pre-test scores and post-test scores should provide an unbiased estimate of the preference change. ${ }^{6}$ The majority of studies including a then-test approach have been conducted in educational research. ${ }^{57-12}$ The then-test has also been applied in health-related quality-of-life (HRQoL) cancer research. ${ }^{13-18}$

In a longitudinal (conventional Pretest-Posttest) design, preference measurements, which reflect the (change in) importance of health state dimensions, directly measure response shift effects with regard to changes in values (reprioritization). Indirect evidence of response-shift effects regarding value changes is provided in the study by Lenert et al., ${ }^{19}$ which analyzed whether health status and preferences are associated. Because of their cross-sectional design, however, they were unable to confirm changes in preferences, which can only be assessed in a longitudinal design. Adang et al. ${ }^{20}$ used such a longitudinal design and found a significant difference between retrospectively measured preferences and prospectively measured preferences in a population of successfully transplanted diabetes patients with end-stage renal disease. Patients underestimated their pre-test quality-of-life, which was explained by a change in health status and adaptation to the illness in the pre-transplant period. ${ }^{21}$ Change in health status of diabetic patients, however, was not measured. A lack of response shift in preferences was found in patients with hearing impairment, a mild health condition. $^{22}$ In both studies, preferences were measured with non-choice-based methods.

The goal of the present study was to provide direct evidence of recalibration response shift in preferences. To assess recalibration response shift in preferences, which are inextricably bound up with health status, response shift in health status should be avoided. In other words, response shift in health status should be eliminated as much as possible i.e. health states should not be changed. 
If unchanged health state dimensions are used, recalibration response shift in health-related quality of life evaluations can be established. To establish recalibration response shift we added a then-test to the conventional Pretestposttest design. The design of the study is visualized in Figure 5.2 .

\section{Figure 5.2. Design of the study}

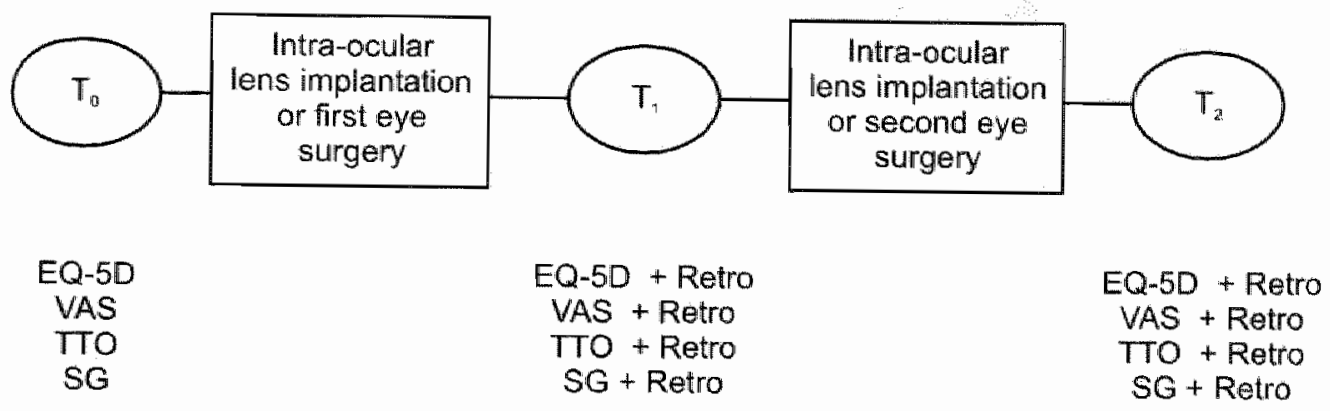

$$
\begin{gathered}
T_{0}=\text { Pre-test } \\
T_{1}=\text { Post-test after first eye surgery } \\
T_{2}=\text { Post-test after second eye surgery } \\
E Q-5 D=\text { EuroQol-5D } \\
\text { VAS }=\text { Visual Analogue Scale } \\
\text { TTO = Time Trade-Off } \\
\text { SG = Standard Gamble measured conventional over time } \\
\text { Retro = Then-test measurement for EQ-5D, VAS, TTO or SG }
\end{gathered}
$$

A population of senile cataract patients was interviewed. Senile cataract is an age-related vision problem and is defined as opacity in the crystalline lens of the eye. ${ }^{23}$ In 1994, the prevalence of cataract among men aged over 50 in the Netherlands was approximately $3 \%$ and that for women $5 \%$. The incidence in the over-50 category is approximately $0.5 \%$ for men and $0.9 \%$ for women. ${ }^{24}$ The only treatment for cataract is surgery. Although indications for cataract surgery are based on objective vision tests (e.g. visual functioning, visual acuity, contrast sensitivity), there are no guidelines for ophthalmologists to decide when surgery is indicated. ${ }^{25}$ Furthermore, objective measures of visual functioning only moderately correlate with subjective measures of satisfaction. ${ }^{26}$ Since moderate correlations between objective and subjective outcome measures are often seen in responseshift research ${ }^{3}$, health state evaluations of cataract patients were expected to be 
subject to response shift. Response shift can be demonstrated by Pretest-Posttest and Retrospective Pretest-Posttest designs.

The following hypotheses were formulated: (1) Pre-test preferences differ from post-test preferences in overall health status after first and second eye surgery, (2) Then-test preferences differ from pre-test preferences in overall health status after first and second eye surgery. Both hypotheses are applied to unchanged health state dimensions to attribute recalibration response shift to preference change not to a health status change.

\section{METHOD}

\section{PARTICIPANTS}

This preference study was part of a randomized contralled trial (RCT) comparing patient satisfaction and cost-effectiveness of the implantation of monofocal or multifocal intraocular lenses in cataract patients. The medical files of 1218 consecutive cataract patients awaiting surgery were screened for the following inclusion and exclusion criteria: bilateral senile cataract, no ocular co-morbidity, preoperative keratometric astigmatism $\leq 1.5$ Diopters (D), axial length between $19.5 \mathrm{~mm}$ and $26 \mathrm{~mm}$, preoperative sphere between $-6 \mathrm{D}$ and $+4 \mathrm{D}$. Patients were excluded in case of professional night driving, mental retardation, inability to complete the questionnaire in Dutch and pseudophakia. For this preference study, patients implanted with monofocal or multifocal intraocular lenses were analyzed as one cohort. The surgery was performed on an outpatient basis at one of the following centers: Atrium Medical Center Heerlen (AMCH), University Hospital Maastricht (UHM), and Medical Center Maastricht Annadal (MCMA). The nature and purpose of the study, including effects and possible side effects of the treatment, were explained to each patient by the ophthalmologist in attendance. Additionally, a patient information brochure and an informed consent form were sent to all selected patients awaiting cataract surgery. The medical ethics committees of all three centers approved the research protocol. Enrollment of 190 patients occurred from August 1999 until January 2001. 


\section{INTERVEWS AND INSTRUMENTS}

Patients were interviewed one to two weeks before their first eye surgery (pre-test), three months after the first eye surgery (post-test 1 and then-test1) and up to three months postoperatively after implantation of the second intraocular lens (post-test2 and then-test2). The interval between the first and second eye surgeries was approximately 16 weeks. Assessments took place by two experienced interviewers at the UHM department of ophthalmology. Patients from other medical centers were also interviewed at the UHM department of ophthalmology.

The effectiveness of the surgery was measured by means of patient preferences, which evaluates a patient's particular (self-reported) health state." Self-reported health state was measured with the EuroQol-5D (EQ-5D). In this study only the descriptive classification system of the EQ-5D was used, which defines HRQoL in terms of five dimensions (mobility, self-care, usual activities, pain/discomfort and anxiety/depression). Each dimension is recorded at three levels of severity: $1=$ no problems, $2=$ moderate problems and $3=$ severe problems. A patient's current EQ-5D health state is expressed by a five-digit code based upon a classification of problems for all five dimensions. For example, health state 11312 means no problems of mobility, no problems of self-care, severe problems with usual activities, no problems of pain/discomfort, and moderate problems of anxiety/depression. ${ }^{27}$ The EQ-5D was used to assess change in health status and HRQoL dimensions.

Prospective measurement of patient preferences used non-choice-based preference (Visual Analogue Scale) and choice-based preference instruments (Time Trade-Off and Standard Gamble)..$^{28}$ The Visual Analogue Scale (VAS) is a horizontal $10 \mathrm{~cm}$ line ranging from 0 to 10 . Patients can mark their current generic health state on the line. The VAS values directly equal their preference value. VAS preferences were transformed to a $0-1$ scale representing the worst HRQOL state (0) or the best HRQoL state (1) to allow for comparison of non-preference-based values with preference-based values or utilities.

The TTO is defined as a choice between two alternatives. In the present study, the first alternative was "living 10 years with cataract", the second "living 10 years in full health". The second alternative was then changed from 10 to 9 years, from 9 to 8 years and so on, until the patient was indifferent between the two alternatives. To compute the preference value for cataract, $0-10$ scales were transformed to $0-1$ scales using the formula [cataract=number of years in full health/10]. 
The $S G$ is a technique in which choices are offered to patients between living with cataract for the remainder of their lives or undergoing surgery, with a chance of returning to perfect health $(p)$ or a chance that the surgery results in blindness $(1-p)$. The probability of surgery success is varied until the patient is indifferent between remaining in the cataract state and risking surgery. At this indifference point, the utility equals $p$. The probabilities are measured as proportions. In economic evaluations, the utility scale is a $0-1$ scale with endpoints perfect health and death. In the present study, the endpoint was blindness. Utilities (chance p) were recalculated to a $0-1$ scale with endpoints perfect health and death by multiplying chance $(1-p)$ by the mean utility for blindness ${ }^{29}$ and adding chance $\left(p^{*}\right)$. Visual aids were used to enhance the comprehensibility of the probabilities for TTO and $S G^{30}$

The VAS, TTO and SG were converted into a then-test measuring preferences retrospectively, which was administered immediately after the posttest. This procedure presumes that internal standards are equal for the posttest and the then-test, while both tests are measured at the same time. This procedure also should exclude recall bias, defined as bias in self-reported information from the past due to faulty memory. ${ }^{5}$ In the then-test, patients were specifically asked not to recall their preferences before the first cataract surgery, but to provide a renewed judgment of their preferences before the first cataract surgery.

The then-test approach for the TTO was described as follows: 'in the next questions, you can choose between two options. The first is living with cataract for the rest of your life $(=10$ years). The second is living in full health for 9 years. Would you have chosen option one or two before your cataract surgery?' If the answer was option two, the next question was 'the first option is living with cataract for the rest of your life ( $=10$ years), the second is living in full health for 8 years. Would you have chosen option one or two before your cataract surgery?' The last sentence was repeated at every choice. At the pre-test or post-test, this sentence read: 'Would you choose option one or two?'

\section{STATISTICAL ANALYSIS}

Data analysis incorporated response and attrition analyses. Logistic regression analysis was applied to assess selection caused by dropout. Baseline characteristics of cataract patients who completed all structured interviews and dropouts were assessed by descriptive analysis. Conventional scores (post-test minus pre-test), scale recalibration scores (then-test minus pre-test) and then-test 
scores (post-test minus then-test) were computed from the raw preference scores. The distribution of the data was tested for normality with the Kolgomorov-Smirnov test. Since VAS preferences were non-hormally distributed, comparisons of VAS preferences were conducted using the non-parametric Wilcoxon Signed Rank test. Following Jansen et al., ${ }^{17}$ paired t-tests were used for comparisons of TTO preferences and SG preferences. The results are presented as means and standard deviations. Subgroup analyses were used for unchanged health state dimensions to assess recalibration response shift in the evaluation of these HRQDL dimensions. Since large numbers of tests were conducted, conservative criteria for statistical significance were applied, and the level of statistical significance was restricted to $p<.005$. All analyses were performed using SPSS 11.0.

\section{RESULTS}

\section{RESPONSE AND ATTRITION ANALYSES}

Response and attrition was examined in the 1218 consecutive cataract patients awaiting surgery. Eligibility criteria were not met for 704 patients, while 316 patients refused to participate. Unspecified other reasons applied to eight patients. Table 5.1 presents the baseline characteristics of patients involved in all three measurement moments $(n=145)$ and dropouts $(n=43)$. Dropouts did not differ significantly from responding patients on baseline characteristics thus, selective dropout could not be established. One patient missed too many responses on the valuation tasks after the second eye surgery and was deleted from the analyses. Nine patients had randomly distributed missing answers, so it was decided to retain these patients in the analyses. Thus, 144 patients were considered in further analyses.

\section{RECALIBRATION RESPONSE SHIFT IN PREFERENCES FOR THE HEALTH STATUS CATARACT}

Figure 5.3a presents scale recalibration after first eye surgery. Figure 5.3b scale recalibration after second eye surgery. Wilcoxon Signed Rank tests (VAS) and paired t-tests (TTO and SG) showed no significant differences in non-choice-based or choice-based preferences between pre-test and post-test 1 or between pre-test and post-test2. Thus, no conventional preference change was found. 
Table 5.1. Baseline characteristics of cataract patients at three measurement moments and dropouts

\begin{tabular}{|c|c|c|c|}
\hline & $\begin{array}{l}\text { Patients (1) } \\
(n=145)\end{array}$ & $\begin{array}{l}\text { Drop-outs (0) } \\
\qquad(n=43)^{\mathrm{a}}\end{array}$ & Odds Ratio $(95 \% \mathrm{Cl})$ \\
\hline \multicolumn{4}{|l|}{$\begin{array}{l}\text { Demographic } \\
\text { characteristics }\end{array}$} \\
\hline Age (mean; sd) & $70.7(s d=9.3)$ & $72.6(\mathrm{sd}=7.4)$ & $1.02(0.96-1.08)$ \\
\hline Female gender $(0)$ & $68.3 \%$ & $55.8 \%$ & $1.66(0.75-3.68)$ \\
\hline Male gender (1) & $31.7 \%$ & $44.2 \%$ & \\
\hline \multicolumn{4}{|l|}{ Educational level: } \\
\hline - low & $57.9 \%$ & $60.5 \%$ & $0.81(0.22-3.01)$ \\
\hline - middle & $33.8 \%$ & $30.2 \%$ & $1.12(0.28-4.43)$ \\
\hline - high & $8.3 \%$ & $9.3 \%$ & 1.00 \\
\hline \multicolumn{4}{|l|}{ Marital status: } \\
\hline - Living alone (0) & $39.3 \%$ & $48.8 \%$ & $2.01(0.92-4.36)$ \\
\hline - Living together (1) & $60.7 \%$ & $51.2 \%$ & \\
\hline \multicolumn{4}{|l|}{ Employment status: } \\
\hline - unemployed & $31.0 \%$ & $20.9 \%$ & $0.30(0.06-1.62)$ \\
\hline - employed & $3.4 \%$ & $14.0 \%$ & $1.43(0.56-3.66)$ \\
\hline - retired & $65.5 \%$ & $65.1 \%$ & 1.00 \\
\hline \multicolumn{4}{|l|}{ Preferences } \\
\hline VAS (mean, sd) & $0.72(s d=0.18)$ & $0.73(\mathrm{sd}=0.18)$ & $0.93(0.17-5.09)$ \\
\hline TTO (mean, sd) & $0.69(\mathrm{sd}=0.27)$ & $0.70(\mathrm{sd}=0.29)$ & $0.77(0.21-2.90)$ \\
\hline SG (mean, sd) & $0.94(\mathrm{sd}=0.06)$ & $0.94(\mathrm{sd}=0.07)$ & $1.73(0.01-498.9)$ \\
\hline
\end{tabular}

Then-test changes were found for VAS preferences between then-test scores after first eye surgery and post-test 1 scores (Wilcoxon Signed Rank test, $p<.001)$ and between then-test scores after second eye surgery and post-test2 scores (Wilcoxon Signed Rank test, $p<.001$ ).

Then-test VAS preferences after first (mean $=0.61$, standard deviation ( $=$ sd) $=0.23$ ) and second eye surgery (mean $=0.63, \mathrm{sd}=0.22$ ) were significantly lower than pre-test VAS preferences (mean $=0.72, s d=0.21$ ), indicating that response shift occurred after first and second eye surgery (Wilcoxon Signed Rank test, $p<.001$ ). This difference can be explained by a scale recalibration effect. Table 5.2 presents the overall mean scores and standard deviations after first eye surgery whereas Table 5.4 shows the overall mean and standard deviations after second eye surgery. 
Figure 5.3a

Conventional change (pre-post1), scale recalibration (pre-then1) and then-test change (then1-post1) in overall preferences, measured with VAS, TTO or SG, in cataract patients $(n=144)$ after first eye surgery

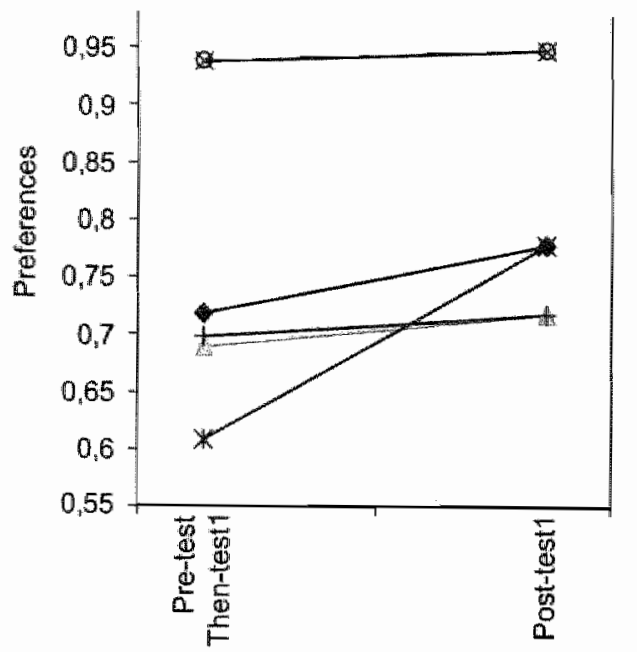

\footnotetext{
- Pre-Post1 VAS * Then1-Past1 VAS

- A Pre-Post1 TTO + Then1-Post1 TTO

* Pre-Post SG $\bullet$ Then1-Past1 SG
}

\section{Figure 5.3b}

Conventional change (pre-post2), scale recalibration (pre-then 2 ) and then-test change (then2-post2) in overall preferences, measured with VAS, TTO or SG, in cataract patients ( $n=144)$ after second eye surgery

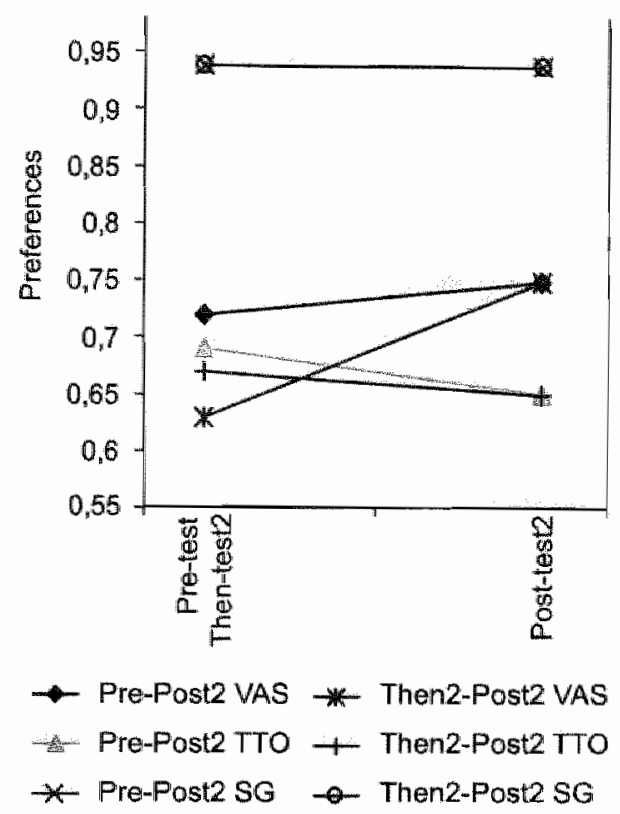

\footnotetext{
Pre-Post1 $=$ pre-test - post-test after first surgery

Then1-Post1 $=$ then-test - post-test after first surgery

Pre-Post2 $=$ pre-test - post-test after second surgery

Then2-Post2 $=$ then-test - post-test after second surgery

VAS $=$ Visual Analoque Scale, TTO $=$ Time Trade-Off, $S G=$ Standard Gamble
}

\section{RECALIBRATION RESPONSE SHIFT IN PREFERENCES FOR UNCHANGED HEALTH STATE}

\section{DIMENSIONS AFTER FIRST EYE SURGERY}

Table 5.2 presents the mean VAS preference scores and standard deviations after first eye surgery for patients" unchanged health state dimensions. It also shows the mean (sd) conventional change scores, scale recalibration scores and then-test change scores.

After first eye surgery, pre-test and post-test preference scores did not differ significantly (Wilcoxon Signed Rank test, $p>.005$ ), indicating no significant 
differences with regard to conventional change in preferences after first eye surgery.

A then-test change was observed for all unchanged health state dimensions (Wilcoxon Signed Rank test, p<.001). Mean then-test preference scores for mobility, self-care, performing daily activities, feeling pain or discomfort, and feeling depressed or anxious were significantly lower than the post-test preference scores after first eye surgery. The then-test changes can be explained by a scale recalibration effect. The mean then-test scores were significantly lower than the mean pre-test preference scores.

Table 5.3 presents the pre-test, then-test and post-test means and standard deviations of TTO preferences and SG preferences after first eye surgery, as well as the mean conventional change, the mean scale recalibration and the mean then-test change scores. Table 5.3 shows no significant TTO preference or SG preference differences in conventional changes, then-test changes or scale recalibration after first eye surgery (t-tests, $p>005$ ).

RECALIBRATION RESPONSE SHIFT IN PREFERENCES FOR UNCHANGED HEALTH STATE DIMENSIONS AFTER SECOND EYE SURGERY

Table 5.4 presents the mean VAS preference scores and standard deviations after second eye surgery for the overall health status and the unchanged health state dimensions. The table also shows mean (sd) conventional and then-test change scores, and scale recalibration after second eye surgery.

Pre-test VAS preference scores did not differ significantly from post-test scores after second eye surgery (Wilcoxon Signed Rank test, $p>.005$ ), indicating no conventional change after second eye surgery for the overall health status as well as the unchanged health state dimensions.

Then-test changes were observed in all unchanged health state dimensions. Mean then-test preference scores were significantly lower than the mean post-test preferences after second eye surgery. This can be explained by a scale recalibration effect. Mean then-test scores were significantly lower than mean pretest scores (Wilcoxon Signed Rank test, $p<.001$ ). Table 5.5 presents the change scores for TTO preferences and SG preferences after second eye surgery. TTO preferences showed no significant differences between pre-test and post-test (conventional change), between then-test and post-test (then-test change) or between pre-test and then-test (scale recalibration). 


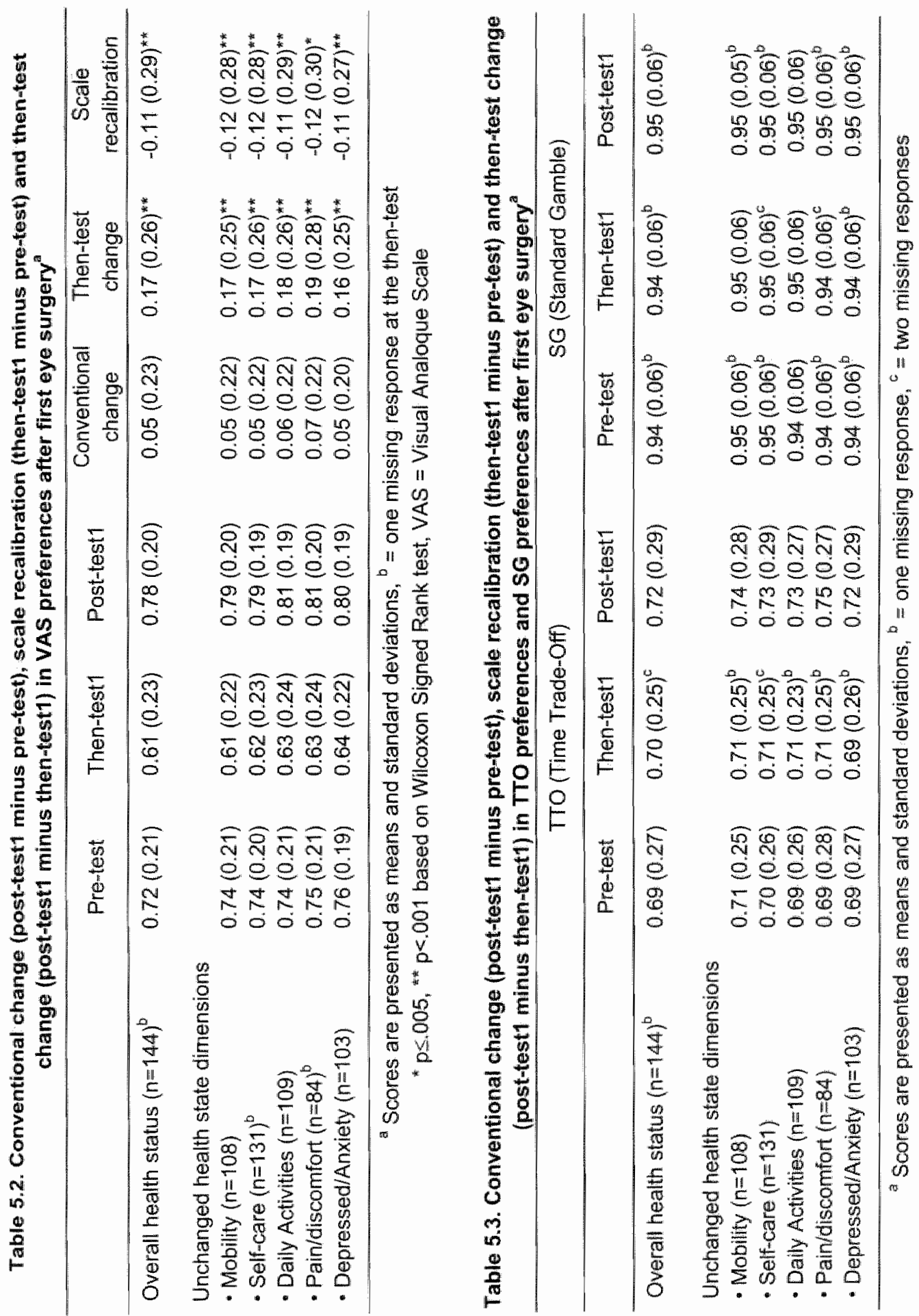




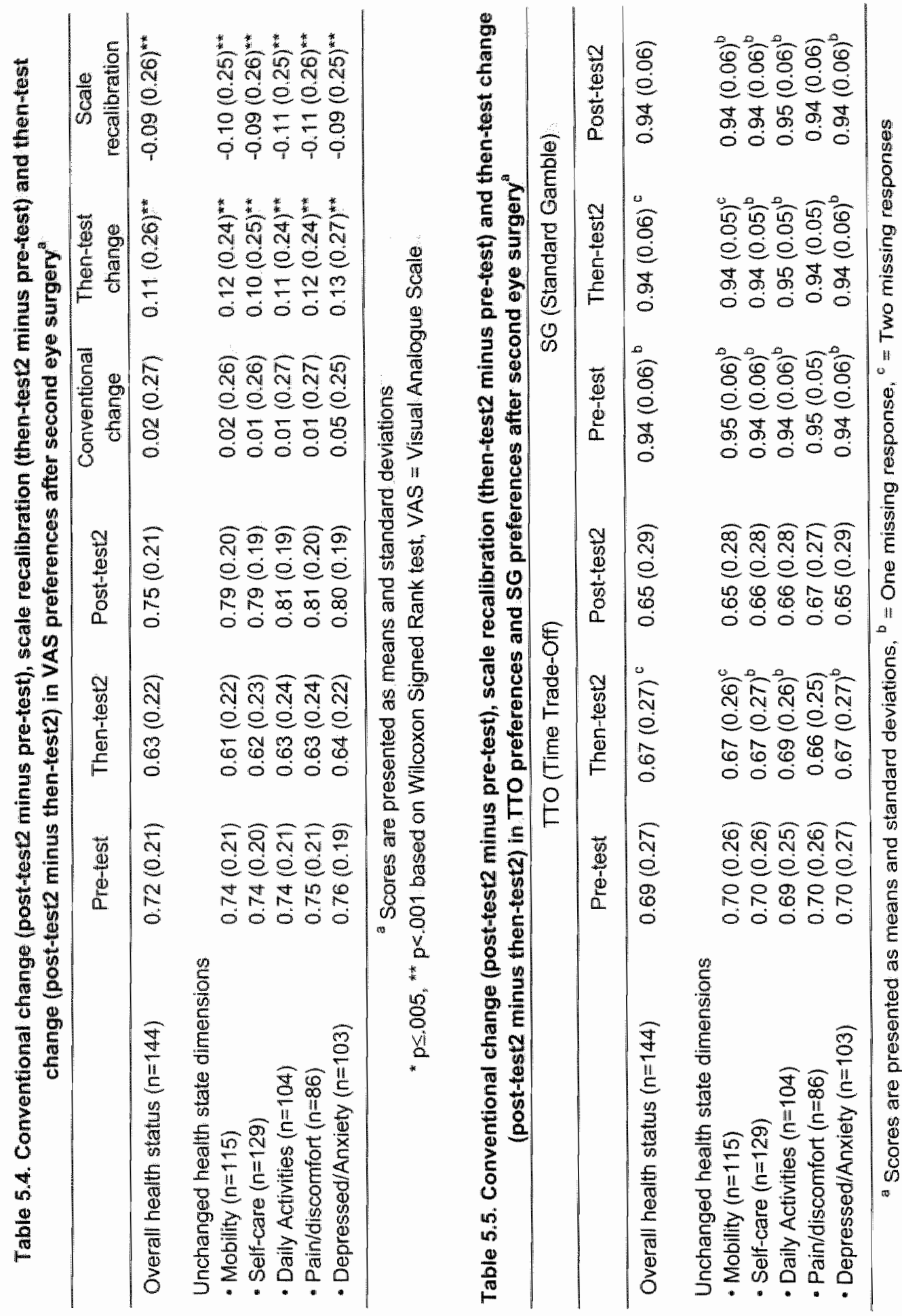




\section{COMMENT}

The conventional Pretest-Posttest design used in this study found no significant differences between preferences measured with non-choice-based or choicebased methods. This result may be contaminated by response shift, since patients" initial interpretation of the quality-of-life construct may have been changed by the experimental treatment. Response shift can be attributed to a scale recalibration effect, reprioritization or reconceptualization. The present study assessed only scale recallibration in preferences. We used unchanged quality-of-life dimensions to avoid recalibration response shift in heaith status.

Like others, ${ }^{13-18}$ we assessed scale recalibration using a then-test approach. We were unable to assess recalibration response shift in the Time Trade-Off and Standard Gamble methods. This result seems to indicate that choice-based preferences are likely to be stable over time. In a study of the stability of preferences for adjuvant chemotherapy, Jansen et al. ${ }^{31}$ also found stable choicebased preferences. The fact that we were unable to assess response-shift bias in TTO preferences and SG preferences can be explained by three other factors. First, cataract is a mild health condition and a ceiling effect in TTO and SG preferences can be expected. ${ }^{32-34}$ Second, a mild health condition was measured with a generic quality of life instrument. ${ }^{35}$ It might be possible that the dimensions were too generic or that the answering categories were too crude to detect the relevant changes in health status of cataract patients. Third, the cataract patients were elderly patients. Choice-based methods seem to be very difficult to comprehend, especially for the elderly. ${ }^{30}$ Converting these methods into a then-test approach adds another difficulty level. Our findings show that it is questionable whether the Time Trade-Off and Standard Gamble methods are suitable for thentesting. Further research to develop a reliable and valid then-test instrument for choice-based preferences should be encouraged, as well as then-testing in other patient groups (younger and for seriously ill patients). If further research confirms that preferences are stable over time, it might not be necessary to use a prospective design in the future. Instead, the choice-based preferences from a cross-sectional design could then be used for QALY calculations in costeffectiveness ratios. Since scale recalibration reflects changes over time, thentesting is not applicable to cross-sectional designs.

Recalibration response shift was found in the overall assessment of preferences using the VAS method. Like Adang, ${ }^{20}$ we found that cataract patients 
underestimated their quality-of-life before surgery. In Adang's study, this underestimation was explained by a change in health status. ${ }^{21}$ in our study, however, most scale recalibration effects occurred in unchanged health state dimensions, avoiding the interconnectedness between health status and preferences. Although health state dimensions remained unchanged over time, cataract patients evaluated these health states more favorably after first and second eye surgery. This seems to indicate that before surgery, cataract patients adapt to their visually impaired health states. This is illustrated by an anecdotal report of a patient: "Before surgery, $\|$ bought a coat. I thought the color of the coat was green. After surgery, I saw the color was pink. I did not realize that my vision was that bad". Furthermore, this result indicates that recalibration response shift in health state evaluations is not catalyst by a health state change, but is merely viewed as a passage of time."

We found scale recalibration in the Visual Analogue Scale, a non-choilcebased preference method. Here the level of measurement might be important. The Visual Analogue Scale can be seen, on the one hand, as an intervall scale, assuming the difference between two points to have the same meaning throughout the scale. However, the endpoints (e.g. worse, best quality-of-life) are highly flexible. This flexibility might be a cause of recalibration response shift. If, on the other hand, the Visual Analogue Scale is seen as an ordinal scale, the differences between two points have different meanings, and recalibration response shift is more likely to occur. Furthermore, a theoretical foundation is lacking in the VAS elicitation method. ${ }^{36}$ The VAS method might be an inferior preference elicitation method compared to the TTO and SG. However, if response-shift bias is taken into account, the calculation of QALYs, serving as input in resource allocation decisions can be based on non-choice-based preference methods and choice-based methods. Therefore, two major aspects have to be considered regarding this choice. Choice-based methods are difficult to comprehend, but are likely to reveal preferences without response shift bias, whereas non-choice-based methods are easy to understand, but are more likely to be biased by response shift. In the latter case a then-test approach should be added to the design.

A recalibration response-shift effect was assessed in non-choice-based preference methods. In cataract, QALY calculations based on TTO preferences and SG preferences at any point in time seem to be suitable, whereas QALY calculation differs when VAS preferences are used before or after treatment. 
Patients underestimate their pre-treatment quality-of-life. Taking this bias into account may result in different clinical and health care decisions.

\section{REFERENCES}

1. Drummond MF, O'Brien BJ, Stoddart GL, Torrance GW. Methods for the economic evaluation of health care programmes. Second ed. Oxford: Oxford University Press: 1997.

2. Postulart D, Adang EM. Response shift and adaptation in chronically ill patients. Med Decis Making 2000;20:186-193.

3. Schwartz CE, Sprangers MAG. Adaptation to changing health: response shift in quality-of-life research. Washington, DC, US: American Psychological Association; 2000 .

4. Sprangers MA, Schwartz CE. Integrating response shift into health-related quality of life research: a theoretical model. Soc Sci Med 1999;48:1507-1515.

5. Howard GS, Ralph KM, Gulanick NA, Maxwell SE. Internal invalidity in pretestposttest self-report evaluations and a re-evaluation of retrospective pretests. Appl Psych Meas 1979;3:1-23.

6. Bray JH, Maxwell SE, Howard GS. Methods of analysis with response-shift bias. Educ Psych Meas 1984;44:781-804.

7. Howard GS, Dailey PR. Response-shift bias: a source of contamination of self-report measures. J Appl Psych 1979;64:144-150.

8. Howard GS, Dailey PR, Gulanick NA. The feasibility of informed pretests in attenuating response-shift bias. Appl Psych Meas 1979;3:481-494.

9. Bray JH, Howard GS. Methodological considerations in the evaluation of a teachertraining program. J Educ Psych 1980;72:62-70.

10. Hoogstraten $\mathrm{J}$. The retrospective pretest in an educational training context. $J$ Exp Educ 1982;50:200-204.

11. Hoogstraten $\mathrm{J}$. Influence of objective measures on self-reports in a retrospective pretest-posttest design. $J$ Exp Educ 1985:53:207-210.

12. Sprangers $M$, Hoogstraten $\mathrm{J}$. On delay and reassessment of retrospective preratings. J Exp Educ 1988;56:148-153.

13. Bernhard J, Hurny $C$, Maibach R, Herrmann R, Laffer U. Quality of life as subjective experience: reframing of perception in patients with collon cancer undergoing radical resection with or without adjuvant chemotherapy. Swiss Group for Clinical Cancer Research (SAKK). Ann Oncol 1999; 10:775-782.

14. Breetvelt IS, Van Dam FS. Underreporting by cancer patients: the case of responseshift. Soc Sci Med 1991;32:981-987.

15. Sprangers MA. Response-shift bias: a challenge to the assessment of patients quality of life in cancer clinical trials. Cancer Treat Rev 1996;22:55-62. 
16. Sprangers MA, Van Dam FS, Broersen J, Lodder L, Wever L, Visser MR, et al. Revealing response shift in longitudinal research on fatigue-the use of the thentest approach. Acta Oncol 1999;38:709-718.

17. Jansen S』, Stiggelbout AM, Nooij MA, Noordijk EM, Kievit J. Response shift in quality of life measurement in early-stage breast cancer patients undergoing radiotherapy. Qual Life Res 2000;9:603-615.

18. Sprangers MA. Quality-of-life assessment in oncology. Achievements and challenges. Acta Oncol 2002; $41: 229-237$.

19. Lenert LA, Treadwell JR, Schwartz CE. Associations between health status and utilities implications for policy. Med Care 1999;37:479-489.

20. Adang EM, Kootstra G, Engel GL, van Hooff JP, Merckelbach HL. Do retrospective and prospective quality of life assessments differ for pancreas-kidney transplant recipients? Transpl Int 1998:11:11-15.

21. Adang EM, Kootstra G, Baeten CG. Engel GL. Quality-of-life ratings in patients with chronic illnesses. JAMA 1997;277:1038.

22. Joore MA, Potjewijd J, Timmerman AA, Anteunis LJ. Response shift in the measurement of quality of life in hearing impaired adults after hearing aid fitting. Qual Life Res 2002;11:299-307.

23. Khaw PT, Hughes DS, Keightley SJ, Walters RF. Ophthalmology revision aid.: BMJ Publishing Group; 1996.

24. Prevalence and incidence of cataract. Available at: http:/www.rivm.nl/vtv/data/kompas/gezondheidstoestand/ziekte/gezichtsstoornis/ gezichtsstoornis_omvang_har.htm. Accessed October 27, 2004.

25. Superstein R. Indications for cataract surgery. Curr Opin Ophthalmol 2001; $12: 58-62$.

26. Nijkamp MD, Nuijts RM, Borne B, Webers CA, van der Horst F, Hendrikse F. Determinants of patient satisfaction after cataract surgery in 3 settings. I Cataract Relract Surg 2000;26:1379-1388.

27. The EuroQol Group. EuroQol-a new facility for the measurement of health-related quality of life. Health Policy 1990;16:199-208.

28. Torrance GW. Measurement of health state utilities for economic appraisal. $J$ Health Econ 1986;5:1-30.

29. Brown MM, Brown GC, Sharma S, Kistler J, Brown $H$. Utility values associated with blindness in an adult population. Br J Ophthalmol 2001;85:327-331.

30. Torrance GW. Social preferences for health states: an empirical evaluation of three measurement techniques. Socio-Econ Plan Sci 1976;10:129-136.

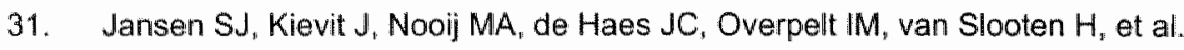
Patients" preferences for adjuvant chemotherapy in early-stage breast cancer: is treatment worthwhile? Br J Cancer 2001;84:1577-1585.

32. Austin $\mathrm{PC}$, Hoch JS. Estimating linear regression models in the presence of a censored independent wariable. Stat Med 2004:23:411-429. 
33. Badia $X$, Schiaffino $A$, Alonso J, Herdman $M$. Using the EuroQol 5-D in the Catalan general population: feasibility and construct validity. Qual Life Res 1998;7:311-322.

34. Saigal CS, Gornbein J, Reid K, Litwin MS. Stability of time trade-off utilities for health states associated with the treatment of prostate cancer. Qual Life Res 2002;11:405414.

35. Nijkamp MD, Dolders MGT, de Brabander J, van den Bome B, Hendrikse F, Nuijts RM. Effectiveness of multifocal intraocular lenses to correct presbyopia after cataract surgery: a randomized controlled trial. Ophthaimology 2004:111:1832-1839.

36. Bleichrodt $\mathbb{H}$, Johannesson M. An experimental test of a theoretical foundation for rating-scale valuations. Med Decis Making 1997;17:208-216. 


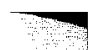


6

\title{
INDIVIDUAL SPECIFIC FACTORS INFLUENCING RESPONSE SHIFT IN PATIENT PREFERENCES. THE CASE OF CATARACT PATIENTS
}

\author{
M. Dolders, A. Ament, M. Nijkamp, R. Nuijts, M. Candel, W. Groot \\ Submitted for publication
}

\begin{abstract}
Aim: To determine individual specific factors influencing response shift in (cataract) patients' HRQoL evaluations.

Methods: Cataract patients $(n=190)$ undergoing bilateral surgery were interviewed before and after first and second eye surgeries using a structured questionnaire, measuring prospective and retrospective Visual Analogue HRQoL evaluations. Response shift was defined as the difference between prospective and retrospective HRQOL evaluations. Multilevel analysis was used to examine the influence of the following explanatory variables on response shift: change in EuroQol-5D health status, coping strategies, sociodemographics, expectations and surgical outcome. Medical outcomes were assessed by ophthalmic tests.

Results: Gender and problem-based coping behavior explained the response shift between pre-test and first post-test. Response shift between pre-test and second post-test was explained by none of the explanatory variables. Muttilevel analysis showed that the parameter estimate for problem-based coping was significantly different for the response shift after first and that after second eye surgery.

Conclusion: Results indicate that response shift can be corrected for by controlling for individual specific factors (gender and coping strategy).
\end{abstract}


Health-related quality of life (HRQOL) is an important outcome parameter of health care interventions. HRQoL and 'life years gained' are the two components needed to calculate Quality Adjusted Life Years (QALYs). QALY's provide a generic outcome parameter of cost-utility analysis, and serve as input in clinical and health care decision-making, together with cost estimates. Measuring HRQoL requires identification of generic health states, which can be evaluated by eliciting preferences. Preferences are defined as quantitative expressions or valuations for certain health states, and reflect the relative importance of these health states." 'Preferences' and 'HRQoL evaluations' are used interchangeably in this chapter.

The methodology used to assess preferences influences the outcomes of cost-utility analyses. ${ }^{2}$ Preferences measured prospectively (in a conventional Pretest-Posttest design) might be contaminated by response shift. ${ }^{3}$ A working definition of response shift has been given by Schwartz and Sprangers ${ }^{3,4}$

"response shift refers to a change in the meaning of one's self-evaluation of a target construct as a result of: (a) a change in the respondent's internal standards of measurement (scale recalibration), (b) a change in the respondent's values (reprioritization), or (c) a redefinition of the target construct (i.e. reconceptualization)".

Previously we assessed recalibration response shift. In this chapter we examine components or factors influencing the change in internal standards of measurement. To our knowledge, no studies have been conducted to predict response shift in HRQoL evaluations among patients. It would be very useful to study predictors of response shift in order to prevent response shift bias in future research.

Three major components may influence response shift, which in turn may affect perceived HRQoL.. ${ }^{4}$ The first component is the catalyst, which refers to a health state or changes in health states, as well as health-related events, treatment interventions or other events, that impact on HRQoL. Antecedents, the second component, refer to stable or dispositional characteristics such as sociodemographics or personality characteristics (e.g., self-esteem). The third component involves mechanisms, which refer to behavioral, cognitive and affective processes to accommodate the catalyst (e.g., coping strategies). However, according to Sprangers and Schwartz ${ }^{4}$ it seems "conceivable that response shifts 
occur merely with the passage of time, without clear changes in health status". To our knowledge, evidence supporting this idea is lacking.

Adang et al. ${ }^{5}$ found that retrospectively assessed HRQOL evaluations were significantly lower than prospectively assessed HRQoL evaluations in successfully treated diabetic patients with end-stage renal disease (ESRD). This significant difference was explained by a change in health status, the catalyst in the theoretical model, and adaptation. Unfortunately, changes in health status and adaptation were assumed, not measured. Nevertheless, future expectations, the antecedents in the model, were measured and it was found that this factor was unable to explain the recalibration response shift. Furthermore, unsuccessfully treated patients were not taken into account. Kiebert et al ${ }^{6}$ found significantly higher retrospectively than prospectively assessed HRQoL evaluations in unsuccessfully transplanted ESRD patients compared to successfully transplanted patients. It seems that the difference between the findings of these studies may be explained by the surgical outcome of the intervention (successful or unsuccessful).

The goal of the present study was to determine individual specific factors influencing retrospectively and prospectively assessed preferences, using patients with senile cataract as an example.

Cataract is an age-related vision problem and is defined as opacity of the crystalline lens of the eye. ${ }^{7}$ In 1994, the prevalence of cataract among men aged over 50 in the Netherlands was approximately $3 \%$ and that for women $5 \%$. The incidence in the over-50 category is approximately $0.5 \%$ for men and $0.9 \%$ for women. The only treatment for cataract is surgery. In the present study, cataract surgery was standardized as much as passible (see Figure 6.1).

Whereas the theoretical model specifies the catalysts, antecedents and mechanisms associated with response shift, empirical research to explain response shift effects in HRQoL evaluations has been sparse. Given the assumed explanations for the difference between retrospectively and prospectively assessed HRQOL evaluations, as discussed above, it is interesting to examine the following individual specific factors: change (or lack of change) in health status, demographic characteristics, expectations, outcome of the intervention, and coping strategies. Although the theoretical model also includes other individual specific explanatory factors, these were not measured in our stuidy. We used a random effects model also known as a multilevel approach to analyze the longitudinal data on selfreported HRQoL evaluations. ${ }^{9}$ 


\section{Figure 6.1. Standardized surgical procedure}

- Small $3.2 \mathrm{~mm}$ posterior limbal incision

- Subtenon retrobulbar anesthesia

- No-stitch technique in wound closure

- Postoperative topical steroids and antiblotics

- Postoperative refraction aimed at emmetropia

- Implantation of an intraocular lens (Allergan, Irvine, CA)

\section{METHODS}

\section{STUDY PARTICIPANTS}

The present study was part of a randomized controlled trial (RCT) comparing patient satisfaction ${ }^{10}$ and cost-effectiveness ${ }^{11}$ after implantation of monofocal versus multifocal intraocular lenses in cataract patients. In the period from August 1999 to January 2001, 190 patients had bilateral surgery at one of the following outpatient centers: University Hospital Maastricht (UHM), Medical Centre Maastricht Annadal (MCMA) or the Atrium Medical Centre Heerlen (AMCH). The medical files of 1218 consecutive cataract patients awaiting surgery were screened for eligibility. Patients were included in case of bilateral age-related cataract, no ocular co-morbidity, preoperative keratometric astigmatism $\leq 1.5$ Diopters (D) "axial length between 19.5 and $26 \mathrm{~mm}$, and preoperative sphere between $-6 \mathrm{D}$ and $+4 \mathrm{D}$. Exclusion criteria were: professional night driving, mental retardation, inability to complete the questionnaire in Dutch, and pseudophakia. The nature and purpose of the study, including effects and possible side effects of the treatment, were explained to each patient by the ophthalmologist in attendance. Additionally, a patient information brochure and an informed consent form were sent to all selected patients awaiting cataract surgery. The medical ethics committees of all three centers approved the research protocol. For the present study, 190 enrolled patients implanted with monofocal or multifocal intraocular lenses were analyzed as one longitudinal cohort.

\section{OUTCOME MEASURES}

Patients were interviewed one to two weeks before their first eye surgery, (pretest). Subsequently, they were interviewed three months after the first eye surgery (post-test1 and then-test1) and up to three months postoperatively after implantation of the second intraocular lens (post-test2 and then-test2). The interval 
between the first and second eye surgeries was approximately 16 weeks. The design of the study is visualized in Figure 6.2. Assessments of all included patients took place at the UHM Department of Ophthalmology by two experienced interviewers. Before the structured interviews, ophthalmologists conducted standardized ophthalmic tests, which were used to compute the surgical outcome after the first and second eye surgeries.

\section{Figure 6.2. Design of the study}

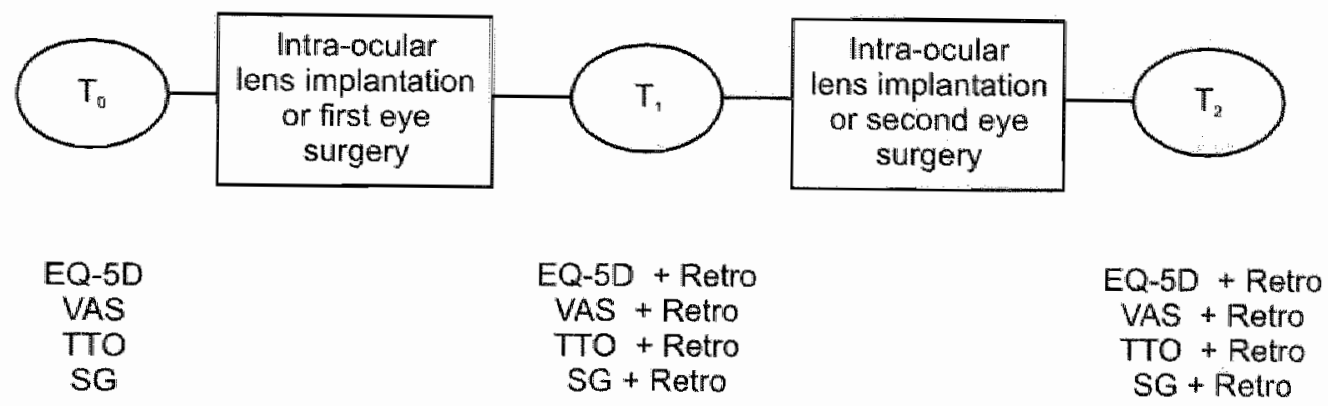

$$
\begin{gathered}
T_{0}=\text { Pre-test } \\
T_{1}=\text { Post-test after first eye surgery } \\
T_{2}=\text { Post-test after second eye surgery } \\
E Q-5 D=\text { EuroQal- } 5 D \\
\text { VAS }=\text { Visual Analogue Scale } \\
\text { TTO = Time Trade-Off } \\
S G=\text { Standard Gamble measured conventional over time } \\
\text { Retro = Then-test measurement for EQ-5D, VAS, TTO or SG }
\end{gathered}
$$

HRQOL evaluations "were measured prospectively with the Visual Analogue Scale (VAS). ${ }^{12}$ The VAS is a horizontal $10 \mathrm{~cm}$ line, on which patients mark their current generic health status. The VAS scores ranged from 0 to 10 and were transformed to a $0-1$ scale representing the worst HRQoL state (0) or the best HRQoL state (1). The VAS values directly equal patients' preference values.

The VAS preferences were measured retrospectively as well. Hence, response shift was defined as a difference between the prospectively assessed VAS preferences and the retrospectively assessed VAS preferences. Since patients were treated twice, recalibration response shift after the first eye surgery was defined as the difference between pretest and then-test at $T_{1}$, and recalibration 
response shift after the second eye surgery was defined as the difference between pretest and then-test at $T_{2}$.

Self-reported health status was measured with the EuroQol-5D (EQ-5D), a descriptive classification system which defines HRQOL in terms of five dimensions (mobility, self-care, usual activities, pain/discomfort and anxiety/depression). Each of the five dimensions is recorded at three levels of severity: 1=no problems, $2=$ moderate problems and $3=$ severe problems. Hence, a patient's current EQ-5D health state is expressed by a five-digit code based upon a classification of problems for all five dimensions. For example, health state 12312 means no problems with mobility, moderate problems with self-care, severe problems with performing usual activities, no problems with feeling pain or discomfort, and moderate problems with feeling anxiety or feeling depressed. ${ }^{13}$ According to Dolan, ${ }^{14}$ this self-reported health state can be categorized into three levels of severity: healthy, mild or very mild and severe or very severe. The explanatory variable in the model was defined as the difference between the health state severity values at $T_{0}$ and $T_{1}$, and the difference between the health state severity values at $T_{0}$ and $T_{2}$.

The antecedents for recalibration response shift in the model were: gender ( $0=$ male, $1=$ female), age, education at low, intermediate or high level (coded as dummy variables with low educational level as the reference category), marital status ( $0=$ unmarried/single/divorced/widowed, $1=$ married or living together), employment status $(0=$ not employed/retired, $1=$ employed), co-morbidity $(0=$ no, $1=y e s$ ), expectations dichotomized as little or some improvement $(0)$ and much or very much improvement ( 1 ), and surgical outcome ( 0 =unsuccessful, $1=$ successful) at $T_{1}$ and surgical outcome ( $0=$ unsuccessful, $1=$ successful $)$ at $T_{2}$.

The mechanism measured in this study was coping strategy, which was measured with the Utrecht Coping List (UCL). ${ }^{15}$ The validity and reliability of the UCL have been extensively tested. ${ }^{16}$ We used the short form of the list, the UCL14 , as this short form is more comprehensible to elderly patients. The items were scored on a scale ranging from 1 'seldom or never' to 4 'very often'. The UCL-14 items were summed to distinguish three behavioral strategies: problem-based coping ( 5 items), emotional coping ( 5 items) and denial coping (4 items). A high score on the problem-based coping scale indicates that patients make more use of the following strategies: intervene directly, looking at a problem from different angles, think of different options or act purposeful to resolve a probiem, and putting problems into perspective or in line. A high score on the emotional coping scale 
means that in problematic situations feelings are expressed. Stress reducing techniques are used more often if a high score is measured on the denial coping scale. The reliability coefficient was for the problem-based coping strategy at $T_{0}$ 0.78 ; at $T_{1} 0.73$ and at $T_{2} 0.74$. For the emotional coping strategy the reliability coefficients were $0.67,0.66$ and 0.75 , for the three measurement moments respectively. The denial coping strategy measured a reliability coefficient of 0.71 , 0.75 and 0.64 for the three measurement moments, respectively. The three strategies were measured at $T_{1}$ and $T_{2}$, and were added to the model.

\section{STATISTICAL ANALYSIS}

The effect of individual specific factors on response shift was assessed by means of an analysis with a random effect linear regression model. The intercept was treated as a random effect. Explanatory variables were the difference between health state severity values at $T_{0}$ and $T_{1}$, the difference between health state severity values at $T_{0}$ and $T_{2}$, socio-demographic characteristics at $T_{0}$, expectations at $T_{0}$, surgical outcome at $T_{1}$ and $T_{2}$, coping strategies at $T_{1}$ and $T_{2}$, time, and interactions of time with the remaining explanatory variables. Time was first dummy coded as 0 for $T_{1}$ and 1 for $T_{2}$ and then as 0 for $T_{2}$ and 1 for $T_{1}$. The random effect analysis with the first dummy coding for time provided information about the effect of individual specific factors on the response shift after the first eye surgery. The analysis with the second coding for time provided information about the effect of individual specific factors on the response shift after the second eye surgery. Both analyses comprised parameters that show whether the influence of the individual specific factors differs between the response shifts after the first and second eye surgeries. These analyses were conducted with the MIXREG ${ }^{17}$ statistical computer program. The intra-individual correlation coefficient for the random effects regression model was 0.48 , which justifies the choice of random effects modeling. 
The model specification is as follows:

$$
\begin{gathered}
\Delta y_{i j}=B_{0}+B_{01} x_{1 i}+B_{02} x_{2 i}+B_{0 n} x_{0 n}+U_{0 i}+\left(B_{1}+B_{11} x_{1 i}+B_{12} x_{2 i}+B_{1 n} x_{n i}\right)^{*} D_{i 1}+\varepsilon_{i i j} \\
\text { Explanation of the symbols: } \\
\begin{array}{r}
\Delta y_{i j} \text { is the response shift after first or second eye surgery } \\
i \text { is an index for the person } \\
j \text { is an index for the then-test at } T_{11} \text { or } T_{2} \\
D \text { is a dummy for time }
\end{array} \\
\begin{array}{r}
1,2, \ldots . n \text { is the index for the different explanatory variables } \\
U_{0 i} \text { is the random intercept }
\end{array} \\
B_{001} \text { is the effect of the first explanatory variable } \\
B_{12} \text { is the effect of the difference between the short and long term response shift } \\
\varepsilon_{i j} \text { is an error term }
\end{gathered}
$$

\section{RESULTS}

Table 6.1 presents the summary statistics of the catalyst, the antecedents and the mechanism at $T_{0}$ (pre-test), $T_{1}$ (post-test after first eye surgery) and $T_{2}$ (post-test after second eye surgery). About one third of the cataract patients regarded themselves as healthy, whereas more than half of the sample regarded themselves as mildly ill. Slightly more than $10 \%$ of the patients regarded themselves as severely ill at the pre-test, which declined to slightly less than $10 \%$ after the first and second eye surgeries. Although cataract is considered to be a mild health condition, more than $5 \%$ of the patients perceived themselves as being in a severely ill health state. Most of these patients, however, perceived themselves as severely ill due to the fact that they suffered from co-morbidity $(14.3 \%)$. The success rate of the first cataract surgery was almost $60 \%$, that of the second surgery almost $47 \%$. Expectations with regard to the outcome of the surgery were very high. Almost $93 \%$ expected much or very much improvement in vision. 
Table 6.1. Sample statistics of the explanatory variables by measurement moment

$T_{0}(N=190) \quad T_{1}(N=174) \quad T_{2}(N=153)$

\section{Catalyst}

Health state severity $(\%)$ :

- healthy

32.8

34.9

36.6

- (very) mild

52.9

56.6

53.6

- (very) severe

14.3

8.6

9.8

Antecedents

Gender ratio $(\%)$ :

- female:male

$65.4: 34.6$

Age (mean (sd))

$72.2(7.9)$

NA

NA

Education $(\%)$ :

- low

58.5

33.0

8.5

- high

Marital status (\%):

- married, living together

- unmarried, single, widowed, divorced

Employment (\%):

- employed

- not employed, retired

Co-morbidity ( $\%$ ):

- yes

- no

Surgical outcome $(\%)$ :

- successful

- unsuccessful

Expectations (\%):

- small improvement

- some improvement

- much improvement

- very much improvement

\section{Mechanisms}

Coping (mean (sd)):

- Problem-based

- Emotional

- Denial
58.5

41.5

5.9

94.1

53.7

46.3

NA

NA

2.3

4.6

37.6

55.5

$13.6 \cdot(3.6)$

$10.4(3.3)$

$9.4(2.9)$

NA

NA

NA

NA

NA

NA

NA

NA

NA

NA

NA

NA

NA

NA

NA

NA

NA

NA

NA

NA

59.6

46.6

40.4

53.4

NA

NA

NA

NA

NA

NA

NA

NA

$\mathrm{NA}=$ not applicable

$\mathrm{sd}=$ standard deviation 
Table 6.2 presents the parameter estimates for the linear regression model for the difference in prospective and retrospective VAS preferences between pre-test and first post-test and for the difference between pre-test and second post-test.

Table 6.2. Summary of parameter estimates for the linear regression models to explain response shift between pre-test and first post-test $\left(T_{0}-T_{1}\right)$ and between pre-test and second post-test $\left(T_{0}-T_{2}\right)$

\begin{tabular}{|c|c|c|}
\hline & Response shift $\left(\mathrm{T}_{0}-\mathrm{T}_{1}\right)$ & Response shift $\left(T_{0}-T_{2}\right)$ \\
\hline & $\begin{array}{c}\text { Regression coefficient } \\
\text { (Standard error) } \\
\mathrm{R}^{2}=.14\end{array}$ & $\begin{array}{l}\text { Regression coefficient } \\
\text { (Standard error) } \\
\mathrm{R}^{2}=.09\end{array}$ \\
\hline Intercept & $-.122(.419)$ & $.331(.379)$ \\
\hline \multicolumn{3}{|l|}{ EXPLANATORY VARIABLES } \\
\hline Difference in health state severity $\left(T_{0^{-1}} T_{1}\right)$ & $.001(.053)$ & $-.012(.044)$ \\
\hline $\begin{array}{l}\text { Difference in health state severity }\left(T_{0}-T_{2}\right) \\
\text { Antecedents }\end{array}$ & $.002(.049)$ & $-.012(.045)$ \\
\hline Gender & $.113(.057) *$ & $.058(.054)$ \\
\hline Age & $-.001(.004)$ & $-.002(.004)$ \\
\hline Intermediate education & $.023(.056)$ & $-.016(.051)$ \\
\hline High education & $-.024(.097)$ & $.031(.089)$ \\
\hline Marital status & $.068(.057)$ & $.038(.053)$ \\
\hline Employment & $-.179(.177)$ & $=.085(.148)$ \\
\hline Co-morbidity & $.037(.053)$ & $-.023(.048)$ \\
\hline Surgical outcome & $.076(.056)$ & $.056(.049)$ \\
\hline Expectations & $.062(.109)$ & $.018(.099)$ \\
\hline \multicolumn{3}{|l|}{ Mechanisms } \\
\hline Problem-based coping & $.025(.009)$ & $.001(.009)^{\#}$ \\
\hline Emotional coping & $-.014(.011)$ & $-.007(.009)$ \\
\hline Denial coping & $.006(.010)$ & $-.018(.011)$ \\
\hline
\end{tabular}

$$
\text { " } p<0.05, " * * 01
$$

"The random effects analysis showed that the parameter estimates for the response shift after first eye surgery $\left(T_{0}-T_{1}\right)$ and the response shift after second eye surgery $\left(T_{0}-T_{2}\right)$ differed significantly $(B=-.025, \mathrm{se}=.009, \mathrm{p}<.001)$ 
With respect to the response shift between $T_{0}$ and $T_{1}$ the parameter estimate for the change in health status between $T_{0}$ and $T_{1}$ did not contribute significantly to the explanation of this response shift. Gender contributed significantly to the explanation of the response shift between $T_{0}$ and $T_{1}(B=.113$, se $=.057, p<.05)$. After the first eye surgery, female patients had a more positive/optimistic response shift than male patients. Problem-based coping behavior was a statistically significant mechanism explaining the response shift between $T_{0}$ and $T_{1}(B=.025$, $\mathrm{se}=.009, \mathrm{p}<.01)$. Patients who made more use of problem-based coping strategies had a more positive/optimistic response shift than those who made less use of problem-based coping strategies.

None of the explanatory variables in the analysis model predicted the response shift between $T_{0}$ and $T_{2}$ (See Table 6.2, third column).

Only the parameter estimate for problem-based coping for the response shift between $T_{0}$ and $T_{1}$ differed significantly from the corresponding parameter estimate for the response shift between $T_{0}$ and $T_{2}(B=-.025$, se $=.009, p<.001)$. As we have seen, the influence of problem-based coping strategies no longer existed after the second eye surgery.

\section{DISCUSSION}

The theoretical model developed by Sprangers ${ }^{4}$ was used to explain response shift in HRQoL evaluations of cataract patients who received intraocular lenses bilaterally. Three components were analyzed: the catalyst (change in health status), the antecedents (socio-demographic characteristics, expectations and surgical outcome), and the mechanisms (problem-based coping, emotional coping and denial coping).

In contrast with the study by Adang, ${ }^{5}$ we found that the response shift in HRQOL evaluations after the first and second surgeries could not be explained by a change in health status. This is not surprising, as we had chosen a patient group in whom a health status change would not be easily detected. We were interested in response shift and the explanation of the shift in HRQOL evaluations, rather than in the explanation of response shift in terms of self-reported health status. Selfreported health status might be affected by response shift. However, we tested whether the EQ-5D dimensions were influenced by response shift. The results showed that none of the dimensions were influenced by response shift (data not shown). 
Since $\mathrm{Adang}^{5}$ reported the retrospective pre-transplant quality of life to be lower than the prospective pre-transplant quality of life in pancreas-kidney transplant recipients, and Kiebert ${ }^{6}$ found the opposite for unsuccessfully transplanted patients, we had assumed that surgical outcome would be a significant predictor of response shift. However, our results show that surgical outcome did not contribute to the explanation of response shift. At least not among cataract patients. The response shift in HRQoL evaluations after the first surgery was explained by gender and patients' problem-based coping strategy. After the first eye surgery, fernale patients and patients who made more use of problembased coping strategies had a more positive/optimistic response shift than male patients and patients who made less use of problem-based coping strategies, respectively. Since the theoretical development of the response shift construct is still at a very early stage, we were not able to find studies explaining response shift by gender. However, it seems that female patients are better able to adapt to their pre-test condition than males.

Our study was unable to establish the contribution of the catalyst, the antecedents and the mechanisms in the explanation of recalibration response shift after the second eye surgery. Since the theoretical model incorporates other factors, which were not assessed in our study, it is likely that those unobserved mechanisms and antecedents may contribute to the prediction of response shift. Recently, Rapkin and Schwartz ${ }^{19}$ distinguished variance associated with standard predictions from residual variance that remains after controlling for these standard variables. Residual variance from unobserved individuall specific effects can be explained by a random effects estimation technique using longitudinal data, as was done in our study.

Nevertheless, the random effects model showed that the influence of problem-based coping as a predictor of recalibration response shift declined after the second surgery and that this factor became irrelevant in predicting the response shift between pre-test and second post-test. Possibly "with the passage of time, response shift may become much smaller and thus harder to explain from individual specific factors.

The present study was hampered by the fact that patients had bilateral eye operations. The study would have been more accurate in explaining response shift in HRQoL evaluation if it had been done in a patient group undergoing one intervention and followed longitudinally. Nonetheless, the findings of our study 
indicate that characteristics explaining recalibration response shift effects in HRQoL evaluations should be explicitly measured.

\section{REFERENCES}

1. Drummond MF, O'Brien BJ, Stoddart GL, Torrance GW. Methods for the economic evaluation of health care programmes. Second ed. Oxford: Oxford University Press; 1997.

2. Postulart D, Adang EM. Response shift and adaptation in chronically ill patients. Med Decis Making 2000;20:186-193.

3. Schwartz CE, Sprangers MAG. Adaptation to changing health: response shift in quality-of-life research. Washington, DC, US: American Psychological Association; 2000.

4. Sprangers MA, Schwartz CE. Integrating response shift into health-related quality of life research: a theoretical model. Soc Sci Med 1999;48:1507-1515.

5. Adang EM, Kootstra G, Engel GL, van Hooff JP, Merckellbach HL. Do retrospective and prospective quality of life assessments differ for pancreas-kidney transplant recipients? Transpl 1998;11:11-15.

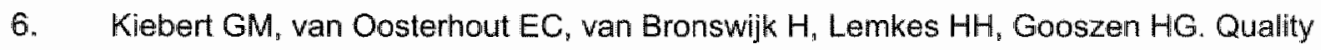
of life after combined kidney-pancreas or kidney transplantation in diabetic patients with end-stage renal disease. Clin Transp/ 1994;8:239-245.

7. Khaw PT, Hughes DS, Keightley SJ, Walters RF. Ophthalmology revision aid: BMJ Publishing Group; 1996.

8. Prevalence and incidence of cataract. Available at: http://www.rivm.nl/vtv/data/kompas/gezondheidstoestand/ziekte/gezichtsstoornis/ gezichtsstoornis_omvang har.htm. Accessed October 27, 2004.

9. Snijders T, Bosker R. Longitudinal Data. In: Snijders T, Bosker R, eds. Multilevel Amalysis: an introduction to basic and advanced multilevel modeling. London: Sage Publications; 1999. p. 166-99.

10. Nijkamp MD, Dolders MGT, De Brabander J, van den Borne B, Hendrikse F, Nuijts RMMA. Effectiveness of multifocal intraocular lenses to correct presbyopia after cataract surgery: a randomized controlled trial. Ophthalmology 2004;111:1832-1839.

11. Dolders MGT, Nijkamp MD, Nuijts RMMA, van den Borne B. Hendrikse F, Ament A, et al. Cost-effectiveness of foldable multifocal intraocular lenses compared to foldable monofocal intraocular lenses for cataract surgery. Br J Ophthalmol 2004;88:11631168.

12. Torrance GW. Measurement of health state utilities for economic appraisal. $J$ Health Econ 1986;5:1-30.

13. The EuroQol Group. EuroQol--a new facility for the measurement of health-related quality of life. Health Policy 1990;16:199-208. 
14. Dolan P. Modeling valuations for EuroQol health states. Med Care $1997 ; 35: 1095$ 1108.

15. Schreurs PJG, Willige GV, Tellegen B. De Utrechtse Coping Lijst: UCL. Omgaan met problemen en gebeurtenissen. [The Utrecht Coping List: UCL. Coping with problems and events]. Lisse: Swets and Zeitlinger; 1988.

16. Sanderman $R$, Ormel J. De Utrechtse Coping Lijst (UCL): validiteit en betrouwbaarheid. [The Utrecht Coping List (UCL): Validity and reliability]. Gedrag en Gezondheid: Tijdschrift voor Psychologie en Gezondheid 1992;20:32-37.

17. Hedeker D, Gibbons RD. MXXREG: A computer program for mixed-effects regression analysis with autocorrelated errors. Comput Meth Prog Biomed 1996;49:229-252.

18. Schwartz CE, Sprangers MAG, Carey $A_{*}$ Reed $G$. Exploring response shift in longitudinal data. Psychol Health 2004;19:51-69.

19. Rapkin BD, Schwartz CE. Toward a theoretical model of quality-of-life appraisal: implications of findings from studies of response shift. Heath Quality of Life Outcomes 2004:2:14. 


\section{7 \\ Conclusions and Discussion}

INTRODUCTION

The studies reported in this thesis address some methodological aspects of the measurement of patient and population preferences. The findings allow several conclusions. The most important findings are discussed in the next section. The third section then summarizes the methodological limitations of the studies reported on. In addition the conclusions of the studies should be implemented in economic evaluations. This is followed by a section providing recommendations for future research, and the chapter ends with some concluding remarks.

\section{MAIN FINDINGS}

In economic evaluations it has been recommended to measure costs and consequences from a societal perspective. ${ }^{1}$ The resulls of our cost-effectiveness analysis of monofocal and multifocal intraocular lenses showed that the consequences appeared to be equal for both types. However, although we did indeed use the societal perspective for the calculation of the costs, we ignored it for the effects, since the cost-effectiveness study used patient preferences as the outcome measure. A major shortcoming of this study was that patient preferences might be biased by response shift and adaptation. However, consistent use of a societal perspective would have required population preferences to be assessed. It is largely unknown if it matters whether one uses patient or population preferences in economic evaluations aimed at resource allocation at the societal level. The most important requirement is that both patient and population preferences are unbiased.

Population preferences were assessed directly, in order to elicit representative and unbiased population preferences that might be used for resource allocation decisions at the macro-level. Population preferences were assessed directly from a randomly selected sample of the Dutch population. Valuation differences between individuals more inclined to respond were not found. Although, the response of the randomly selected sample was non-randomly distributed, preferences obtained from this survey did result in the measurement of unbiased population preferences. 
To decide if it matters whether patient or population preferences are used in economic evaluations, we systematically rewiewed the literature and performed a meta-analysis. The health states were stratified into actual or hypothetical health states in patients and/or population. This led to three separate meta-analyses, which assessed actual/actual, actual/hypothetical, and hypothetical/hypothetical health states in patients and population. Patient preferences were significantly lower than population preferences for actual health status. Patients' preferences for their actual health status did not differ significantly from the hypothetical population preferences. When patients were also asked to value a hypothetical health status, these hypothetical preferences did not differ significantly from the hypothetical population preferences.

Several factors, including preference elicitation methods, health state severity assessment methods, research assessment methods, socio-demographic characteristics, and disease characteristics, influenced the pooled effect estimate. However, the direction and magnitude of the contributions of these factors was different for the three strata used. We concluded that both patient and population preferences can be used in economic evaluations based on a societal perspective. However, retrospective pre-test designs have never been used for studies assessing patient preferences. Thus, patient preferences from the literature may be biased in terms of response shift and adaptation.

The next study addressed response shift bias and adaptation in patient preferences. It first examined whether response shift could be found in patient preferences. Whereas response shift was indeed established in patient preferences measured with the Visual Analogue Scale, measurements of patient preferences with the Time Trade-Off and Standard Gamble methods did not indicate response shift. Second, a theoretical model was used to explain the established response shift in patient preferences. Although gender was found to predict response shift after the first intervention, this characteristic did not explain the response shift after the second intervention. However, the parameter estimates for response shift after the first and second interventions did not differ significantly. Problem-based coping behavior was a significant predictor of response shift after the first intervention. After the second intervention, the predictive contribution significantly diminished and ultimately disappeared. 


\section{METHODOLOGICAL LIMITATIONS}

This thesis has highlighted some methodological aspects of the measurement of patient and population preferences. However, the studies reported in this thesis suffered from certain methodological limitations in terms of study design, the population studied, and the measurement instruments used.

Economic evaluation designs are usually divided into four methods: costbenefit analysis (CBA), cost-effectiveness analysis (CEA), cost-utility analysis (CUA), and cost-minimization analysis (CMA). The cost-effectiveness analysis presented in this thesis started as a cost-utility analysis and resulted in a costminimization analysis. Choosing an economic evaluation design in advance is sometimes difficult. What is more important is that economic evaluations should be performed from a societal perspective, using population preferences. Our economic evaluation, however, used patient preferences to calculate the QALY outcome measure.

The questionnaire for the population survey was structured as if the population were being studied in a randomized controlled trial. This resulted in an enormous battery of questions for the elicitation of preferences for the health state of "cataract" and a health state of "wearing reading glasses, otherwise healthy". Although the questionnaire was pre-tested on key characteristics ${ }^{2}$ such as specific objectives, straightforwardness of the questions, and reliability and validity of the survey instruments, the ambitious questionnaire strategy may have hampered the response by the population.

The studies included in the meta-analyses comparing patient and population preferences were designed as observational studies. This implies that numerous factors, other than the design, may have influenced the estimation of the outcome parameter. Therefore, it was important to carefully account for the impact of the various sources of heterogeneity on the summarized effect parameter. ${ }^{3}$ Although we extensively scrutinized several factors, such as the preference elicitation methods, health state severity assessment methods, study assessment methods, socio-demographic characteristics and disease characteristics, we do not pretend to be exhaustive. Furthermore, the conclusions of these meta-analyses are limited, because the input studies used observational designs rather than experimental designs.

The study assessing response shift in patient preferences used a retrospective pre-test design, a so-called then-test approach, which exclusively 
assesses recalibration response shift. The retrospective pre-test design has been criticized, because this approach might also, or exclusively, determine recall bias. However, since recall bias was not measured directly in this study, the contribution of this kind of bias remains unknown.

Furthermore, patients were interviewed face-to-face, whereas population preferences were assessed by mail questionnaires. Research has shown that different assessment methods do not generate the same information. ${ }^{6}$ This invalidates a comparison between patient and population preferences.

Response shift in patient preferences was analyzed in a longitudinal crosssectional cohort of patients, applying a theoretical model of factors that might influence response shift. A limitation of this study was that we only looked at coping to explain recalibration response shift, while ignoring other mechanisms that might influence response shift.

Patient preferences were studied among patients with senile cataract, a mild health condition occurring in eiderly patients. Since, however, elderly patients may suffer from severe co-morbidity, the actual self-reported health state of the patient might not be purely the health state of "cataract". The effect of not integrating comorbidities into the assessment of preferences is likely to have led to an overestimation of the health benefit. ${ }^{7}$

The studies in this thesis measured preferences with the Visual Analogue Scale, the Time Trade-Off, and the Standard Gamble. The Standard Gamble is based on expected utility theory and is seen as the gold standard to measure preferences. However, this method also has its limitations, especially among elderly people. The method is cognitively demanding and involves the use of visual aids. This adds another difficulty, because at pre-test these visual aids were blurred for the visually impaired patients with senille cataract.

The mailed questionnaire also used the Standard Gamble method. It has been claimed that this should not be done. However, a recent study to assess the reliability of a paper Standard Gamble questionnaire concluded that the SG can be used in mailed surveys.

Stated preferences refer to hypothetical behavior whereas revealed preferences are based on actual behavior. Conflicting evidence exists with regard to bias in stated or revealed preferences. ${ }^{10}$ However, this evidence is mostly based on the Willingness-to-Pay (WTP) technique. ${ }^{11-13}$ The WTP technique was not used in this thesis. Consistency tests between stated or revealed preferences could not be performed, since only stated preferences were measured in this thesis. 


\section{POLICY IMPLICATIONS}

A societal perspective in economic evaluation studies for both costs and consequences was recommended by the US Panel on Cost-Effectiveness." This kind of economic evaluation serves as input for the decision-making process on allocating scarce resources available at the macro-level. However; the literature is ambiguous about the question whose preferences count when allocating scarce resources at the societal level. In this thesils, the study of preferences obtained from a survey among a randomly drawn population sample showed that the response was not randomly distributed. The preferences obtained in this study resulted in unbiased population preferences, since the preferences did not differ between individuals inclined to respond. These population preferences might therefore be used in economic evaluations. Policymakers should be aware of the drawbacks of using population preferences. At least, they should be informed about the representativeness of the population preferences used in economic evaluations.

The alternative to using population preferences is using patient preferences. However, patient preferences might be biased as a result of the design used to measure them. ${ }^{14}$ This thesis showed that patient preferences were biased when the Visual Analogue Scale was used as a preference elicitation method. Using the Time Trade-Off or Standard Gamble method led to the conclusion that, on the one hand, these methods are not feasible for then-testing, and on the other hand, the design simply does not matter. The latter implies that both patient preferences and population preferences can be used in economic evaluations from a societal perspective. Our meta-analysis of the difference between patient's" actual health state preferences and the hypothetical health state preferences of the population supports this conclusion.

\section{RECOMMENDATIONS FOR FUTURE RESEARCH}

The results of the studies presented in this thesis give rise to several recommendations for future research.

In the study on the assessment of population preferences from a randomly drawn sample of the Dutch population (Chapter 3 ) it became clear that it is possible to gather information about the reasons for non-response. 
A recent study ${ }^{9}$ assessing the reliability of a Standard Gamble questionnaire on paper showed that this preference elicitation method can be used in postal surveys. Since the Standard Gamble questionnaire in our population study differed from that used in the recent study, however, research using a paper version of the Standard Gamble questionnaire in mailed surveys should be encouraged. Furthermore, a study comparing unbiased patient and population preferences should be added. This could not be done in the research reported on in this thesis, because research assessment methods differed between elicited patient preferences and population preferences. Thus, the effect of different methods of collecting data for preference measurements should be established.

The meta-analysis described in Chapter 4 gives rise to the recommendation that more experimental designs are needed to standardize the impact of the sources of heterogeneity on patient and population preferences.

With regard to the assessment of patient preferences among elderly patients, we recommend incorporating the preference assessment of the health state under consideration with co-morbidities and the preference assessment for the health state of "healthy, but with co-morbidities". Bias introduced by ignoring co-morbidity in the assessment of preferences is thereby avoided.

Health-related quality of life evaluations and recalibration response shift effects were assessed simultaneously, which may mean that the two concepts cannot be distinguished. The two concepts might be distinguished by adding a choice between different stretched or condensed scales.

Recalibration response shift was not established with the Time Trade-Off method and the Standard Gamble method. Whether these methods are feasible for then-testing should be addressed in further research, which should also involve patients with conditions of different severity.

To explain response shift, the following mechanisms should also be included and investigated: social comparison, social support, goal reordering, and reframing expectations.

Our finding that problem-based coping explains recalibration response shift over a short period of time implies that adaptation and response shift are two different and distinguishable concepts. The then-test approach does justice to the human capacity to adapt to changing circumstances. Therefore, unlike Adang et al. ${ }^{15}$ and Jansen et al. $_{2}{ }^{16}$ we suggest incorporating the then-test approach as a standardized measurement method in longitudinal research on the elicitation of preferences assessed with the Visual Analogue Scale. 


\section{CONCLUDING REMARKS}

The answer to the question whether to use patient or population preferences in cost-effectiveness studies for an efficient allocation of scarce resources depends on the bias in either patient or population preferences. Our Reference Case study of popullation preferences showed that it is difficult to obtain representative population preferences. The meta-analysis showed that patient and population preferences do not differ significantly, so that either can be used in costeffectiveness analysis. This meta-analysis was hampered, however, by the fact that patient preferences could have been biased by adaptation and response shift. The studies on preferences in cataract patients revealed that the use of the VAS method to elicit preferences led to preferences being biased by response shift and adaptation. Thus, preferences should be measured with the TTO or the $\mathrm{SG}_{\text {, }}$ as this allows both patient and population preferences to be used in cost-effectiveness analysis. From a practical point of view, it is much easier to obtain patient preferences in the context of clinical trials, which corresponds to the proposition in the welfare economic framework that patients are the best judges of their own situation.

\section{REFERENCES}

1. Gold MR, Siegel JE, Russell LB, Weinstein MC. Cost-effectiveness in health and medicine. New York, Oxford: Oxford University Press; 1996.

2. Fink A. The survey handbook. Thousand Oaks, London, New Delhi: Sage Publications; 1995.

3. Stroup DF, Berlin JA, Morton SC, Olkin I. Williamson GD, Rennie D, et al. Metaanalysis of observational studies in epidemiology: a proposal for reporting. Metaanalysis Of Observational Studies in Epidemiology (MOOSE) group. JAMA 2000;283:2008-2012.

4. Rapkin BD, Schwartz CE. Toward a theoretical model of quality-of-life appraisal: implications of findings from studies of response shift. Health Qual Life Outcomes $2004: 2: 14$

5. Schwartz CE, Sprangers MAG, Carey $A$, Reed G. Exploring response shift in longitudinal data. Psychol Health 2004,19:51-69.

6. Bergmann MM, Jacobs EJ, Hoffmann $K$, Boeing $H$. Agreement of self-reported medical history: comparison of an in-person interview with a self-administered questionnaire. Eur J Epidemiol 2004:19:411-416. 
7. Harris RA, Nease RF, $J r$. The importance of patient preferences for comorbidities in cost-effectiveness analyses. J Health Econ 1997:16:113-119.

8. Torrance GW. Social preferences for health states: an empirical evaluation of three measurement techniques. Socio-Econ Plan Sci 1976;10:129-136.

9. Littenberg $B$, Partilo S, Licata A, Kattan MW. Paper Standard Gamble: the reliability of a paper questionnaire to assess utility. Med Decis Making 2003;23:480-488.

10. Azevedo $\mathrm{CDH}$, Joseph A.; Kling, Catherine L. Combining revealed and stated preferences: consistency tests and their interpretations. Am J Agr Econ 2003;85:525537.

11. Walton $S M$, Grawes $P E$, Mueser $P R, D o w ~ d K$. The bias against new innovations in health care: value uncertainty and willingness to pay. Value Health 2002;5:67-70.

12. Olsen $J A_{s}$ Smith $\mathrm{RD}$. Theory versus practice: a review of 'willingness-to-pay' in health and health care. Health Econ 2001;10:39-52.

13. Smith RD. The discrete-choice willingness-to-pay question format in health economics: should we adopt environmental guidelines? Med Decis Making 2000;20:194-206.

14. Postulart D, Adang EM. Response shift and adaptation in chronically ill patients. Med Decis Making 2000;20:186-193.

15. Adang EM, Kootstra G, Engel GL, van Hooff JP, Merckelbach HL. Do retrospective and prospective quality of life assessments differ for pancreas-kidney transplant recipients? Transpl Int 1998;11:11-15.

16. Jansen SJ, Stiggelbout AM, Nooij MA, Noordijk EM, Kievit J. Response shift in quality of life measurement in early-stage breast cancer patients undergoing radiotherapy. Qual Life Res 2000;9:603-615. 


\section{SUMMARY}

This thesis reports on research into bias in patient and population preferences. Preferences are used as quality of life weights in the calculation of QALYS, the outcome measure in cost-effectiveness analysis. If this cost-effectiveness analysis is aimed at the allocation of scarce resources at the societal level, it is recommended that preferences from a representative sample of the population serve as input in the QALY calculation. However, it is largely unknown whether it matters to use patient or population preferences; the main concern is whether preferences represent those of the appropriate population. In other words, both patient and population preferences should be unbiased.

Chapter 1 defines preferences in a welfare economic framework. It explains the rationale behind the use of individual preferences, which can be divided into patient or population preferences. Bias in population preferences is described with regard to the representativeness of a randomly drawn population sample. Since individuals in the population do not experience the disease under study, while patients actually do, patient preferences are likely to be biased by adaptation and response shift. This bias is described using response shift theory.

Historically, cost-effectiveness analysis has used patient preferences assessed in the context of randomized clinical trials. Chapter 2 is an example of such a traditional cost-effectiveness analysis. This analysis adopted a societal perspective and was applied to patients with senile cataract undergoing surgery to implant bilateral monofocal or multifocal intraocular lenses. Patient preferences were obtained before and after the operation by structured interviews using the Visual Analogue Scale, Time Trade-Off, and Standard Gamble techniques. Costs of spectacles were added. The incremental costs, mean costs per patient and differences in preferences were computed. The resuits revealed that the monofocal intraocular lens was just as cost-effective as the multifocal intraocular lens, as we did not find significant differences in effects. Thus, the cost-effectiveness analysis was reduced to a cost-minimization analysis. In this economic evaluation, patient preferences were used to calculate the quality of life weights. However, since this economic evaluation study used a societal perspective, it meant that we had to assess population preferences in a so-called Reference Case study.

Chapter 3 reports on such a Reference Case study. Using the various preference-based measurement methods, population preferences with regard to cataract were obtained by mailed questionnaires from a random sample of the 
Dutch poputation. However, since the response rate was only $12 \%$, the random sample resulted in a non-random, unrepresentative sample of the Dutch population, especially in terms of demographic characteristics. Middle-aged respondents, married and highly educated respondents, and respondents having a job were over-represented, whereas respondents not wearing spectacles were underrepresented. Individuals who have greater affinity with or knowledge about the disease were inclined to respond. However, there preferences did not differ. It was concluded that population preferences might be suitable for use in costeffectiveness analysis.

Whether to use patient or population preferences in cost-effectiveness analysis for an efficient allocation of scarce resources is an empirically unresolved question. We decided that a systematic review of the literature might provide an answer to this question. Chapter 4 presents three meta-analyses of observational studies comparing patient and population preferences. The meta-analyses included 26 articles and involved 243 independent preference studies. The first meta-analysis compared actual patient and population preferences. The results revealed that patient preferences were $6 \%$ lower than population preferences. The second meta-analysis compared actual patient preferences with hypothetical population preferences. This analysis showed no significant differences between patient and population preferences. However, actual patient preferences might have been biased by the experience of having a disease. Therefore, a third metaanalysis was performed, on hypothetical patient and population preferences. Comparing patient and population preferences for hypothetical health states assumes that adaptation to a disease does not play a role. This meta-analysis revealed no significant differences between patient and population preferences. It was concluded that patient and population preferences can both be used in costeffectiveness analysis aimed at resource allocation decisions at the macro-level.

The preferences in the stratified meta-analysis comparing actual patient preferences with hypothetical population preferences were mostly extracted from cross-sectional studies. In pretest-posttest or longitudinal designs, prospectively assessed patient preferences might differ significantly from retrospectively assessed preferences. This result may be contaminated by response shift bias, which is often not taken into account in the clinical and health-care decision-making process. The study discussed in Chapter 5 assessed the response shift bias in preferences among patients with senile cataract undergoing bilateral surgery. Patients were interviewed before and after their first and second eye surgery, using 
a structured questionnaire. This questionnaire measured prospective and retrospective Visual Analogue Scale, Time Trade-Off, and Standard Gamble preferences for overall self-reported health status and five health status dimensions defined by the EuroQol-5D. Retrospective pretest preferences were assessed with the then-test method. No significant differences were found in prospectively assessed preferences. Retrospectively assessed VAS preferences were significantly lower than prospectively assessed VAS preferences. The use of the TTO or SG technique did not reveal any significant differences in prospectively or retrospectively assessed preferences. It can be concluded that response shift bias is present in VAS preferences among cataract patients. This bias could not be established in TTO or SG preferences. Therefore, it is questionable whether TTO and $S G$ are feasible for then-testing.

Chapter 6 reports on a study explaining the response shift bias found in the comparison between prospectively and retrospectively assessed VAS preferences of patients with senile cataract. The study aimed to determine individual specific factors influencing response shift bias. These individual specific factors were categorized into a catalyst, antecedents, and mechanisms. A change in health status may catalyze, for example, a coping mechanism that is influenced by demographic and personal characteristics. Response shift was defined as the difference between prospective and retrospective preferences. Multilevel analysis was used to examine the influence of the following explanatory variables on response shift: change in EuroQol-5D health status, coping strategies, sociodemographic variables, expectations, and surgical outcome. The hypothesis that surgical outcome would predict response shift was rejected. The response shift in preferences after the first surgery was explained by gender and patients' problembased coping strategy. After the first eye surgery, female patients and patients who made more use of problem-based coping strategies had a more positive/optimistic response shift than male patients and patients who made less use of problembased coping strategies. It seems that female patients are better able to adapt to their pre-test condition than males. None of the variables explained response shift between the pretest and second posttest. The multilevel random effects model showed that the influence of problem-based coping as a predictor of response shift declined after the second surgery and that this factor became irrelevant in predicting the response shift between pre-test and second post-test. Possibly, with the passage of time, response shift may become much smaller and thus harder to 
explain from individual specific factors. It was concluded that response shift can be corrected for by controlling for individual specific factors.

It was the recommendation to use population preferences in costeffectiveness studies from a societal perspective which led to the goal of the research project reported on in this thesis, to analyze bias in patient and population preferences. Only if unbiased preferences can be assessed, can the question whether it matters to use patient or population preferences be answered. The major conclusion of this thesis is that both patient and population preferences, provided they are measured with the Time Trade-Off method or the Standard Gamble technique, can be used in cost-effectiveness analysis used to allocate scarce resources at the societal level. From a practical point of view, it is much easier to obtain patient preferences in the context of a clinical trial than to obtain population preferences in a sample of the general population. Assessing patient preferences corresponds with the proposition of the welfare economic framework that patients are the best judges of their own situation. 


\section{SAMENVATTING}

Dit proefschrift analyseert bias in patiënten en populatie preferenties. Preferenties worden gedefinieerd als waarderingen voor de kwaliteit van leven en gebruikt in de berekening van QALYs; een uitkomstmaat in kosten effectiviteit analyses. Als deze kosten effectiviteit analyses worden gebruikt om schaarse middelen in de gezondheidszorg efficiënt te verdelen, dan worden voor de berekening van de kwaliteit van leven gewichten, preferenties van een representatieve steekproef van de algemene bevolking aanbevolen. Het is echter niet bekend of het er inderdaad toe doet of patiënten dan wel populatie preferenties worden gebruikt in deze analyses. Hoofdzaak is echter wel dat de preferenties de voorkeuren van de ondervraagde populatie weerspiegelen, met andere woorden dat de preferenties niet zijn vertekend.

Hoofdstuk 1 definieert preferenties vanuit een welvaarts economisch denkkader. Dit denkkader gaat uit van individuele preferenties. Deze kunnen in twee groepen worden onderverdeeld: de patiënten preferenties en de populatie preferenties. Vertekening in populatie preferenties wordt beschreven aan de hand van de representativiteit van een willekeurig getrokken steekproef uit de bevolking. Omdat individuen in de populatie geen ervaring hebben met een ziekte en patiënten wel, worden patiënten preferenties mogelijk vertekend door adaptatie. Een aspect van adapteren is het veranderen van interne standaarden, het zogenoemde response shift effect. Response shift theorie is gebruikt om deze vorm van vertekening te beschrijven.

Sinds het bestaan van kosten effectiviteit analyses worden preferenties in gerandomiseerde klimische onderzoeken gemeten. Vanzelfsprekend zijn dit dan patiënten preferenties. Hoofdstuk 2 is een voorbeeld van zo'n traditionele kosten effectiviteit analyse. Deze analyse werd vanuit een maatschappelijk perspectief bij patiënten met cataract uitgevoerd. Deze patiënten werden bilateraal geopereerd en ontvingen ofwel een multifocale dan wel een monofocale ooglens. Patiënten preferenties werden vóór en na de operatie gemeten door middel van gestructureerde interviews. De methoden om patiënten preferenties te meten waren de Visual Analogue Scale, the Time Trade-Off en de Standard Gamble techniek. De kosten voor de aanschaf van brillen werden tevens gemeten. De incrementele kosten, de gemiddelde kosten per patiënt en de verschillen in preferenties werden berekend. De resultaten laten zien dat de monofocale ooglens net zo kosten effectief is als de multifocale ooglens. Dit resultaat kan worden 
toegeschreven aan het feit dat verschillen in preferenties niet konden worden vastgesteld. Dus de kosten effectiviteit analyse werd gereduceerd tot een kosten minimalisatie analyse. In deze economische evaluatie werd gebruikt gemaakt van patienten preferenties om de kwaliteit van leven waarderingen te berekenen, alhoewel het maatschappelijk perspectief werd aangehouden. Als kosten effectiviteit analyses vanuit het maatschappelijk perspectief worden gedaan, dan zouden populatie preferenties moeten worden gebruikt. Deze kunnen worden vastgesteld in een zogenoemde Reference Case studie.

In Hoofdstuk 3 wordt zo'n Reference Case studie gerapporteerd. Populatie preferenties voor cataract werden gemeten met verschillende methoden (VAS, TTO en SG) door middel van een schriftelijke vragenlijst, die naar een willekeurige steekproef van de Nederlandse bevolking werd gestuurd. De response was $12 \%$. De willekeurige sample resulteerde in een selecte, niet willekeurige, niet representatieve steekproef van de Nederlands bevolking. Individuen in de leeftijd van 40 tot 59 jaar, gehuwden, hoger opgeleiden en individuen met een baan waren over vertegenwoordigd, terwijl respondenten die geen bril dragen waren onder vertegenwoordigd. Individuen die meer affiniteit of meer kennis van de ziekte cataract hadden, bleken over vertegenwoordigd te zijn in de steekproef. Desondanks verschillenden hun preferenties niet van elkaar. De conclusie uit deze studie was dat de populatie preferenties ten aanzien van caiaract en bril dragen wellicht bruikbaar zijn in kosten effectiviteit studies uitgevoerd vanuit een maatschappelijk perspectief.

De vraag of patiënten dan wel populatie preferenties moeten worden gebruikt in een kosten effectiviteit analyse vanuit maatschappelijk perspectief, kan vanuit de empirie nog niet worden beantwoord. Een systematisch overzicht van de literatuur zou een antwoord kunnen geven op deze vraag. Hoofdstuk 4 presenteert drie meta-analyses van observationele studies waarin patiënten en populatie preferenties worden vergeleken. De zesentwintig geïncludeerde artikelen genereerden 243 onafhankelijke preferentie studies. In de eerste meta-analyse werden patiënten en populatie preferenties voor de actuele gezondheidstoestand vergeleken. De resultaten lieten zien dat patiënten preferenties $6 \%$ lager waren dan populatie preferenties. De tweede meta-analyse vergeleek actuele patiënten preferenties met hypothetische populatie preferenties. Deze analyse gaf als resultaat dat patiënten en populatie preferenties niet significant van elkaar verschillen. Actuele patiënten preferenties kunnen worden vertekend door ervaring met de ziekte. Daarom is een derde meta-analyse uitgevoerd om hypothetische 
patiënten en populatie preferenties te vergelijken. Hypothetische patiènten preferenties worden niet door adaptatie beinvloed. Er werden in deze metaw analyse geen significante verschillen tussen patienten en populatie preferenties gevonden. Deze twee laatste meta-analyses leiden tot de conclusie dat zowel patiẻnten als populatie preferenties kunnen worden gebruikt in kosten effectiviteit analyses die tot doel hebben de beslissing op macro niveau voor de verdeling van schaarse middelen in de gezondheidszorg te ondersteunen.

De preferenties in de meta-analyse die actuele patiënten preferenties vergeleek met hypothetische populatie preferenties komen meestal uit dwarsdoorsnede onderzoek. Als preferenties worden vastgesteld in onderzoek met een vóór-en nameting of in longitudinaal onderzoek dan kunnen prospectieve of retrospectieve patiënten preferenties van elkaar verschillen. Dit kan leiden tot een vertekening in de resultaten van dit soort onderzoek. Deze vertekening wordt response shift bias genoemd. Deze bias wordt niet meegenomen in klinische of gezondheidszorg beslissingen. De studie in Hoofdstuk 5 presenteert de vaststelling van deze response shift bias in preferenties van patiênten met cataract die bilateraal worden geopereerd. Patiënten worden vóór en na de eerste en tweede operatie geïnterviewd. Door middel van een gestructureerde vragenlijst werden prospectieve en retrospectieve preferenties gemeten. De preferenties voor de algemene gezondheidstoestand en voor vijf dimensies van deze toestand werden via de Visual Analogue Scale, Time Trade-Off en Standard Gamble verkregen. Retrospectieve voormeting preferenties werden met de then-test methode verkregen. Er werden geen significante verschillen gevonden in prospectieve preferenties. Retrospectieve VAS preferenties waren significant lager dan prospectieve VAS preferenties. Dit resultaat werd niet gevonden voor de TTO of de SG techniek. Er kan dan ook worden geconcludeerd dat response shift bias in VAS preferenties aanwezig is en dat dezelfde bias in TTO en SG preferenties afwezig is. Het is echter de vraag of de TTO en SG zich lenen voor de methode van thentesting.

Hoofdstuk 6 rapporteert een studie waarin de response shift bias, die in de vergelijking van prospectieve en retrospectieve VAS preferenties bij cataract patiënten is gevonden, wordt verklaard. Het doel van deze studie was individu specifieke factoren die response shift bias beinwloeden, wast te stellen. Deze individu specifieke factoren werden ingedeeld in drie categorieün: een katalysator, antecedenten en mechanismen. Een verandering in gezondheidstoestand dient als katalysator om bijvoorbeeld een coping mechanisme aan te sturen dat kan worden 
beinvloed door demografische en persoonlijke karakteristieken. Response shift is gedefinieerd als het verschil tussen prospectieve en retrospectieve preferenties. Multilevel analyse werd gebruikt om de invloed van de volgende verklarende variabelen op response shift te onderzoeken: een verandering in de EuroQol-5D gezondheidstoestand, coping strategieën, socio-demografische variabelen, verwachtingen en de uitkomst van de operatie. De hypothese was dat met name de uitkomst van de operatie response shift zou kunnen voorspellen. Deze hypothese kon echter worden verworpen. Response shift in preferenties na de eerste oogoperatie werd verklaard door geslacht en de probleem georiënteerde coping strategie. Vrouwelijke patiënten en patiënten die meer gebruik maken van een probleem georiënteerde coping strategie hebben een meer positieve response shift dan mannelijke patiënten en patiënten die minder gebruik maken van een probleem georiënteerde coping strategie. Het lijkt dat vrouwelịke patiënten beter in staat zijn te adapteren aan de ziekte dan mannelijke patiënten. Response shift tussen de voormeting en de tweede nameting kon door geen van de variabelen worden verklaard. Het multilevel random effect model laat zien dat de invloed van probleem georiënteerde coping als predictor voor response shift, afneemt na de tweede oogoperatie. Deze factor wordt zelfs irrelevant om response shift tussen de voormeting en de tweede nameting te voorspellen. Het is mogelijk dat door invloed van het verstrijken van de tijd de response shift kleiner wordt en dus moeilijker voorspelbaar door individu specifieke factoren.

De aanbeveling om populatie preferenties in kosten effectiviteit studies vanuit een maatschappelijk perspectief te gebruiken heeft tot het doel van dit proefschrift geleid. Het doel van dit proefschrift was de vertekening in patiënten en populatie preferenties te analyseren. De vraag of patiënten dan wel populatie preferenties moeten worden gebruikt in kosten effectiviteit analyses vanuit een maatschappelijk perspectief kan alleen worden beantwoord als onvertekende preferenties kunnen worden vastgesteld. De belangrijkste conclusie van dit proetschrift is dat zowel patiënten als populatie preferenties kunnen worden gebruikt, mits deze worden vastgesteld met de TTO of SG methode. Het is echter veel praktischer om patiënten preferenties tijdens een klinisch onderzoek te meten dan populatie preferenties in een steekproef van de Nederlands bevolking. Het vaststellen van patiënten preferenties doet echter meer recht aan de veronderstelling in het welfare economische denkkader dat een patiënt de beste beoordelaar is van zijn/haar eigen situatie. 


\section{APPENDIX A}

\section{LIST OF EXCLUDED REFERENCES BELONGING TO CHAPTER 4: \\ Whose values count? A meta-analysis of patient and population.}

1. Boyle MH, Furlong W, Feeny D, Torrance GW, Hatcher J. Reliablhty of the Heath Utilities Index-Mark III used in the 1991 cycle 6 Canadian general socias survey health questionnaire. Qual Life Res 1995;4:249-257.

2. Gold MR, Franks P. McCoy KI, Fryback DG. Toward consistency in cost-uthity analyses: using national measures to create condition-specific values. Med Care 1998;36:778-792.

3. Jean Louis G, Kripke DF. Ancoli Israel S. Sleep and quality of well-being. Sleep 2000;23:1115-1121.

4. Rosenberg MA. Fryback DG, Lawrence WF. Computing population-based estimates of health-adjusted life expectancy. Med Decis Making 1999;19:90-97.

5. Fryback DG, Lawrence WF, Martin PA, Klein R, Klein BE. Predicting quality of wellbeing scores from the SF-36: results from the Beaver Dam Health Outcomes Study. Med Decis Making 1997;17:1-9.

6. Erickson P, Kendall EA, Anderson JP, Kaplan RM. Using composite heaith status measures to assess the nation's health. Med Care 1989;27(3 Suppl):S66-S76.

7. Kaplan RM, Bush JW, Berry CC. Health status: types of validity and the index of wellbeing. Health Senv Res 1976;11:478-507.

8. Kaplan RM. Feeny D, Revicki DA. Methods for assessing relative importance in preference based outcome measures. Qual Life Res 1993;2:467-475.

9. Nease RF, Jr., Tsai R, Hynes LM, Littenberg B. Automated utility assessment of global health. Qual Life Res 1996,5:175-182.

10. Hallert C, Granno C, Grant C., Hulten S, Midhagen G, Strom M, et al. Quality of life of adult coeliac patients treated for 10 years. Scand J Gastroentero 1998:33:933-938.

11. Hann DM, Jacobsen PB, Martin SC, Kronish LE, Azzareilo LM, Flelds KK. Quality of life following bone marrow transplantation for breast cancer: a comparative study. Bone Marrow Transpl 1997:19:257-264.

12. Littlefield C, Abbey S, Fiducia D, Cardella C, Greig P. Levy G, et al. Quality of life following transplantation of the heart, liver, and lungs. Gen Hos Psychiat 1996;18(6 Suppl):36s-47s.

13. Guest JF "Das Gupta R. Health-related quality of life in a UK-based population of men with erectile dysfunction. PharmacoEconomics 2002;20:109-117.

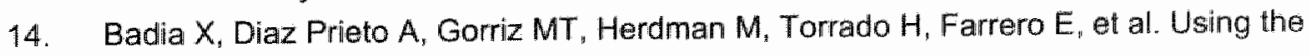
EuroQol-5D to measure changes in quality of life 12 months after discharge from an intensive care unit. Intens Care Med 2001:27:1901-1907. 
15. Tian $Z$ M, Miranda DR. Quality of life after intensive care with the sickness impact profile. Intens Care Med 1995;21:422-428.

16. Brooks $R$, Kerridge $R$, Hiliman $K$, Bauman $A$, Daffurn $K$. Quality of life outcomes after intensive care. Comparison with a community group. Intens Care Med 1997:23:581586.

17. Ridley SA, Chrispin PS, Scotton H, Rogers $J$, Lloyd D. Changes in quality of life after intensive care: comparison with normal data. Anaesthesia 1997;52:195-202.

18. Vickrey BG, Hays RD, Harooni R, Myers LW, Ellison GW. A health-related quality of life measure for multiple sclerosis. Qual Life Res 1995;4:187-206.

19. Rothwell $P M_{1}$ McDowell $Z$, Wong $C K$, Dorman PJ. Doctors and patients don't agree:" cross sectional study of patients' and doctors" perceptions and assessments odf disability in multiple sclerosis. BMJ 1997;314:1580.

20. Hawthorne $G_{i}$ Richardson J, Day NA. A comparison of the assessment of quality of life (AQOL) with four other generic utility instruments. Ann Med 2001;33:358-370.

21. Rose MS, Koshman ML, Spreng $S$, Sheldon R. The relationship between healthrelated quality of life and frequency of spells in patients with syncope. I Clin Epidemiol 2000;53:1209-1216.

22. Badia $X$, Roset $M$, Herdman $M$. Inconsistent responses in three preference-elicitation imethods for health states. Soc Sci Med 1982 1999;49:943-950.

23. Dorman PJ, Slattery J, Farrell B, Dennis MS, Sandercock PAG. A randomised comparison of the EuroQol and Short Form-36 after stroke. BMJ 1997;315:461.

24. Miners AH, Sabin CA, Tolley KH, Jenkinson $C$, Kind $P$, Lee CA. Assessing healthrelated quality-of-life in individuals with haemophilia. Haemophilia 1999;5:378-385.

25. Dorman P, Slattery J, Farrell B, Dennis M, Sandercock P. Qualitative comparison of the relliability of health status assessments with the EuroQol and SF-36 questionnaires after stroke. United Kingdom Collaborators in the International Stroke Trial. Stroke 1998;29:63-68.

26. Sollano JA, Rose EA, Williams DL, Thornton B, Quint E, Apfelbaum M, et al. Costeffectiveness of coronary artery bypass surgery in octogenarians. Ann Surg 1998;228:297-306.

27. Chetter IC, Spark JI, Kent Pل, Berridge DC, Scott D., Kester RC. Percutaneous transluminal angioplasty for intermittent claudication: evidence on which to base the medicine. Eur J Vasc Endowasc 1998;16:477-484.

28. Gudex CM, Hawthorne MR, Butler AG, Duffey PO. Measuring patient benefit from botulinum toxin in the treatment of dystonia. Feasibility of cost-utility analysis.

PharmacoEconomics 1997;12:675-684.

29. Hammerlid $E$, Taft $C$. Health-related quality of life in llong-term head and neck cancer survivors: a comparison with general population norms. Br J Cancer 2001;84:149156.

30. Juul S. Comparing health-related quality of iffe to general population norms. $J$ Clin Epidemiol 2000;53:884. 
31. Wahl $\mathrm{A}_{\mathrm{n}}$ Loge $\mathrm{JH}_{\mathrm{*}}$ Wiklund I, Hanestad BR. The burden of psoriasis: a study concerning health-related quality of life among Norwegian adult patients with psoriasis compared with general population norms. J Am Acad Dermatol $2000 ; 43: 803-808$.

32. Loge $\mathrm{JH}$, Abrahamsen AF, Ekeberg $\mathrm{O}$, Kaasa S. Reduced health-related quality of life among Hodgkin"s disease survivors: a comparative study with general population norms. Ann Oncol 1999;10:71-77.

33. Rose MS, Koshman ML, Spreng $S$, Sheldon $R$. Statistical issues encountered in the comparison of health-related quality of life in diseased patients to published general population norms: problems and solutions. J Clin Epidemiol 1999;52:405-412.

34. March LM, Cross MJ, Lapsley H, Brnabic AJ, Tribe KL, Bachmeier CJ, et al. Outcomes after hip or knee replacement surgery for osteoarthritis. A prospective cohort study comparing patients' quality of life before and after surgery with agerelated population norms. Med J Australia 1999:171:235-238.

35. Sutherland HJ, Fyles GM, Adams G, Hao Y, Lipton JH, Minden MD, et al. Quality of ife following bone marrow transplantation: a comparison of patient reports with population norms. Bone Marrow Transpl 1997;19:1129-1136.

36. Funk GF, Karnell LH, Dawson CJ, Means ME, Colwill ML, Gliklich RE, et al. Baseline and post-treatment assessment of the general health status of head and neck cancer patients compared with United States population norms. Head and Neck-J Sci Spec 1997;19:675-683.

37. Jalukar V, Funk GF, Christensen AJ, Karnell LH, Moran PJ. Health states following head and neck cancer treatment: patient, health-care professional, and public perspectives. Head and Neck-J Sci Spec 1998;20:600-608.

38. Dolan P, Gudex $C$. Time preference, duration and health state valuations. Health Econ 1995;4:289-299.

39. Lenert LA, Cher DJ, Goldstein MK, Bergen MR, Garber A. The effect of search procedures on utility elicitations. Med Decis Making 1998;18:76-83.

40. Gerard K, Johnston K, Brown J. The role of a pre-scored multi-attribute health classification measure in validating condition-specific health state descriptions. Health Econ 1999;8:685-699.

41. Nunes JF. Economic evaluation of rehabilitation: the quality of life approach using EuroQol. Int Adv Econ Res 1998;4:192-201.

42. Arpinelli $F$, et al. Health-related quality of life in asymptomatic patients with HIV: Evaluation of the SF-36 health survey in Italian patients. PharmacoEconomics $2000,18: 63-72$.

43. Watson EK, Firman DW, Baade PD, Ring 1. Telephone administration of the SF-36 health survey: validation studies and population norms for adults in Queensland. Aust NZ J Publ Heal 1996;20:359-363.

44. Dolan $P$, Roberts J. Modelling valuations for $E Q-5 D$ health states: an alternative model using differences in valuations. Med Care 2002;40:442-446. 
45. Brazier $J$, Roberts $J$, Deverill $M$. The estimation of a preference-based measure of health from the SF-36. J Health Econ 2002;21:271-292.

46. Brazier $J_{4}$ Usherwood $T$, Harper $R$. Thomas $K$. Deriving a preference-based single index from the UK SF-36 Health Survey. J Clin Epidemiol 1998;51:11:15-1128.

47. Shmueli A. Subjective health status and health values in the general population. Med Decis Making 1999;19:122-127.

48. The EuroQol Group. EuroQol-a new facility for the measurement of health-related quality of life. Health Policy 1990;16:199-208.

49. Jenkinson C. Stewart Brown S, Petersen S, Paice C. Assessment of the SF-36 version 2 in the United Kingdom. J Epidemiol Commun H 1999:53:46-50.

50. Patrick DL, Bush JW, Chen MM. Toward an operational definition of health. $J$ Health Soc Behav 1973;14:6-23.

51. Torrance GW. Measurement of health state utilities for economic appraisal. J Health Econ 1986:5:1-30.

52. Essink-Bot ML, Bonsel GJ, van der Maas PJ. Valuation of health states by the general public: feasibility of a standardized measurement procedure. Soc Sci Med $19824990 ; 31: 1201-1206$.

53. Kind P, Dolan P. The effect of past and present illness experience on the valuations of health states. Med Care 1995;33(4 Suppl):As255-As:263.

54. Blischke WR, Bush JW, Kaplan RM. Successive intervals analysis of preference measures in a health status index. Health Serv Res 1975;10:181-198.

55. Hadorn DC. Uebersax J. Large-scale health outcomes evaluation: how should quality of life be measured? Part 1--Calibration of a brief questionnaire and a search for preference subgroups. I Clin Epidemiol 1995:48:607-618.

56. Wu SY, Sainfort F, Tomar RH, Tollios JL, Fryback DG, Klein R, et all. Development and application of a model to estimate the impact of type 1 diabetes on health-related quality of life. Diabetes Care 1998;21:725-731.

57. Dolan P. The effect of experience of illness on health state valuations. $1 \mathrm{Clin}$ Epidemiol 1996;49:551-564.

58. Polsky D, Keating NL, Weeks JC, Schulman KA. Patient choice of breast cancer treatment: impact on health state preferences. Med Care 2002;40:1068-1079. 


\section{ACKNOWLEDGEMENTS}

First and foremost, I would like to thank Full professor Wim Groot and Assistant Professor Eddy Adang for giving me the opportunity to carry out the research described in this thesis. Wim, in the course of this project there should have been some kind of recalibration in your preferences with regard to this thesis, so that your preference at the beginning of this thesis should have been at least equal to your retrospective preference today. Eddy, I would like to thank you for the unlimited freedom you gave me in my research efforts.

Dear Associate Professor André Ament, I asked you to be my co-promotor when Eddy left Maastricht University, and you accomplished a wonderful job. I never would have completed this thesis without your stimulating questions, your faith in my research project and the contributions it could make to society.

Part of the research for this thesis was conducted at the Department of Ophthalmology, and I would like to thank Full professor Fred Hendrikse and Assistant Professor Rudy Nuijts for giving me the opportunity to work at their department. They also stimulated me to teach health economics for physicians.

The cooperation of the optometrists was essential in collecting medical data for the effect evaluation of monofocal and multifocal intraocular lenses. To me, they were also indispensable in another way: John de Brabander, Marjolein Kooijman and Vaishali Nabar, thank you for the interest you took in my work and for all your kind words.

As for my research partner, Marjan Nijkamp, I owe you a lot. Your energy and your attitude towards hard work, although it was not always easy, stimulated me to put the extra effort into this research. You always offered me a listening ear. And thank you for the postcards, which always came at the right time.

Emily Brounts, thank you for conducting the structured interviews during my absence.

I would like to thank the MTA group, in which colleagues from the Department of Health Organisation, Policy and Economics of the Maastricht University and the Department of Clinical Epidemiology and Medical Technology Assessment of the University Hospital meet regularly to discuss research, for their critical comments on my presentations, which were very useful to achieve a better understanding of the material presented in this thesis. 
who stimulated me to write a thesis Heck and Ad Vingerhoets at Tilburg derman of the Northern Centre for ironingen; Brenda Dervin, Melissa versity and Bowling Green State der of the Memorial Sloan Kettering -Steineck of the Karolinska Institute; sspital Palliative Medicine Unit; and

e to all the cataract patients, without en doomed to failure.

significant others. First of all, my Inge Houkes, Liezeth Drabbels and ou were my roommate. Thank you. laughter and friendship. Inge, thank ave the valuable ability to recognize $\mathrm{n}$ work. The discussions we had were ions. Liezeth, thank you for your quit Silvia, my research benefited greatly cost-effectiveness analyses. I aiso ned about my irritating habit to think

sther colleagues at the Department of Aggie, thank you for your tremendous vant to thank my colleagues for all the apers, the books and copies of them, ir colleague.

$\checkmark$ to the members of the evaluation ments and suggestions, and the time

I you, a unique researcher and a more how to perform research, nationailly, t-based. In addition, we had a common es friends. Thank you very much for i. 
Dear high school friends, dear Mariaantjes: in sickness and in health, you were always there. Thank you for being my friends for so many years and, hopefully, for many years to come. Dear fellow university students: thank you for always encouraging me to grow professionally and personally. I can truly say that I feel very fortunate to know so many persons I can share laughter and tears with.

Furthermore, I would like to thank my parents. They stimulated me in many ways. Mummy, I know that I have made you very proud (Mamma, ik weet dat je heel erg trots op me zult zijn). To my late father, this thesis would not have made any difference. Daddy, in your arms I always felt tall.

I want to thank my late parents in law for truly respecting the choices I made.

Dear Mrs. Frederiks, for a long time I had hoped that you would be my guest of honor today. I do regret that we are not able to complete this page of my history together. I miss you more than I can say.

My sisters and brothers (in law): although your world and mine are (very) different, at home it is our world. My great gratitude goes out to my brother Johan, for his willingness to assist me through the difficult times before and during the defending of this thesis.

Finally, I would like to thank the three most important men in my life: Herman, Mathijs and Wouter. I can express my gratitude best in the world's three most important words: I love you $\odot$. 



\section{CurRiculum VitAE}

The author of this dissertation was born at March $29^{\text {th }} 1964$ in Sevenum. Following graduation in 1983 at Marianum College Venlo, she studied Health Sciences at the University Limburg (former name of the University Maastricht). She got a masters in Health Education. After her graduation she worked as a research assistant at the Department of Health Education until 1996. She was involved in the following research topics: health education with regard to smoking cessation and smoking prevention and dissemination of nutrition education interventions.

in 1996 she acquired a fellow ship from the Dutch Cancer Society with regard to health education in lower socio-economic strata. At that time she was detached at the department of Psychology of Tilburg University, The Netherlands. During this fellow ship she was able to acquire scientific and practical clinical knowledge at several (foreign) institutes: the Northern Centre for Healthcare Research, University of Groningen, The Netherlands, The Ohio State University and Bowling Green State University, Ohio, United States of America, the Memorial Sloan Kettering Cancer Center and Cornell University, New York City, United States of America, the Karolinska Institute, Stockholm, Sweden, the Trondheim University Hospital, Palliative Medicine Unit, Trondheim, Norway and the Finnish Cancer Society, Helsinki, Finland.

Since February 1999 she has been working at the Department of Health Organisation, Policy and Economics as a PhD-student. With this dissertation her involvement in patient and population preferences is completed. 